Merci d'utiliser le titre suivant lorsque vous citez ce document :

Onodera, O. (2008-02-14), « Faciliter les échanges et l'ajustement structurel : l'expérience de pays non membres ॥, Éditions OCDE, Paris.

http://dx.doi.org/10.1787/244313266478

\title{
Faciliter les échanges et l'ajustement structurel
}

\author{
L'EXPÉRIENCE DE PAYS NON MEMBRES
}

Osamu Onodera

La version originale de ce document a été publiée comme suit :

Onodera, O. (2008-02-05), "Facilitating Trade and Structural Adjustment: Experiences in Non-Member Countries", OECD Trade Policy Papers, No. 69, OECD Publishing, Paris. http://dx.doi.org/10.1787/244320463512 
Organisation de Coopération et de Développement Economiques

Organisation for Economic Co-operation and Development

14-Feb-2008

DIRECTION DES ÉCHANGES ET DE L'AGRICULTURE

Français - Or. Anglais

COMITÉ DES ÉCHANGES

Groupe de travail du comité des échanges

FACILITER LES ÉCHANGES ET L'AJUSTEMENT STRUCTUREL : L'EXPÉRIENCE DE PAYS NON MEMBRES

Document de travail de l'OCDE sur la politique commerciale No 69

par Osamu Onodera

Osamu Onodera : Tél. +33-1-45248937 ; osamu.onodera@oecd.org 


\section{SYNTHÈSE}

Le présent document, aux côtés de cinq autres études de référence, fait partie d'un programme de recherche plus large portant sur les problèmes d'ajustement structurel dans les économies non membres qui a été mené à titre de suivi de l'étude Changer l'ajustement structurel: les enjeux de la mondialisation (OCDE, 2005), qui recensait les stratégies de nature à garantir la réussite de l'ajustement structurel lié aux échanges. Ce document revoit et approfondit certains éléments des Recommandations pour déterminer si elles s'appliquent aux pays en développement. Elle repose sur les cinq études de référence, une étude qui compare l'Asie de l'Est et l'Amérique latine, et quatre études de cas nationales (Chili, Équateur, Philippines et Thaïlande), qui ont été réalisées dans le cadre de ce projet, et est complétée par la documentation existante.

Ce rapport se compose de quatre grandes sections; la première est une introduction et la deuxième donne un aperçu des expériences de libéralisation des quatre pays. Dans la troisième section, certaines Recommandations figurant dans l'étude de l'OCDE (2005) sont révisées en ciblant davantage les pays en développement et en s'intéressant aux aspects suivants : i) la politique commerciale et la politique d'investissement, ii) la politique macroéconomique, iii) les politiques de protection sociale et d'emploi, iv) les politiques visant à faciliter la réaction des exportations, v) le cadre institutionnel et l'environnement réglementaire et concurrentiel, vi) le rôle de la coopération multilatérale et des initiatives régionales et bilatérales, vii) la réalisation de réformes dans une approche globale. La quatrième section formule une conclusion.

Mots clés : commerce, ajustement structurel, réforme des échanges, pays en développement, politique macroéconomique, taux de change, filet de sécurité sociale, réaction des exportations, cadres institutionnels, coopération multilatérale

\section{REMERCIEMENTS}

Ce projet a été mené par Osamu Onodera, sous la supervision d'Anthony Kleitz, de la Direction des échanges et de l'agriculture de l'OCDE. L'auteur souhaite remercier Svenbjorn Blondal, Martina Garcia, Ken Heydon, Przmek Kowalski, Mark Melatos, Sebastien Miroudot, Nanno Mulder, Paul Swaim, et Stefan Tangermann pour leurs commentaires sur la version précédente de ce document, et Csilla Bartok pour son assistance.

Le Groupe de travail du Comité des échanges de l'OCDE a examiné ce rapport et a décidé de diffuser plus largement ses conclusions par une déclassification sous sa propre responsabilité. L'étude est disponible sur le site Web de l'OCDE en anglais et en français : http://oecd.org/trade.

\section{Copyright OCDE, 2008}

Toute demande d'autorisation de reproduction ou de traduction de tout ou partie de ce document doit être adressée à : Publications de l'OCDE, 2 rue André Pascal, 75775 Paris Cedex 15, France 


\section{TABLE DES MATIÈRES}

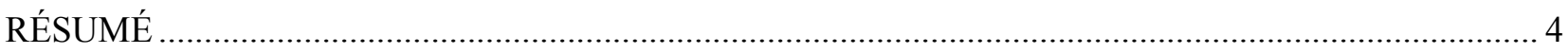

FACILITER LES ÉCHANGES ET L'AJUSTEMENT STRUCTUREL : L'EXPÉRIENCE DE PAYS

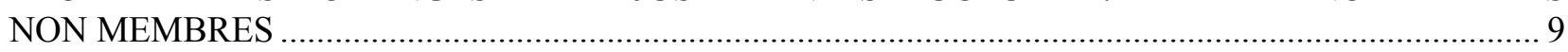

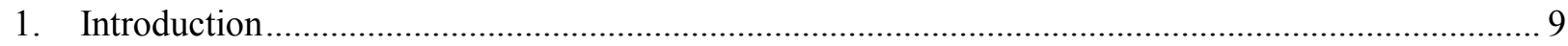

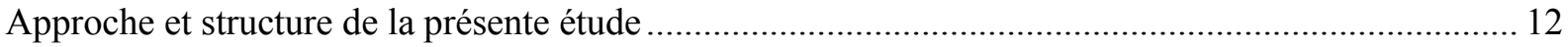

2. La libéralisation des échanges dans les quatre pays à l'étude .......................................................... 13

3. «Échanges et ajustement structurel : Recommandations de bonnes pratiques »............................ 18

1) Politiques en matière d'échanges et d'investissement ........................................................... 18

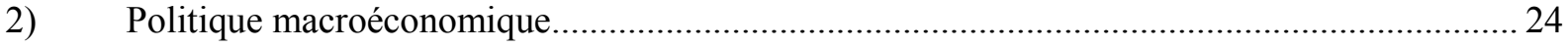

3) Protection sociale et politique du marché du travail ........................................................... 31

4) Politiques visant à faciliter la réaction des exportations à la réforme des échanges................. 34

5) Cadre institutionnel et environnement réglementaire et concurrentiel .................................... 38

6) Rôle de la coopération multilatérale et des initiatives régionales et bilatérales........................ 41

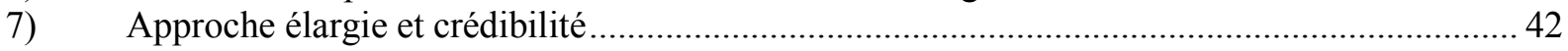

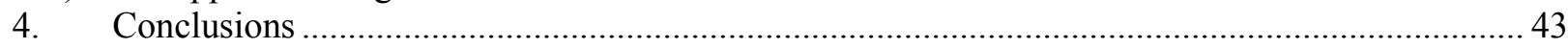

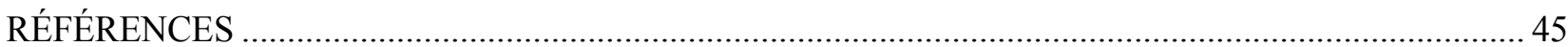

ANNEXE 1. ÉCHANGE ET AJUSTEMENT STRUCTUREL : RECOMMANDATIONS DE BONNES

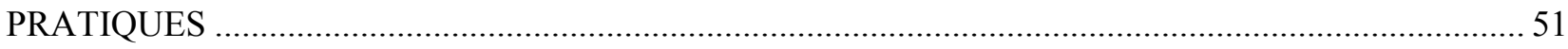

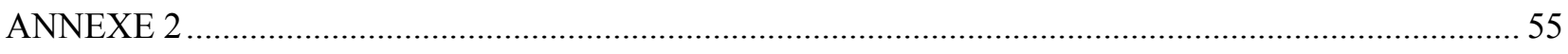

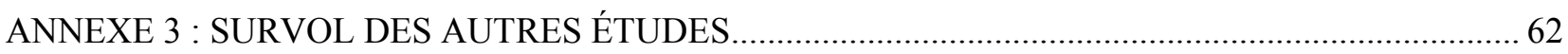

\section{Encadrés}

Encadré 1. Obstacles à la stabilité macroéconomique - libéralisation du marché des capitaux ...............26

Encadré 2. Les défis macroéconomiques des pays riches en ressources - Chili et Équateur.................... 26

Encadré 3. Chili - le taux de change : un point d'ancrage nominal ................................................ 28

Encadré 4. Philippines et Thaïlande - le taux de change : miroir de la compétence du gouvernement.. 28

Encadré 5. Le taux de change et son impact sur la dette publique ..........................................................29

Encadré 6. Impact potentiel sur les recettes douanières ......................................................................... 30 


\section{RÉSUMÉ}

L'étude Changer l'ajustement structurel : les enjeux de la mondialisation (OCDE, 2005) formule des recommandations pour assurer la réussite de l'ajustement structurel lié aux échanges dans les pays développés et les pays en développement (voir l'annexe 1 du présent document « Échanges et ajustement structurel : Recommandations de bonnes pratiques »). La présente étude revoit et approfondit certains éléments des Recommandations pour déterminer si elles s'appliquent aux pays en développement. Elle repose sur cinq études de référence, une étude qui compare l'Asie de l'Est et l'Amérique latine, et quatre études de cas nationales (Chili, Équateur, Philippines et Thaïlande), qui ont été réalisées dans le cadre de ce projet, et est complétée par la documentation existante.

Les quatre pays susmentionnés ont mis en œuvre une réforme des échanges après avoir adopté une stratégie de développement fondée sur le remplacement des importations, qui s'est traduite par un biais anti-exportations prononcé et une mauvaise répartition des ressources. L'ampleur de la réforme, les secteurs visés, le calendrier de réalisation, et, par conséquent, les résultats, varient selon le pays. Dans tous les cas, il s'agissait d'un processus au long cours, comportant plusieurs étapes. Les quatre pays ont persisté dans leurs efforts, maintenant le cap général de la réforme des échanges malgré les retours en arrière. Ces efforts s'inscrivaient dans une réforme globale axée sur le marché, qui englobait notamment les institutions macroéconomiques, la politique d'investissement direct étranger (IDE), la politique de change, les marchés des capitaux et du travail, et les marchés de produits. L'expérience montre que les politiques sont interdépendantes, ce qui fait ressortir l'importance de la réalisation des réformes économiques dans une perspective globale. Dans les quatre pays à l'étude, la réforme des échanges a été suivie d'un ajustement important de la structure des industries, des échanges et de l'emploi.

Une des grandes leçons que nous pouvons tirer des quatre études de cas est que, si les importations et les exportations sont des facteurs clés, l'évolution des exportations au début de la réforme des échanges pourrait être cruciale. Puisqu'en général, les importations augmentent plus rapidement que les exportations au terme d'une réforme des échanges, il convient d'accorder une attention particulière à la réaction des exportations. Si cet impact tarde à se concrétiser, le pays risque d'être confronté à ce qui suit : 1) un déséquilibre croissant de la balance commerciale et l'instabilité macroéconomique ; 2) une montée du chômage à court et à moyen terme ; 3 ) une plus grande vulnérabilité aux chocs extérieurs ; 4) la difficulté d'empêcher l'érosion des appuis à la réforme des échanges.

À notre avis, la plupart des éléments des Recommandations demeurent valables, bien que certains ne s'appliquent pas à certains pays en développement ou doivent être étoffés. Nous avons exposé ci-dessous les conclusions que nous avons tirées relativement i) à la politique commerciale et à la politique d'investissement, ii) à la politique macroéconomique, iii) aux politiques de protection sociale et d'emploi, iv) aux politiques visant à faciliter la réaction des exportations, v) au cadre institutionnel et à l'environnement réglementaire et concurrentiel, vi) au rôle de la coopération multilatérale et des initiatives régionales et bilatérales, vii) à la réalisation de réformes dans une approche globale. Comme il en est fait mention dans l'étude initiale, toute recommandation de bonnes pratiques doit être analysée attentivement. Une approche qui fonctionne dans un pays ne donne pas forcément de bons résultats dans d'autres. En raison des divergences dans l'environnement politique et des contraintes de ressources, les pays devront donner la priorité à des domaines différents. 
i) Politique commerciale et politique d'investissement - L'étude aborde la rapidité et le contenu des réformes des échanges, la politique d'IDE et les services assurés à cet égard, et conclut que les Recommandations sont entièrement corroborées.

S'agissant de la rapidité des réformes, l'approche de choc et l'approche graduelle ont chacune leur profil coûts/avantages. L'approche graduelle pourrait être justifiée si les coûts d'ajustement sont élevés, si les effets des différentes réformes ne se concrétisent pas au même moment et si l'issue de la réforme est incertaine. La progressivité permet également aux institutions de s'adapter. Dans certaines situations, par exemple en cas de crise ou de distorsions graves, l'approche de choc peut toutefois être envisagée. Au plan du contenu, il est particulièrement important d'éliminer rapidement les restrictions quantitatives pour réduire les distorsions graves dès le début du processus. Si l'uniformité des droits de douane - l'application est moins coûteuse, la transparence est accrue et il y a moins de lobbying — la différenciation tarifaire peut également être efficace. Quoi qu'il en soit, la simplification des structures tarifaires semble faire consensus.

Le secteur des services, dont la grande envergure et le dynamisme semblent être une constante dans tous les pays, peut également faciliter l'ajustement structurel en créant des emplois et en contribuant aux gains de productivité enregistrés par les utilisateurs dans les secteurs de l'agriculture et de la fabrication. Le secteur des services a souvent joué le rôle d'un filet de sécurité informel en absorbant une bonne part du chômage de courte durée. Les progrès technologiques permettent aux pays en développement d'exploiter de plus en plus les possibilités qui s'offrent à eux dans le commerce des services (par exemple, les processus opérationnels externalisés aux Philippines). Les fournisseurs de services outre-mer et le tourisme ont apporté beaucoup de devises (par exemple, en Équateur, aux Philippines et en Thaïlande). Par ailleurs, les services sont d'importants intrants agricoles et manufacturiers. L'amélioration du transport aérien explique dans une large mesure la réussite des producteurs de fleurs coupées en Équateur, alors que la déficience des transports a entravé la croissance du secteur de la transformation alimentaire aux Philippines. Ces exemples mettent en relief le rôle complémentaire de premier plan joué par la libéralisation des services dans la réforme des échanges. En revanche, l'étude du secteur thaïlandais des télécommunications met en lumière les difficultés auxquelles se heurte la réforme de la réglementation dans les industries de réseau.

L'IDE peut faciliter l'ajustement structurel en sa qualité 1) de moteur principal de la croissance des exportations (par exemple, de produits électroniques et de voitures en Thaïlande), 2) de relais des transferts de technologie (par exemple, pour le cuivre, les vins et le saumon au Chili ; les fleurs coupées et le thon transformé en Équateur), 3) d'agent de changement structurel dans le cadre des fusions et acquisitions, etc. (par exemple pour le ciment aux Philippines et en Thaïlande après la crise asiatique). Tous les cas viennent étayer la Recommandation visant à optimiser les possibilités de flux d'IDE qui accompagnent la politique commerciale libérale et souligner l'importance d'une politique d'IDE libérale qui complète la réforme des échanges.

ii) Politiques macroéconomiques - Tous les cas avalisent la Recommandation visant à promouvoir la stabilité et la croissance afin de créer un contexte propice à l'ajustement. La stabilité macroéconomique peut contribuer à faciliter l'ajustement structurel (pour le Chili dans les années 90 par exemple). Toutefois, la stabilité ne semble pas essentielle à la réussite du programme de réforme des échanges; au contraire, les échanges ont souvent été libéralisés en période de crise. Il n'en demeure pas moins que la réorientation de la politique commerciale a surtout été motivée par l'instabilité macroéconomique. 
La politique de change est un élément crucial de la réforme des échanges. Durant la première phase de la libéralisation, la surappréciation de la monnaie doit être évitée afin que la réaction des exportations soit généralisée. Cependant, les autorités des pays en développement ont souvent été réticentes à dévaluer la monnaie pour diverses raisons. Il faut veiller à ce que la politique de change appuie la réforme des échanges dès le départ en empêchant dans un premier temps la surappréciation et, dans un deuxième temps, l'asymétrie des monnaies et les ajustements marqués et soudains.

La réforme des échanges et les politiques destinées à l'appuyer peuvent influer sur l'équilibre budgétaire. Les réductions tarifaires peuvent détériorer les finances publiques, et les variations du taux de change durant la réforme peuvent avoir un impact sur les recettes et les dépenses publiques, surtout sur le déficit budgétaire et le service de la dette. Il faut veiller à ce que la détérioration de l'équilibre budgétaire n'amène pas les autorités à faire marche arrière avant que l'effet de la réforme des échanges ne se soit fait sentir sur les exportations. Les réformes des échanges qui ont été couronnées de succès ont souvent été suivies d'une réforme fiscale, par exemple l'adoption d'une taxe à la valeur ajoutée; par conséquent, les responsables de la politique commerciale et les autorités budgétaires doivent coordonner leurs actions pour assurer la réussite de la réforme des échanges. L'élimination des obstacles non tarifaires et la facilitation des échanges, c'est-à-dire des importations et des exportations, peuvent être très porteuses, car les autorités pourraient percevoir davantage de droits de douane advenant une augmentation des flux des échanges.

iii) Protection sociale et politique du marché du travail - Les auteurs de l'étude ont constaté que le filet de sécurité sociale officiel est beaucoup plus rudimentaire dans les pays en développement. Même lorsqu'un tel filet a été mis en place, la couverture est souvent restreinte, et les crises macroéconomiques et les déficits budgétaires ont souvent contraint les autorités à amputer les programmes sociaux. D'autre part, le marché du travail des pays développés se distingue de celui des pays en développement par la taille du secteur informel. Donc, si les Recommandations portant sur des mesures équilibrées de protection de l'emploi et sur un mécanisme flexible de fixation des salaires demeurent valables, les autres Recommandations relatives à la protection sociale et aux autres éléments de la politique du marché du travail telles que les prestations de remplacement du revenu, les programmes actifs du marché du travail, etc. peuvent plus difficilement s'appliquer aux pays en développement.

Dans certains cas, la forte croissance économique, surtout dans le secteur des exportations, et le vaste secteur informel ont été des filets de sécurité sociale de facto. Certains pays en développement ont également mis en place un filet de sécurité sociale restreint constitué de programmes tels que les subventions à l'alimentation, les programmes d'emploi public, les programmes de crédit de subsistance et les programmes de travaux publics à fort coefficient de main-d'oeuvre. À mesure que le pays se développe, les pressions en faveur de la mise en place d'un filet de sécurité social officiel semblent augmenter, comme en témoigne la création d'un régime d'assurance-chômage en Thaïlande en 2004.

iv) Bien que les Recommandations n'en fassent pas explicitement mention, les mesures visant à faciliter la réaction des exportations à la réforme des échanges constituent un élément important de l'ajustement que requiert une telle réforme. Cette dernière entraîne souvent une augmentation des importations. En plus d'être une importante source de technologie, les importations sont une charnière de la réforme des échanges, car ce sont les signaux de prix relayés par les importations qui permettent d'améliorer la répartition des ressources. Toutefois, alors que les importateurs sont assez sensibles aux variations des prix relatifs, les exportateurs tardent souvent à réagir. Si la stabilité macroéconomique et un régime de change approprié jouent un rôle clé dès le début de la 
réforme des échanges en suscitant une réaction marquée des exportations à grande échelle, les administrations publiques peuvent apporter leur contribution en élaborant avec soin des politiques qui favorisent les exportations. De telles politiques peuvent prévoir des mesures qui facilitent l'accès à des intrants et à du financement à un coût concurrentiel, ainsi que des mesures liées à l'obtention d'informations sur les marchés étrangers.

Pour les exportateurs, l'accès à des intrants à prix concurrentiel est essentiel, la concurrence étant de plus en plus forte sur le marché mondial. Diverses exemptions tarifaires applicables aux éléments qui entrent dans la production de biens d'exportation, les remboursements de douane, les zones franches d'exportation et d'autres mécanismes ont été utilisés avec succès (par exemple, les remboursements de douane en Thaillande et les zones franches d'exportation aux Philippines). De même, l'accès au financement à taux concurrentiel est important et peut être favorisé par une réforme des marchés des capitaux. Les études de cas indiquent toutefois qu'une telle réforme et la mise en place d'un cadre réglementaire adéquat n'ont pas été faciles. D'autres mesures peuvent être nécessaires dans l'intervalle. Les informations sur les marchés d'exportation et la technologie sont également précieuses. Cependant, le coût d'acquisition de ces données et l'incertitude entourant cette démarche peuvent dissuader les exportateurs. Les administrations publiques peuvent jouer un rôle, notamment recueillir et diffuser ces informations, aider les entreprises à recentrer leurs activités sur les marchés étrangers, faire connaître les exportateurs du pays et les amener à unir leurs efforts. Le Chili constitue un exemple éloquent à cet égard. Bien que les subventions des exportations soient envisageables, elles sont généralement prohibées par les règles de l'OMC, et constituent des stratégies moins efficaces du point de vue économique car elles peuvent introduire des distorsions et faire obstacle aux objectifs de la libéralisation des échanges.

v) Cadre institutionnel et environnement réglementaire et concurrentiel - L'étude avalise dans une large mesure la Recommandation mettant en relief l'importance d'un cadre institutionnel et politico-administratif qui favorise la réforme structurelle tout en aidant le public à la comprendre et à l'accepter, ainsi qu'un cadre de réglementation et de concurrence qui permet aux entreprises de se transformer et de changer de secteur. Les études de cas font toutefois ressortir que les administrations publiques et les entreprises privées ont parfois eu du mal à s'adapter aux changements institutionnels qui ont accompagné les réformes des échanges. Le cadre de réglementation et l'efficacité du régime de concurrence ont fortement contribué à la croissance de nombreux secteurs (par exemple, le cuivre et la forêt au Chili).

vi) Coopération multilatérale et initiatives bilatérales et régionales - L'étude soutient la thèse voulant que la coopération multilatérale, bilatérale et régionale peut faciliter le processus d'ajustement structurel. Sur le plan des échanges, les engagements internationaux peuvent servir d'élément déclencheur des réformes économiques, mais peuvent également être révélateurs de la détermination des autorités à libéraliser le commerce et donner plus de crédibilité aux réformes (ALENA au Mexique et adhésion de l'Équateur à l'OMC). Les initiatives de coopération peuvent engager les réformes, accroitre la transparence et la prévisibilité des mesures, de même que promouvoir les bonnes pratiques. Sur le plan de l'aide, la coopération multilatérale sous l'égide de la Banque mondiale et la coopération régionale/bilatérale ont contribué à l'ajustement structurel par le biais du soutien financier et du renforcement des capacités.

Le rôle de la libéralisation multilatérale des échanges et des initiatives bilatérales et régionales n'a pas été exposé de façon très explicite dans les Recommandations. Elles peuvent contribuer à l'ajustement structurel en donnant accès aux marchés, ce qui facilite la réaction des exportations. D'après l'étude, le Programme de Doha pour le développement (PDD), et, dans une 
moindre mesure, les initiatives régionales et bilatérales de libéralisation des échanges peuvent faciliter l'ajustement dans les pays en développement en leur permettant de pénétrer de nouveaux marchés, comme ce fut le cas en Équateur (ATPDEA avec les États-Unis) et au Chili.

vii) La réforme dans une perspective globale - L'étude réaffirme la thèse voulant que la réforme des échanges s'inscrive dans une réforme économique globale et que les diverses politiques présentent un degré élevé d'interdépendance. La politique en matière d'échange est étroitement liée aux politiques régissant, entre autres, l'IDE, le régime de change, les finances publiques et les marchés des capitaux ; par conséquent, différents organismes publics doivent coordonner avec soin leurs actions de manière que les politiques soient cohérentes et que les réformes s'enchaînent pour donner de meilleurs résultats. La crédibilité de la réforme des échanges est importante, car elle entraîne une réaffectation des ressources uniquement si le secteur privé estime qu'elle sera soutenue. Pour accroître la crédibilité de leurs initiatives, les pays ont notamment réalisé des réformes approfondies, adopté des politiques cohérentes qui se renforcent mutuellement, multiplié les réformes réussies, et fait fond sur les engagements internationaux.

En conclusion, les pays en développement ont progressivement réformé les échanges dans le cadre d'une réforme économique globale, parfois à l'occasion d'initiatives multilatérales/régionales, mais très souvent sur une base unilatérale. Les réformes des échanges et des autres secteurs de compétence de l'État sont étroitement liées, ce qui oblige les autorités à coordonner attentivement leurs actions pour assurer la cohérence des politiques. Les analyses font ressortir l'importance de la réaction des exportations durant la première phase de la réforme. Les autorités des pays en développement qui enclenchent une réforme des échanges peuvent envisager un éventail de politiques pour faciliter cette réaction. Le PDD, et, dans une moindre mesure, les diverses initiatives régionales et bilatérales de libéralisation des échanges, peuvent contribuer à l'ajustement structurel induit par la réforme des échanges dans les pays en développement, en leur donnant accès à des marchés qui peuvent contribuer à la réaction des exportations et à la réussite de l'ajustement axé sur les domaines conférant un avantage comparatif. 


\section{FACILITER LES ÉCHANGES ET L'AJUSTEMENT STRUCTUREL : L'EXPÉRIENCE DE PAYS NON MEMBRES}

\section{Introduction}

1. L'étude Changer l'ajustement structurel : les enjeux de la mondialisation (OCDE, 2005) formule des recommandations pour assurer la réussite de l'ajustement structurel lié aux échanges dans les pays développés et les pays en développement, c'est-à-dire des politiques qui facilitent les changements structurels par le redéploiement de la main-d'œuvre et du capital vers des utilisations plus efficientes, tout en limitant les coûts d'ajustement pour les personnes, les communautés et la société dans son ensemble. Bien que le contexte et les problèmes d'ajustement auxquels les pays en développement sont confrontés diffèrent par leur nature et leur ampleur de ceux auxquels les pays industrialisés avancés doivent faire face, des principes communs de bonne pratique ont été proposés sur la base d'études de cas ${ }^{1}$ et de l'expérience acquise dans le cadre de la procédure d'examen préalable mutuel de l'OCDE. Les Recommandations portent sur tous les secteurs et sont généralement applicables dans les différents pays, avec toutefois une priorité plus ou moins grande (voir l'annexe 1 du présent document «Échanges et ajustement structurel : Recommandations de bonnes pratiques $\gg)$.

2. Ainsi, tous les pays auraient avantage à adopter :

- des politiques macroéconomiques qui encouragent la stabilité et la croissance ;

- des politiques du marché du travail qui contribuent à développer les qualifications des travailleurs et facilitent le transfert des ressources entre les activités en déclin et celles qui sont en croissance, tout en fournissant une aide adéquate à ceux qui sont confrontés à des coûts d'ajustement du fait de l'évolution structurelle ;

- un solide cadre de réglementation et de concurrence qui réduit le plus possible les charges réglementaires pesant sur les entreprises qui désirent percer un marché, se retirer d'un marché ou se transformer, et qui favorise la concurrence ;

- d'un solide cadre institutionnel et politico-administratif qui favorise la réforme structurelle, et permet dans le même temps de faire mieux comprendre et accepter les mesures de réforme par l'opinion publique ;

- des politiques libérales en matière d'échanges et d'investissement qui soutiennent l'ajustement structurel en contribuant à la croissance, à l'innovation et à la compétitivité et qui sont mises en œuvre de façon suffisamment progressive pour permettre aux parties concernées de s'adapter et suffisamment rapide pour éviter des retours en arrière.

1. Les études de cas portent sur huit secteurs : agriculture, pêches, textiles et vêtements, acier, construction navale, véhicules automobiles, services de santé et acquisition à l'étranger de services de technologie d'information et de processus administratifs. Une étude complémentaire (Engman et al., 2006) sur l'agriculture (café et tabac), les télécommunications et les produits chimiques a livré d'autres conclusions à l'intention des décideurs. 
3. La présente étude vise à décrire le processus d'ajustement structurel réalisé par les pays en développement en analysant tout particulièrement l'expérience de certains de ces pays, ainsi qu'à réexaminer et à approfondir certains éléments du document «Échanges et ajustement structurel: Recommandations de bonnes pratiques ».

4. Les pays en développement ont considérablement libéralisé leurs échanges au cours des 20 dernières années. Par exemple, en Amérique latine et Asie orientale, les niveaux tarifaires moyens sont passés de $15-60 \%$ à 5-20\% (graphique 1). Certaines des réductions ont été unilatérales, alors que d'autres s'inscrivaient dans des initiatives multilatérales ou bilatérales ${ }^{2}$. Les pays en développement, comme tous les membres de l'OMC, sont appelés à prendre d'autres engagements de réduction tarifaire dans le cadre du Programme de Doha pour le développement (PDD). Du fait que l'écart entre les taux consolidés et les taux appliqués (tableau 1) varie beaucoup d'un pays à l'autre et qu'il existe des différences dans l'application des niveaux tarifaires appliqués (tableau 2 et tableau A de l'annexe 2 ) $^{3}$ et le traitement différentiel des obligations ${ }^{4}$, les réductions des taux appliqués qui requièrent un ajustement réel peuvent être très différentes selon le pays 5 .

5. La réduction des droits de douane élevés donne à ces pays la possibilité d'améliorer la répartition des ressources et le bien-être. Cependant, lorsque les réductions tarifaires doivent être suivies d'un ajustement, il est inévitable que des pays sortiront perdants de l'opération. Il ressort de l'expérience des pays en développement que ces derniers ont des obstacles plus importants à surmonter que les pays développés du fait que le contexte politique des échanges et de l'ajustement structurel n'est pas le même. Le niveau de protection est généralement plus élevé dans les pays en développement. Cela signifie que les distorsions de la répartition des ressources sont probablement plus grandes : si les gains prévus à long terme sont plus importants, les coûts à court terme de l'ajustement pourraient également être plus élevés. Il est plus difficile de maintenir la stabilité macroéconomique lorsque les droits de douane représentent une part énorme des recettes publiques, lorsque la dette en devises est lourde et le marché des changes, illiquide, et/ou lorsque le pays est beaucoup trop dépendant de certaines exportations et de l'aide pour se constituer des réserves en devises. En raison du faible niveau de sophistication technologique, des infrastructures inadéquates, du manque de respect des droits de propriété (intellectuelle notamment), de l'accès restreint au capital, et de la difficulté d'obtenir des informations sur les débouchés, les entreprises des pays en développement ont souvent du mal à s'adapter aux nouvelles réalités des marchés et à exploiter les possibilités offertes par la libéralisation des échanges. De plus, il n'est pas rare que l'instabilité politique, la mauvaise gouvernance et la corruption endémique, ainsi que l'absence de protection sociale compliquent le processus d'ajustement dans certains de ces pays.

6. Pour que la réforme des échanges soit viable et efficace, les ressources doivent être redéployées facilement vers des utilisations plus productives, et la société doit arriver à la conclusion que les avantages

2. La Banque mondiale (2005) indique que sur le total des réductions tarifaires mises en œuvre entre 1983 et 2003, $66 \%$ étaient autonomes, $25 \%$ étaient la conséquence d'accords multilatéraux et $10 \%$ résultaient d'accords commerciaux préférentiels.

3. Le tableau 2 montre que, si les niveaux tarifaires sont inférieurs à $20 \%$ dans la plupart des pays, 35 pays continuent d'appliquer des droits de douane moyens supérieurs à ce seuil aux produits agricoles et 12 pays, aux produits non agricoles. Toutes choses égales par ailleurs, dans les pays qui appliquent des droits plus élevés, il est plus probable que des réductions tarifaires devant être ajustées soient nécessaires.

4. Par exemple, aux termes de l'accord-cadre de juillet 2004, il a été convenu que les pays les moins développés ne seraient pas tenus d'appliquer la formule, ni d'adopter l'approche sectorielle, et qu'une augmentation sensible de leur niveau d'engagements de consolidation serait suffisante.

5. À noter que, règle générale, les réductions des droits consolidés qui n'entraînent pas une diminution des droits appliqués ne donnent pas lieu à un ajustement. 
l'emportent sur les coûts et que les résultats sont équitables. En d'autres termes, il est important que le pays arrive à enchaîner de façon optimale les engagements de libéralisation des échanges et les autres réformes en tenant compte de ses engagements actuels et du contexte politique (position budgétaire, taux d'inflation, etc.), de manière 1) à maximiser les gains technologiques et de productivité résultant d'une plus grande ouverture économique et 2) à permettre une évolution favorable des investissements nationaux et étrangers et de l'offre, afin de faciliter l'ajustement vers les secteurs où le pays a un avantage comparatif, (3) tout en minimisant les pertes de production et d'emploi durant la transition.

Graphique 1. Moyenne des droits appliqués NPF en Amérique latine et en Asie orientale

Amérique latine (8 pays)

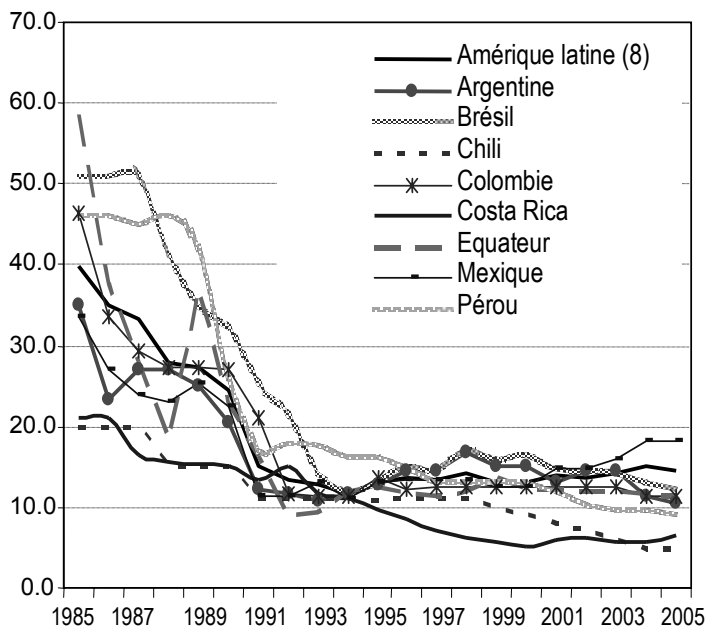

Asie orientale (7 pays)

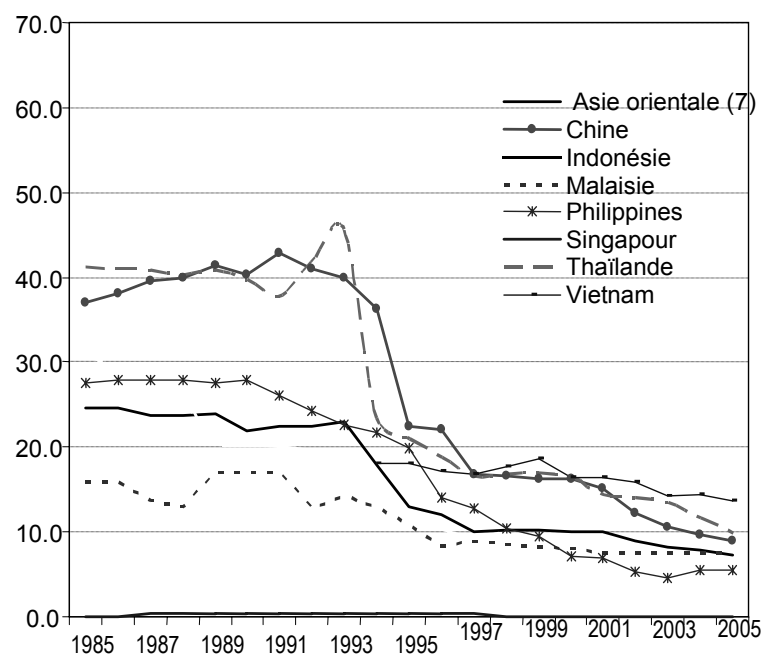

Note. La moyenne régionale correspond à la moyenne des droits nationaux pondérée en fonction de la part des importations de chaque pays dans le total régional.

Source : Étude comparative régionale complémentaire 
Tableau 1. Moyenne simple des droits de douane (2006)

\begin{tabular}{lcccc}
\hline Pays & \multicolumn{2}{c}{ Produits agricoles } & \multicolumn{2}{c}{ Produits non agricoles } \\
\cline { 2 - 5 } & $\begin{array}{c}\text { Droits } \\
\text { consolidés }\end{array}$ & $\begin{array}{c}\text { Droits } \\
\text { appliqués }\end{array}$ & $\begin{array}{c}\text { Droits } \\
\text { consolidés }\end{array}$ & $\begin{array}{c}\text { Droits } \\
\text { appliqués }\end{array}$ \\
\hline Pays de l'OCDE & 45.2 & 26.7 & 9.5 & 4.2 \\
$\begin{array}{l}\text { Pays à faible revenu et à revenu } \\
\text { intermédiaire }\end{array}$ & 61.2 & 16.4 & 33.1 & 10.4 \\
$\quad$ dont : & & & & \\
$\quad \begin{array}{l}\text { Asie orientale et Pacifique } \\
\quad \text { Europe et Asie centrale }\end{array}$ & 46.6 & 15.3 & 27.1 & 8.5 \\
$\quad \begin{array}{l}\text { Amérique latine et Caraïbes } \\
\text { Moyen-Orient et Afrique du }\end{array}$ & 29.0 & 15.6 & 11.6 & 6.3 \\
$\quad$ Nord & 56.3 & 13.2 & 36.8 & 8.5 \\
$\quad \begin{array}{l}\text { Asie méridionale } \\
\text { Afrique subsaharienne }\end{array}$ & 61.2 & 37.7 & 29.0 & 16.5 \\
\hline
\end{tabular}

Source: Profils tarifaires dans le monde, OMC, 2006. Les nombres sont des moyennes simples calculées à partir des données des pays de chaque région. Les régions ont été classées dans les catégories des pays à faible revenu et à revenu intermédiaire à partir de la définition de la Banque mondiale. Les régions englobent les pays suivants : Asie orientale et Pacifique (Cambodge, Chine, Fidji, Îles Salomon, Indonésie, Malaisie, Mongolie, Myanmar, Papouasie-Nouvelle-Guinée, Philippines, Thaïlande et Vietnam) ; Europe et Asie centrale (Albanie, Arménie, Bulgarie, Croatie, Géorgie, Macédoine, Moldova, République kirghize, Roumanie et Turquie); Amérique latine et Caraïbes (Argentine, Belize, Bolivie, Brésil, Chili, Colombie, Costa Rica, Cuba, Dominique, Équateur, El Salvador, Grenade, Guatemala, Guyana, Haïti, Honduras, Jamaïque, Mexique, Nicaragua, Panama, Paraguay, Pérou, République dominicaine, Saint-Kitts-et-Nevis, Sainte-Lucie, Saint-Vincent-et-les-Grenadines, Uruguay et Venezuela); Moyen-Orient et Afrique du Nord (Djibouti, Égypte, Jordanie, Maroc, Oman et Tunisie) ; Asie méridionale (Bangladesh, Inde, Maldives, Népal, Pakistan et Sri Lanka); Afrique subsaharienne (Afrique du Sud, Angola, Bénin, Botswana, Burkina Faso, Burundi, Cameroun, Congo, Côte d'Ivoire, Gabon, Guinée, Guinée-Bissau, Kenya, Lesotho, Madagascar, Malawi, Mali, Mauritanie, Maurice, Mozambique, Namibie, Niger, Nigeria, Ouganda, République centrafricaine, Rwanda, Sénégal, Sierra Leone, Swaziland, Tanzanie, Tchad, Togo et Zambie). La Communauté européenne est considérée comme une seule économie aux fins du calcul.

Tableau 2. Niveaux des droits appliqués des membres de I'OMC (2005)

\begin{tabular}{|c|c|c|c|}
\hline \multicolumn{2}{|c|}{$\begin{array}{c}\text { Moyenne simple - droits appliqués } \\
\text { NPF }\end{array}$} & $\begin{array}{c}\text { Produits agricoles } \\
\text { (nombre de pays) }\end{array}$ & $\begin{array}{c}\text { Produits non } \\
\text { agricoles } \\
\text { (nombre de pays) }\end{array}$ \\
\hline Plus de $30 \%$ & 12 & 2 \\
\hline $25 \%-30 \%$ & 3 & 4 \\
\hline $20 \%-25 \%$ & 20 & 6 \\
\hline $15 \%-20 \%$ & 26 & 23 \\
\hline $10 \%-15 \%$ & 41 & 34 \\
\hline $5 \%-10 \%$ & 31 & 51 \\
\hline $0 \%-5 \%$ & 10 & 26 \\
\hline
\end{tabular}

Source : Secrétariat et données du tableau II des Profils tarifaires, OMC (2005)

Note. 1 Les données englobent les pays développés et les pays en développement, et couvrent la période 19982004.

2 Les données sur les différents pays sont présentées au tableau A1 de l'annexe 2.

\section{Approche et structure de la présente étude}

7. La présente étude réexamine le document «Échanges et ajustement structurel : Recommandations de bonnes pratiques » (annexe 1) en suivant une approche nationale et multisectorielle, par opposition à l'approche sectorielle suivie dans le rapport initial du projet sur les échanges et l'ajustement structurel et l'étude complémentaire. Si l'approche sectorielle permet d'analyser des questions spécifiques telles que les changements technologiques, l'émergence de nouvelles sources de concurrence ou l'évolution des préférences des consommateurs, l'approche nationale se prête, dans une perspective globale, à un examen des relations entre les diverses politiques et le redéploiement intersectoriel des 
ressources que suppose le processus d'ajustement structurel. Le présent document tente de répondre à des questions telles que :

- Quelle a été l'expérience des pays en développement en ce qui concerne le rôle des échanges et de l'investissement direct étranger (IDE) dans le processus d'ajustement structurel global?

- Dans le cadre de la libéralisation des échanges et de l'investissement, quelle est l'importance de l'enchaînement des mesures et du moment choisi pour les concrétiser? Le traitement des secteurs devrait-il être uniforme ou discriminatoire?

- L'expérience nationale nous renseigne-t-elle sur les liens existants entre la réforme des échanges et d'autres mesures de réforme économique telles que le contrôle des prix, la réglementation du travail et les réglementations nationales qui imposent des contraintes aux entreprises qui désirent pénétrer un marché ou s'en retirer? Devrait-on accorder la priorité à certains aspects dans le cadre de la réforme de la politique commerciale? Les différentes réformes sont-elles complémentaires ou séquentielles?

- La transparence et la prévisibilité des réformes sont importantes, car elles facilitent le redéploiement des ressources par le secteur privé. Quelle est l'expérience des pays en développement à cet égard? Quel peut être le rôle de l'OMC ou des engagements régionaux ou bilatéraux?

- De façon générale, comment les initiatives bilatérales, régionales et multilatérales de libéralisation des échanges contribuent-elles au processus d'ajustement?

8. La présente étude analyse les efforts de libéralisation des échanges de certains pays afin de déterminer si les recommandations formulées dans « Échanges et ajustement structurel : Recommandations de bonnes pratiques », OCDE (2005), s'appliquent aux pays en développement, et de les approfondir. L'étude repose sur cinq études de référence (voir l'annexe 3 pour un bref résumé de ces études) et la documentation existante (voir le tableau 2 de l'annexe 2). Les cinq études de référence ont été publiées séparément dans des documents de travail de l'OCDE sur la politique commerciale; une étude qui compare les initiatives de libéralisation des échanges en Amérique latine et en Asie orientale ([TD/TC/WP(2007)6/PART2/A]) et quatre études de cas (Chili, Équateur, Philippines et Thaïlande) qui examinent les liens entre les échanges et l'ajustement structurel ([TD/TC/WP(2007)6/PART2/B] à [TD/TC/WP(2007)6/PART2/E]).

\section{La libéralisation des échanges dans les quatre pays à l'étude}

9. Avant de libéraliser leurs échanges, les quatre pays à l'étude ont mené une stratégie de développement reposant sur le remplacement des importations, qui était caractérisée par des droits de douane élevés et progressifs, la taxation directe ou indirecte des exportations (par exemple, de produits agricoles) et des obstacles non tarifaires ayant conduit à un biais anti-exportations et à une mauvaise répartition des ressources. Les quatre pays ont réalisé une réforme des échanges visant à mettre un terme au biais anti-exportations et à réduire les distorsions dans la répartition des ressources. Ces objectifs ont dans l'ensemble été atteints au terme de l'élimination/réduction des restrictions quantitatives, de la libéralisation des droits de douane et de l'abolition progressive des taxes à l'exportation. La réforme des échanges n'a pas été planifiée ni réalisée en bloc; en général, elle s'inscrivait dans un processus permanent qui comportait plusieurs étapes et qui, dans certains cas, a été annulé (voir tableau 3). La rapidité et l'ampleur de la libéralisation des droits de douane, ainsi que la nature des mesures de réforme, par exemple le traitement des restrictions quantitatives, variaient selon le pays : le Chili a opté pour une réforme radicale en profondeur tandis que l'Équateur, les Philippines et la Thaïlande ont adopté une approche 
graduelle. Dans tous ces pays, la réforme des échanges s'est déroulée dans le cadre d'une réforme économique globale de marché, qui ciblait, entre autres, la politique d'IDE, la politique de change, les marchés des capitaux et du travail, les marchés de produits et les programmes de privatisation.

Tableau 3. Résumé succinct des épisodes de libéralisation des échanges dans les quatre pays

\begin{tabular}{|c|c|c|c|c|c|c|c|c|}
\hline Pays (phase) & Années & $\begin{array}{c}\text { Motif de la } \\
\text { libéralisation }\end{array}$ & $\begin{array}{c}\text { Annulation des } \\
\text { mesures }\end{array}$ & $\begin{array}{c}\text { Motif de } \\
\text { l'annulation }\end{array}$ & $\begin{array}{c}\text { Réduction } \\
\text { des RQ }\end{array}$ & $\begin{array}{c}\text { Réduction } \\
\text { tarifaire }\end{array}$ & Dévaluation & $\begin{array}{c}\text { Pré- } \\
\text { annonce }\end{array}$ \\
\hline Chili 1 & 1973-79 & Crise & $\begin{array}{l}\text { Annulation } \\
\text { durant la } \\
\text { période 1983- } \\
85\end{array}$ & $\begin{array}{l}\text { Crise de la } \\
\text { balance } \\
\text { des } \\
\text { paiements }\end{array}$ & $\begin{array}{c}\text { Oui } \\
\text { (tarification) }\end{array}$ & $\begin{array}{c}100 \%> \\
10 \%\end{array}$ & $\begin{array}{l}\text { Oui }(73-75) \\
\text { Non }(75-79)\end{array}$ & $\begin{array}{l}\text { Non } \\
(1973-75) \\
\text { Oui }(75- \\
79) \\
\end{array}$ \\
\hline Chili 2 & $1985-89$ & $\begin{array}{l}\text { Crise / } \\
\text { conditionnalité } \\
\text { du soutien de } \\
\text { la Banque } \\
\text { mondiale }\end{array}$ & & & $\mathrm{S} / \mathrm{O}$ & $35 \%>15 \%$ & Oui & Non \\
\hline Chili 3 & 1990-05 & $\begin{array}{l}\text { Réduction des } \\
\text { distorsions }\end{array}$ & & & $\mathrm{S} / \mathrm{O}$ & $15 \%>6 \%$ & Oui & Oui \\
\hline $\overrightarrow{\text { Équateur } 1}$ & $1985-88$ & $\begin{array}{l}\text { Réduction des } \\
\text { distorsions / } \\
\text { conditionnalité } \\
\text { du soutien du } \\
\text { FMI }\end{array}$ & $\begin{array}{l}\text { Annulation en } \\
1989\end{array}$ & $\begin{array}{c}\text { Crise de } \\
\text { l'endetteme } \\
\text { nt, crise de } \\
\text { la balance } \\
\text { des } \\
\text { paiements } \\
\text { et crise } \\
\text { sociale }\end{array}$ & Oui & $59 \%>19 \%$ & Oui & Non \\
\hline Équateur 2 & $1989-93$ & $\begin{array}{l}\text { Communauté } \\
\text { andine }\end{array}$ & & & Oui & $37 \%>12 \%$ & Non & Oui \\
\hline Thaillande 1 & 1982 & $\begin{array}{l}\text { Réduction des } \\
\text { distorsions }\end{array}$ & $\begin{array}{l}\text { Annulation } \\
\text { durant la } \\
\text { période 1982- } \\
1984\end{array}$ & $\begin{array}{c}\text { Déficit } \\
\text { budgétaire }\end{array}$ & $\mathrm{S} / \mathrm{O}$ & & Limitée (84) & $\mathrm{S} / \mathrm{O}$ \\
\hline Thaillande 2 & 1993-97 & $\begin{array}{l}\text { Adoption } \\
\text { d'une stratégie } \\
\text { axée sur les } \\
\text { exportations }\end{array}$ & $\begin{array}{l}\text { Annulation en } \\
1997 \text { en raison } \\
\text { de la crise } \\
\text { asiatique }\end{array}$ & $\begin{array}{c}\text { Déficit } \\
\text { budgétaire } \\
\text { après la } \\
\text { crise }\end{array}$ & $\mathrm{S} / \mathrm{O}$ & $\begin{array}{c}\text { Moy. de } \\
40 \%> \\
15 \%\end{array}$ & Non & Oui (1990) \\
\hline Thaïlande 3 & 1999- & $\begin{array}{l}\text { Redressement } \\
\text { post-crise ; } \\
\text { Accord sur les } \\
\text { technologies } \\
\text { de } \\
\text { l'information et } \\
\text { accords de } \\
\text { libre-échange }\end{array}$ & & & $\mathrm{S} / \mathrm{O}$ & $\begin{array}{l}\text { Moy. de } \\
15 \%> \\
10 \%\end{array}$ & Oui (97) & Oui \\
\hline Philippines 1 & $1981-90$ & $\begin{array}{l}\text { Crise / } \\
\text { conditionnalité } \\
\text { du soutien de } \\
\text { la Banque } \\
\text { mondiale }\end{array}$ & $\begin{array}{l}\text { Interruption } \\
\text { provisoire en } \\
\text { 1983. Reprise } \\
\text { en } 1986\end{array}$ & $\begin{array}{l}\text { Crise de } \\
\text { l'endette- } \\
\text { ment et } \\
\text { crise de la } \\
\text { balance } \\
\text { des } \\
\text { paiements }\end{array}$ & Oui & $\begin{array}{l}\text { Moy. de } \\
43 \%> \\
\text { Moy. de } \\
28 \%\end{array}$ & Oui & Oui \\
\hline Philippines 2 & 1991-94 & $\begin{array}{l}\text { Simplification } \\
\text { de la structure } \\
\text { tarifaire }\end{array}$ & $\begin{array}{l}\text { Augmentation } \\
\text { des droits de } \\
\text { douane en } \\
\text { remplacement } \\
\text { des RQ }\end{array}$ & $\begin{array}{c}\text { Déficit } \\
\text { budgétaire }\end{array}$ & $\begin{array}{c}\text { Oui } \\
\text { (tarification) }\end{array}$ & $\begin{array}{c}10-50 \%> \\
3-30 \%\end{array}$ & Non & Oui \\
\hline Philippines 3 & 1994-97 & $\begin{array}{l}\text { Réduction des } \\
\text { distorsions }\end{array}$ & & & Oui & $\begin{array}{l}\text { Moy. de } \\
15 \%>\text { Moy. } \\
\text { de } 5 \%\end{array}$ & Non & Oui \\
\hline Philippines 4 & $2000-$ & $\begin{array}{l}\text { Réduction des } \\
\text { distorsions }\end{array}$ & $\begin{array}{l}\text { Interruption en } \\
2003\end{array}$ & $\begin{array}{l}\text { Secteurs } \\
\text { sensibles }\end{array}$ & $\mathrm{S} / \mathrm{O}$ & $\begin{array}{l}\text { Taux } \\
\text { uniforme de } \\
5 \%\end{array}$ & Oui & Oui \\
\hline
\end{tabular}

1. La définition et la numérotation des « phases » de la réforme des échanges sont très arbitraires. Par exemple, Papagergiou (1990) divise en deux étapes le processus de libéralisation du Chili, Chili 1(1956-61) et Chili 2 (1974-81). La numérotation vise uniquement à faciliter la consultation.

Source : Auteur, à partir des études de cas 
10. Des différences notables ont été constatées au chapitre du contenu de la réforme des échanges et des réformes complémentaires, ainsi que des résultats. S'agissant de la croissance du PIB, le Chili et la Thaillande ont surpassé l'Équateur et les Philippines. Dans la plupart des cas, la réforme des échanges a été suivie d'une augmentation des importations, des exportations et du ratio échanges/PIB. La rapidité et l'ampleur des hausses variaient, les importations ayant généralement augmenté plus rapidement que les exportations (tableau 4).

Graphique 2. Ratio échanges/PIB des quatre pays

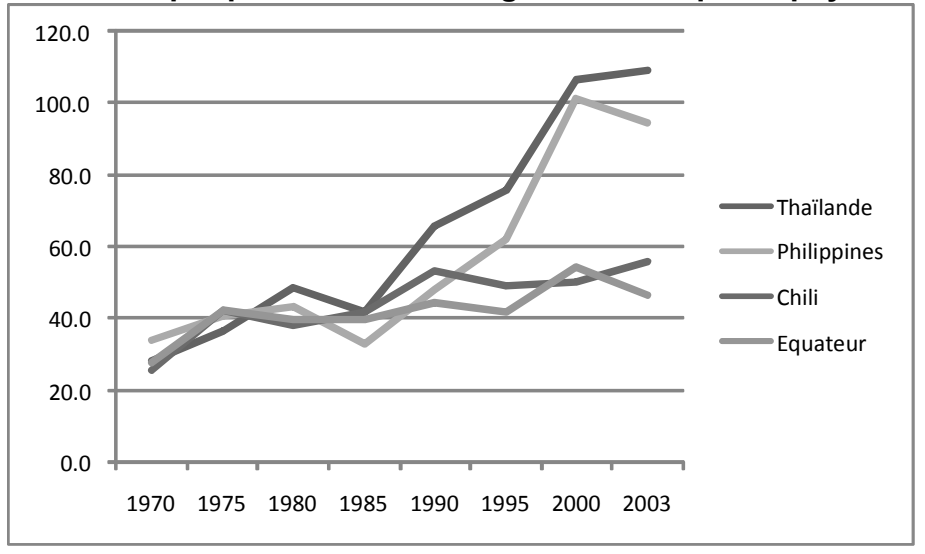

Source : Auteur, d'après les données des Indicateurs du développement dans le monde de la Banque mondiale

Tableau 4. Réaction des importations et des exportations à la réforme des échanges

\begin{tabular}{|c|c|c|c|c|c|}
\hline & & Année 1 & Année 2 & Année 3 & Année 4 \\
\hline \multirow[t]{2}{*}{ Moyenne } & Exportations & $13.7 \%$ & $15.7 \%$ & $13.3 \%$ & $16.1 \%$ \\
\hline & Importations & $16.9 \%$ & $17.2 \%$ & $10.3 \%$ & $8.5 \%$ \\
\hline \multirow[t]{2}{*}{ Chili 1973} & Exportations & $37.0 \%$ & $33.0 \%$ & $-0.9 \%$ & $15.3 \%$ \\
\hline & Importations & $23.4 \%$ & $20.2 \%$ & $1.1 \%$ & $19.0 \%$ \\
\hline \multirow[t]{2}{*}{ Chili 1985} & Exportations & $11.1 \%$ & $23.5 \%$ & $26.9 \%$ & $20.5 \%$ \\
\hline & Importations & $7.5 \%$ & $20.4 \%$ & $30.7 \%$ & $23.4 \%$ \\
\hline \multirow[t]{2}{*}{ Chili 1990} & Exportations & $6.5 \%$ & $3.3 \%$ & $9.6 \%$ & $18.8 \%$ \\
\hline & Importations & $13.7 \%$ & $14.8 \%$ & $14.7 \%$ & $17.0 \%$ \\
\hline \multirow[t]{2}{*}{ Équateur 1985} & Exportations & $-6.6 \%$ & $-7.9 \%$ & $2.8 \%$ & $10.4 \%$ \\
\hline & Importations & $3.2 \%$ & $-1.6 \%$ & $1.3 \%$ & $-1.2 \%$ \\
\hline \multirow[t]{2}{*}{ Équateur 1989} & Exportations & $9.2 \%$ & $8.9 \%$ & $3.0 \%$ & $10.5 \%$ \\
\hline & Importations & $11.5 \%$ & $11.2 \%$ & $12.9 \%$ & $17.1 \%$ \\
\hline \multirow{2}{*}{ Philippines 1981} & Exportations & $-2.5 \%$ & $0.4 \%$ & $5.1 \%$ & $-0.6 \%$ \\
\hline & Importations & $0.3 \%$ & $-6.9 \%$ & $-4.7 \%$ & $-11.9 \%$ \\
\hline \multirow[t]{2}{*}{ Philippines 1991} & Exportations & $11.1 \%$ & $14.6 \%$ & $21.0 \%$ & $22.1 \%$ \\
\hline & Importations & $13.4 \%$ & $21.0 \%$ & $22.6 \%$ & $22.7 \%$ \\
\hline \multirow{2}{*}{ Philippines 1994} & Exportations & $22.1 \%$ & $23.6 \%$ & $19.3 \%$ & $19.7 \%$ \\
\hline & Importations & $22.7 \%$ & $19.4 \%$ & $4.9 \%$ & $-1.3 \%$ \\
\hline \multirow[t]{2}{*}{ Thaïlande 1982} & Exportations & $-4.1 \%$ & $6.6 \%$ & $20.5 \%$ & $30.8 \%$ \\
\hline & Importations & $6.1 \%$ & $18.8 \%$ & $-10.3 \%$ & $0.6 \%$ \\
\hline \multirow[t]{2}{*}{ Thaïlande 1993} & Exportations & $44.4 \%$ & $46.0 \%$ & $24.7 \%$ & $-0.2 \%$ \\
\hline & Importations & $41.2 \%$ & $48.4 \%$ & $27.7 \%$ & $-22.1 \%$ \\
\hline \multirow[t]{2}{*}{ Thaïlande 1999} & Exportations & $25.8 \%$ & $14.0 \%$ & $4.8 \%$ & $29.1 \%$ \\
\hline & Importations & $41.3 \%$ & $23.9 \%$ & $10.0 \%$ & $30.1 \%$ \\
\hline
\end{tabular}

(Source : auteur, à partir de la base de données COMTRADE des Nations Unies)

Note : La croissance des exportations et des importations représentée sur le graphique correspond à une moyenne mobile sur trois ans des augmentations des échanges. Par exemple, pour Chili 1973, l'année 1 est la moyenne des hausses enregistrées en 1973, 1974 et 1975. 
11. Dans les quatre pays, on a assisté à un ajustement considérable de la structure de la production industrielle, des échanges et de l'emploi (graphique 3$)^{6}$. Si cet ajustement s'explique en partie par les changements technologiques (par exemple, dans l'industrie des textiles des quatre pays), et les réformes structurelles et le développement économique en général (par exemple, dans le secteur des produits plastiques de tous ces pays à l'exception de l'Équateur), l'évolution des échanges a également eu une grande incidence (par exemple, dans le secteur des produits électroniques aux Philippines et en Thaillande) ${ }^{7}$. Étant donné que la réforme des échanges s'inscrivait dans une réforme structurelle globale, il est difficile d'isoler les effets économiques de la libéralisation du commerce. Toutefois, l'enchaînement des réformes et la cohérence des politiques semblent avoir influé sur les résultats. Des facteurs externes tels que le resserrement de l'offre de capital et/ou la volatilité des prix des produits de base (pétrole, cuivre, etc.) ont également eu un impact.

Graphique 3. Évolution structurelle de l'emploi manufacturier des années 80 à la période récente

(Variation absolue en \% de la part des industries)

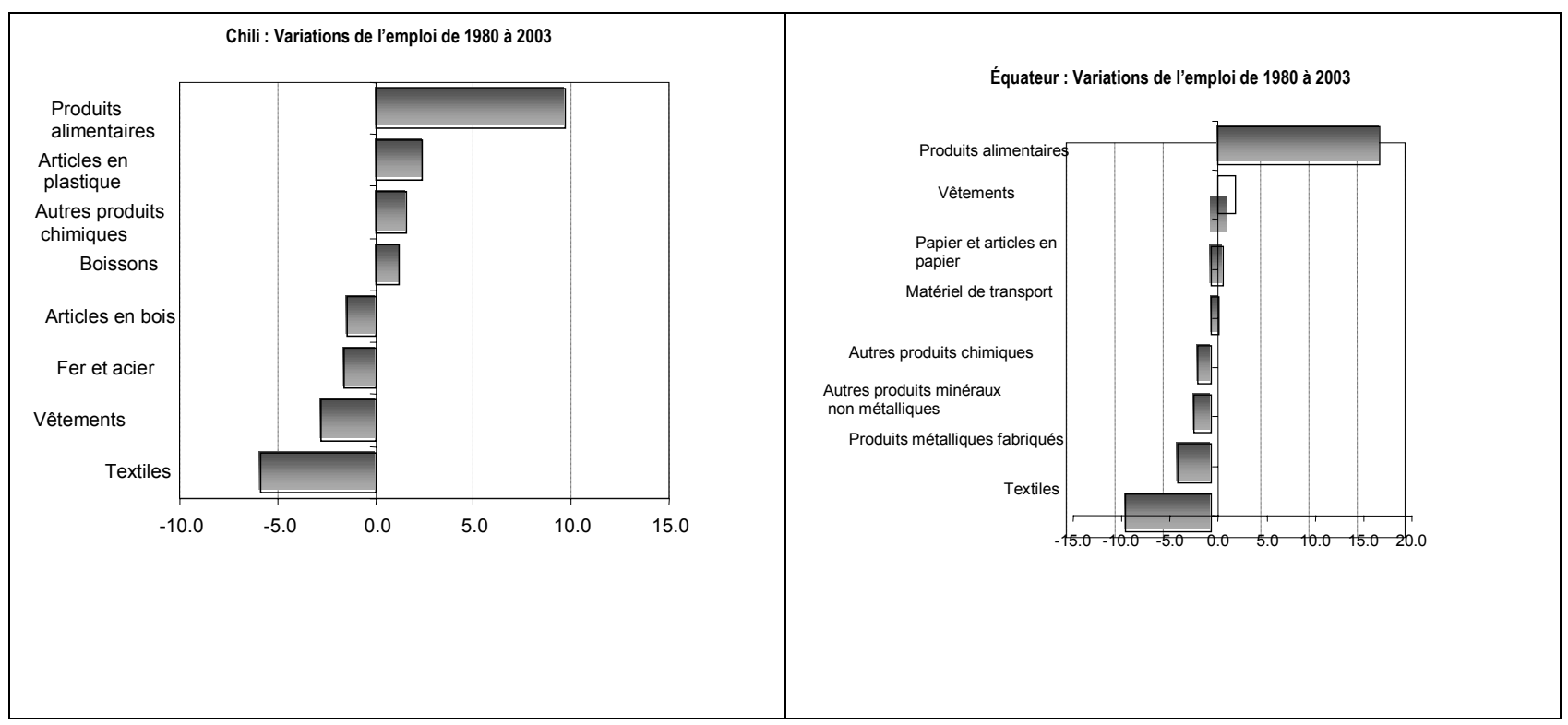

6. Le graphique 3 fait état des variations de la part de l'emploi manufacturier total correspondant à différentes industries. Par exemple, entre 1980 et 2003, l'industrie des produits alimentaires au Chili a vu sa part augmenter de $10 \%$ alors que celle des textiles a diminué d'environ $5 \%$. Voir l'étude régionale et les études de cas pour obtenir des précisions sur les variations structurelles de la production, des échanges et de l'emploi.

7. Les produits alimentaires au Chili et en Équateur, ainsi que l'équipement de transport en Thaïlande sont d'autres exemples d'industries où les exportations ont contribué aux changements structurels. En revanche, les vêtements et les produits du fer au Chili, les produits alimentaires aux Philippines sont des exemples d'industries où l'augmentation des importations a contribué à des pertes d'emploi. 


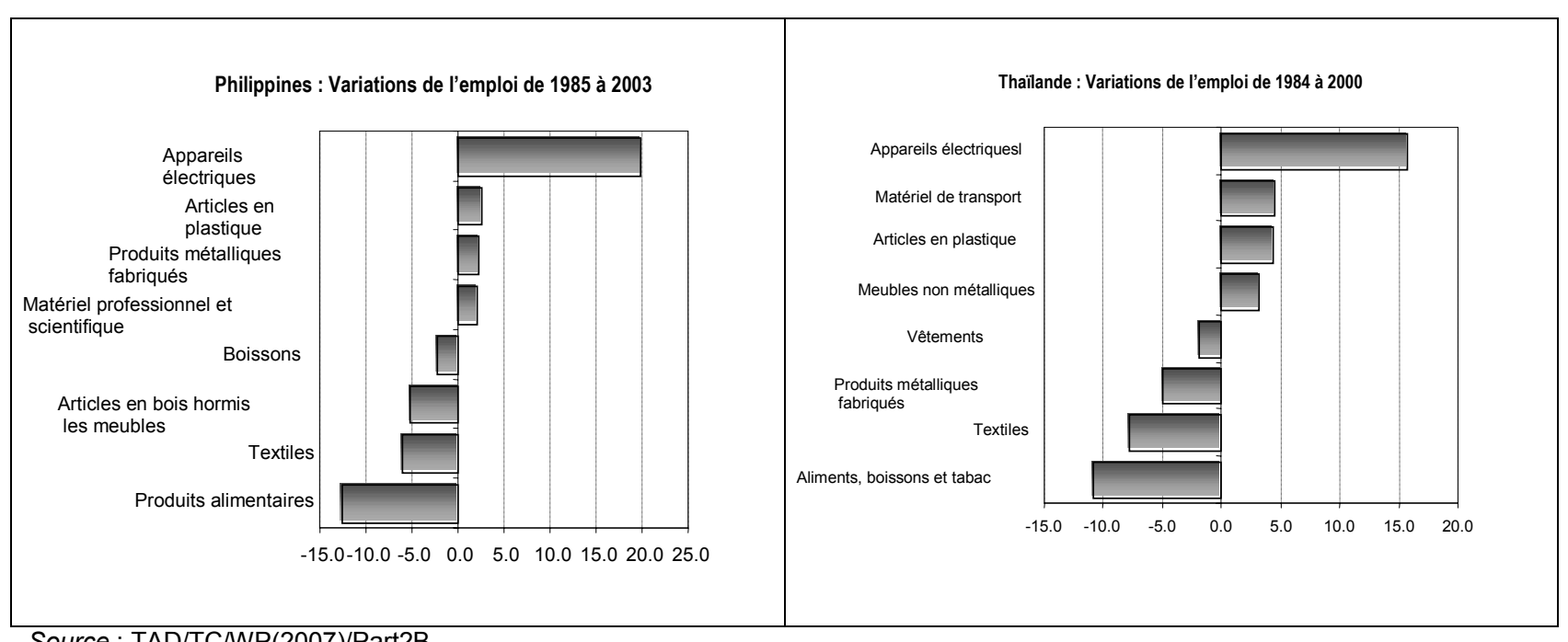

Source : TAD/TC/WP(2007)/Part2B

12. Une des principales leçons tirées des quatre études de cas est que, sans vouloir minimiser le rôle des importations, il faut dire que la réaction des exportations est cruciale de par son impact sur l'ajustement à la réforme des échanges. Dans les deux pays ayant réussi leur réforme des échanges, les exportations ont augmenté et ont été plus diversifiées dès le début du processus. En revanche, dans les deux pays où la réforme a été moins réussie, l'Équateur et les Philippines, l'augmentation et la diversification des exportations ont tardé à se concrétiser ou ont été insuffisantes ${ }^{8}$. Cela s'explique du fait que les exportations sont davantage limitées par des contraintes d'offre à court terme que les importations ${ }^{9}$. L'augmentation rapide des importations conjuguée à une réaction tardive des industries exportatrices peut entraver la réforme des échanges en ayant plusieurs conséquences: 1) un déséquilibre croissant de la balance commerciale pouvant être une source d'instabilité macroéconomique ; 2) une progression du chômage à court et à moyen terme; 3 ) une plus grande vulnérabilité aux chocs extérieurs ${ }^{10}$; 4) la difficulté d'empêcher l'érosion des appuis à la réforme des échanges ${ }^{11}$. Les exportations sont donc essentielles à la réalisation d'autres objectifs importants, soit une libéralisation plus poussée des importations et une croissance économique plus robuste (Hachete, 1991).

8. D'après des études récentes, les importations augmentent généralement plus vite que les exportations après la libéralisation des échanges, et la croissance des exportations est décalée (Santos-Paulino et Thirlwall, 2004 et Parikh, 2002). Ces conclusions semblent s'appliquer aux quatre pays à l'étude, à quelques exceptions près. Par exemple, lorsque l'économie nationale ralentit, les importations pourraient demeurer inchangées malgré une libéralisation poussée. Par contre, les exportations pourraient croître tout de suite après la libéralisation des échanges si la capacité de production est excédentaire. L’Équateur à la fin des années 80 constitue un exemple de la première exception et le Chili dans les années 70 , de la deuxième exception.

9. S'ils peuvent être confrontés à des contraintes de financement et de transport et/ou aux obstacles non tarifaires qui subsistent, les importateurs connaissent suffisamment les marchés et n'ont pas de contrainte d'offre, car ils peuvent s'approvisionner partout dans le monde. En revanche, les exportateurs n'ont pas forcément une connaissance suffisante de leurs marchés et doivent composer avec de plus grandes contraintes d'offre à court terme, puisque cela suppose une réorganisation de la production.

10. Du fait qu'un petit nombre de produits d'exportation tels que le pétrole, et les produits de base sont ses seules sources de devises, l'économie est plus sensible aux variations des prix des produits de base.

11. Lorsque des industries en concurrence avec les importations ont souffert de la réforme des échanges, le soutien à la réforme des échanges doit reposer sur une masse critique d'exportateurs. 


\section{3. «Échanges et ajustement structurel : Recommandations de bonnes pratiques »}

13. Dans les sections qui suivent, nous examinerons certaines des recommandations présentées dans le document susmentionné (OCDE, 2005) et les approfondirons en nous attardant aux pays en développement. Nous avons accordé une attention particulière aux questions de macroéconomie et d'économique politique dont devrait tenir compte le pays qui réalise une réforme des échanges. Nous avons conclu que, si la plupart des Recommandations sont avalisées par notre examen, certaines ne s'appliquent pas à certains pays en développement ou doivent être étoffées. Comme il en est fait mention dans l'étude initiale, toute recommandation de bonne pratique doit être étudiée avec attention. L'approche ne peut pas forcément être efficace partout. Il convient également de reconnaître que ces constatations sont dans une large mesure fondées sur les quatre études de cas, même si elles renvoient à d'autres études.

\section{1) Politiques en matière d'échanges et d'investissement}

14. Sur la question de la libéralisation des échanges, il ressort des Recommandations que les pays devraient adopter une politique de libéralisation des échanges qui facilite l'ajustement structurel, encourage la concurrence et l'innovation, améliore l'accès aux importations essentielles et accroît la synergie entre des pays ayant des avantages comparatifs différents. Une telle politique contribue à l'ajustement structurel en facilitant l'accès aux marchés étrangers et aux intrants offerts à des prix concurrentiels, et en réduisant les distorsions des prix attribuables aux droits de douane élevés et aux autres obstacles au commerce. Si les sauvegardes et les autres recours commerciaux peuvent atténuer les pressions exercées par l'ajustement, ces obstacles aux échanges ont rarement permis d'éviter l'ajustement à long terme.

15. Nous allons examiner plusieurs aspects des politiques en matière d'échanges et d'investissement et leur impact sur le processus d'ajustement afin de tirer des conclusions sur a) le rythme de la libéralisation des échanges (approche de choc ou graduelle); b) les restrictions quantitatives ; c) les avantages de l'uniformité et de la différenciation des droits de douane ; d) les services ; e) les politiques d'investissement.

a)

Rythme de la libéralisation des échanges - approche de choc ou graduelle

16. Sur la question du rythme de la libéralisation des échanges, les «bonnes pratiques » préconisent un calendrier de mise en œuvre suffisamment long pour que les parties concernées puissent s'ajuster, mais assez court pour éviter qu'elles ne fassent marche arrière. Selon la théorie économique, en l'absence de coûts d'ajustement, une libéralisation intégrale et immédiate (l'approche de choc) est souhaitable, car elle permet de tirer plus rapidement parti des avantages de la réforme ${ }^{12}$; de plus, aucun ajustement intermédiaire n'est effectué ${ }^{13}$. Des arguments d'économie politique militent également en faveur de l'approche de $\operatorname{choc}^{14}$. Nombre de pays ont tout de même suivi une approche plus graduelle. Les coûts

12. Dans la mesure où les avantages futurs seront actualisés en utilisant un taux d'intérêt, plus les avantages se concrétisent rapidement, plus leur valeur actualisée est grande.

13. Dans la mesure où les participants économiques procèdent à des ajustements intermédiaires, l'approche graduelle peut être plus coûteuse. Par exemple, un pays désireux de réduire la protection tarifaire des vêtements peut décider de réduire les droits par tranche de $10 \%$ durant quatre ans pour les faire passer de $50 \%$ à $10 \%$. Même si un taux de $10 \%$ ne peut assurer leur rentabilité, les entreprises de cette industrie peuvent effectuer des investissements intérimaires pour maintenir la production. Cet effet serait plus important si l'industrie jugeait peu crédible les réductions tarifaires à venir.

14. Par exemple, une approche de choc comportant des réformes en profondeur est souvent considérée plus crédible ; une réforme à petits pas pourrait être une indication de l'indécision des décideurs. À l'aide d'un modèle économétrique, Rodrik (1989a) démontre comment un gouvernement résolument réformiste peut se distinguer de ses homologues plus indécis en dépassant ses objectifs. De plus, l'approche graduelle peut 
d'ajustement, le cas échéant, peuvent être minimisés par une modulation des changements ${ }^{15}$. De même, on peut invoquer des arguments d'économie politique pour justifier l'approche graduelle ${ }^{16}$.

17. Parmi les quatre pays à l'étude, les expériences varient. Dans une situation de crise, le gouvernement peut réussir à "vendre " politiquement l'approche de choc. Celle-ci a parfois (mais pas toujours) été utilisée ${ }^{17}$, comme en témoignent les réformes réalisées par le Chili dans les années 70 , celles des Philippines dans les années 80 et la réforme des échanges en Thaïlande après la crise asiatique de $1997^{18}$. Au Chili, le biais anti-exportations marqué et l'importante capacité inutilisée ont fait en sorte que la réduction des grandes distorsions au début du processus a amené les exportateurs présents sur le marché à réagir rapidement. En revanche, aux Philippines, les réductions tarifaires relativement substantielles appliquées au début du processus n'ont pas eu un impact immédiat sur les exportations, en raison, entre autres, des obstacles non tarifaires et de la hausse du taux de change. En Thaïlande, la forte baisse du taux de change provoquée par la crise monétaire a constitué une occasion unique de libéraliser les échanges, une réforme qui a fait perdre leur raison d'être à la plupart des obstacles commerciaux, tout en facilitant la réaction des exportations.

18. Toutefois, certaines des réformes réalisées en période de crise ont été annulées par la suite (c'est ce qui s'est produit au Chili dans les années 70, en Équateur dans les années 80 et aux Philippines au début des années 80 ). De plus, ces réformes ont été jugées très coûteuses. Cela pourrait prouver que l'approche de choc devrait être écartée. Il convient toutefois de souligner que même lorsque les autorités ont fait marche arrière, l'orientation générale de la réforme a été maintenue, et une deuxième tentative a été fructueuse ${ }^{19}$.

19. Par contre, l'expérience de la Thaïlande montre que le gradualisme peut donner de bons résultats. Ce pays a procédé lentement, avec prudence, pour libéraliser ses échanges, prenant parfois des mesures peu orthodoxes. Cela lui a permis d'aller de l'avant avec la réforme tout en veillant à ce que les finances

laisser plus de temps aux opposants à la réforme pour s'organiser, et peut donc se traduire par une résistance farouche (Krueger, 1993).

15. Mussa (1986) donne un argument qui justifie l'approche graduelle lorsque des industries protégées utilisent des ressources qui ne peuvent être employées ailleurs. En pareil cas, ces ressources cesseront d'être utilisées au terme d'une réduction des niveaux de protection. Si l'ajustement résulte principalement de la dépréciation et de l'attrition, une libéralisation qui se déroule à un rythme plus rapide que ce qui serait nécessaire pour éviter que des capitaux soient injectés et que des travailleurs soient formés pour travailler dans les industries en déclin ne permettrait guère d'accroître l'efficience.

16. Lorsque la mise en œuvre de la réforme est graduelle, il se pourrait que les appuis mobilisés ne cessent de croître (quoique, comme nous l'avons vu ci-dessus, cela pourrait tout aussi bien laisser le temps aux opposants de se regrouper).

17. Une crise peut être synonyme d'état de grâce pour les réformateurs, qui pourraient ainsi prendre des mesures politiquement impossibles dans une situation normale (Haggard et Webb, 1994). Une analyse empirique nationale décrite dans OCDE (2007a) révèle qu'un profond ralentissement économique est généralement associé à une réforme plus intensive.

18. Il convient de souligner que, au Chili, les réformes ont été réalisées sous la dictature militaire. Aux Philippines, la réforme des échanges a été amorcée sous la dictature et a été relancée par le régime mis en place au terme de la « révolution du pouvoir du peuple» de 1986.

19. Les pays d'Europe de l'Est et le Pérou ont mené à bien un programme de stabilisation tout en réduisant les obstacles au commerce et en réalisant de nombreuses autres réformes (Nash et Takacs, 1998). Dans ces pays, l'approche de choc a généralement été jugée efficace. De l'avis de certains, elle a donné de meilleurs résultats dans le centre et l'est de l'Europe qu'en Russie du fait qu'il y avait suffisamment d'affinités culturelles et institutionnelles pour que les institutions puissent être importées. D'autres ont imputé l'échec russe au fait que la réforme était incomplète (Kramer, 1999). 
publiques en souffrent le moins possible et à ce que les institutions puissent s'adapter. La réduction tarifaire effectuée par le Chili - de 11 à $6 \%$ - dans les années 90 avait été progressive et annoncée au préalable, et semble avoir engendré des coûts d'ajustement beaucoup plus faibles. En revanche, la dernière réforme des échanges réalisée aux Philippines, qui avait fait l'objet d'une préannonce, a été interrompue, ce qui confirme que le préavis n'est pas un gage de succès.

20. Les deux approches ont donné lieu à des réussites et à des échecs ${ }^{20}$; l'efficacité de l'approche dépend visiblement des circonstances particulières. Une approche graduelle pourrait être justifiée si les coûts d'ajustement sont élevés, si les différentes réformes n'atteignent pas leurs objectifs au même rythme, et si les effets de la réforme sont incertains. En outre, une réforme progressive permet aux institutions de s'adapter. Par ailleurs, on a démontré qu'elle peut entraîner des coûts moindres si les distorsions sont moins prononcées (la Thaillande; le Chili dans les années 90). Toutefois, dans certaines situations, par exemple en cas de crise et de distorsions graves, l'approche de choc peut toute de même être viable d'un point de vue politico-économique et économique. Dans les pays confrontés à des distorsions marquées, une amorce de réforme qui vient à bout des distorsions les plus dévastatrices pourrait bien se solder par des coûts élevés à court terme (par exemple au Chili dans les années 70). Par contre, une réforme différée ou une approche graduelle ne se traduit pas forcément par des coûts plus bas (par exemple, aux Philippines).

b)

Restrictions quantitatives

21. Bien que les restrictions quantitatives ne soient pas explicitement mentionnées dans les Recommandations, leur réduction ou élimination fait partie intégrante de la réforme des échanges. En effet, leur impact sur l'efficience économique et les échanges est plus nuisible que celui des droits de douane du fait que les ressources sont affectées par les gestionnaires de l'État, plutôt que par les mécanismes de détermination des prix (Czaga, 2005). Les contingents permettent également aux importateurs de vendre leurs produits à meilleur prix, et par conséquent, de réaliser une rente de contingentement ou un plus grand bénéfice, ce qui peut ouvrir la voie à la corruption.

22. On constate de grandes différences entre les quatre pays au chapitre de la réforme des échanges, qui témoigne de l'importance de l'élimination des restrictions quantitatives au début du processus. En Thaillande, ces restrictions ont historiquement joué un rôle secondaire. Le Chili est l'exemple-type du pays qui a aboli les restrictions quantitatives pour les remplacer par des droits de douane à l'amorce de la libéralisation des échanges. L'absence de restrictions quantitatives (Thaïlande) et leur élimination rapide (Chili) ont grandement facilité les échanges et simplifié leur libéralisation. Aux Philippines, la réduction de ces restrictions a été graduelle, s'étalant sur plus de 15 ans. Fait intéressant à souligner, la croissance des échanges permise par les réformes a été faible au début des années 80 et ne s'est accélérée vraiment qu'à partir de 1986, lorsque les autorités ont réactivé les réformes tarifaires en mettant l'accent sur l'élimination des restrictions quantitatives. Au Chili et aux Philippines, le remplacement des contingents d'importation par des droits de douane a accru la transparence et réduit le lobbying pour l'obtention des licences d'importation et la maximisation de la rente.

20. Il convient également de préciser que la frontière entre l'approche de choc et l'approche graduelle n'est pas clairement délimitée. Par exemple, on pourrait considérer que la première réforme des échanges réalisée par le Chili dans les années 70 porte la marque de l'approche de choc, car les droits de douane ont été abaissés de plus de $100 \%$ à $10 \%$ en cinq ans et l'initiative a été complétée par d'autres mesures de réforme telles que des privatisations, la réforme du marché du travail, la libéralisation du secteur financier, etc. On peut également soutenir qu'elle était graduelle, puisque les réformes étaient incomplètes et n'étaient pas simultanées. De plus, une forte réduction tarifaire (par exemple, de $200 \%$ à $30 \%$ ) peut avoir peu d'impact, tandis qu'une baisse relativement modeste (par exemple, de $15 \%$ à $5 \%$ ) peut avoir une grande incidence en fonction de la pente de la courbe de la demande et de la courbe de l'offre. 
23. En Équateur, l'élimination des restrictions quantitatives a été lente et partielle (imposition de contingents tarifaires), les distorsions des signaux prix ayant subsisté. L'absence de variation des échanges malgré les réductions tarifaires pourrait être en partie attribuable à l'existence de restrictions quantitatives non transparentes. Cela illustre également la difficulté d'abolir ces mesures une fois que le processus est bien entamé. Il a parfois été difficile de supprimer les restrictions quantitatives en raison de leur utilité : pour l'administration publique, il est plus facile de prévoir les niveaux des échanges ; pour les entreprises nationales, elles sont synonymes de protection, et pour les importateurs qui détiennent des contingents, de rente substantielle. Selon toutes les études qui ont été réalisées, la réduction des restrictions est primordiale au début de la réforme des échanges. Papageorgiu et al. (1990) vont jusqu'à affirmer qu'il s'agit d'un des faits qui sont ressortis le plus clairement. Les quatre études de cas nationales corroborent ces constatations.

\section{Avantages de l'uniformité et de la différenciation tarifaires}

24. Si elles ne sont pas explicitement mentionnées dans les bonnes pratiques, l'uniformité et la différenciation tarifaires peuvent cependant influer sur le processus d'ajustement. L'uniformité tarifaire se justifie du fait qu'elle engendre généralement moins de distorsion et présente plusieurs avantages aux plans administratif $^{21}$ et politico-économique ${ }^{22}$. Quant à la différenciation tarifaire, c'est davantage la marge de manœuvre qu'elle procure aux autorités (par exemple, une distorsion délibérée des prix peut favoriser certaines industries et les taxes sur les produits de luxe permettent une redistribution des revenus).

25. À cet égard, l'expérience des pays à l'étude est très différente. Le Chili a démontré que l'uniformité des droits de douane peut donner de très bons résultats en réduisant le lobbying. Les secteurs des produits exportables et des produits non échangeables étaient favorables à la libéralisation des échanges, même si elle était unilatérale, car la diminution des droits de douane rend les intrants plus abordables. L'uniformité tarifaire est un des arguments invoqués en faveur de l'annulation de la décision de porter les droits de douane à $35 \%$ dans les années 80 , nombre d'industries (exportatrices ou non) qui utilisaient des ressources importées ayant fait pression sur les autorités pour qu'elles fassent marche arrière.

26. Les trois autres pays (Équateur, Philippines et Thaïlande) avaient mis en place une structure tarifaire différenciée, caractérisée par la progressivité des droits (les produits de consommation étaient assujettis à des droits plus élevés et les produits intermédiaires et les biens d'équipement, à des droits plus bas). Tous ont conclu que, dans les faits, cette structure accordait un niveau élevé de protection aux industries de remplacement des importations, ce qui s'est traduit par un surinvestissement dans les industries inefficientes de produits substituables et un sous-investissement dans les industries où le pays détient un avantage comparatif. Les trois pays ont réalisé une réforme tarifaire.

27. La Thaillande a d'abord suivi une politique de remplacement des importations comportant une structure de droits de douane élevés et progressifs, tout en remédiant en partie au biais anti-exportation au moyen de divers exemptions tarifaires et remboursements. Si l'on en juge d'après les résultats obtenus dans les années 70 et au début des années 80 , cette stratégie a dans une large mesure atteint ces deux objectifs. Il convient toutefois de souligner que, à moyen terme, la Thaïlande est arrivée à la conclusion

21. D'un point de vue administratif, l'uniformité se justifie comme suit. Puisqu'elles n'ont pas à se demander quel taux de droit doit être appliqué, les autorités douanières n'ont pas à vérifier dans le détail la classification des produits. Le dédouanement devrait être accéléré, et les investisseurs consacrent moins de ressources pour comprendre une structure tarifaire complexe (Panagariya, 1990).

22. Un des principaux arguments en faveur de l'uniformité tarifaire est lié à l'économie politique. Seules les entreprises qui font du lobbying doivent en acquitter le coût. Par contre, les droits de douane élevés — le fruit du lobbying - profitent à tous, y compris aux entreprises qui n'en font pas. Par conséquent, l'éventualité du « parasitisme » réduit le lobbying. 
que sa structure tarifaire complexe et sa multitude d'exemptions et remboursements étaient de plus en plus inefficients et coûteuses pour les petites et moyennes entreprises, et a réduit tous les droits de douane. Les Philippines et l'Équateur ont également simplifié leur structure tarifaire en abaissant les droits de douane généraux. Par conséquent, bien que l'uniformité tarifaire présente des avantages importants, on ne peut pas conclure qu'elle est forcément préférable à la différenciation. Quoi qu'il en soit, on a assisté à une convergence vers la simplification des structures tarifaires avec en toile de fond l'augmentation des niveaux des échanges.

d)

Services

28. Suivant les Recommandations, les pays devraient adopter une politique commerciale libérale qui maximise le bien-être et les avantages découlant de la libéralisation des échanges de services. Selon OCDE (2005a), la libéralisation de ces échanges sera vraisemblablement très bénéfique pour trois raisons. Premièrement, elle peut accroître le bien-être beaucoup plus que ne le ferait la libéralisation des échanges de biens de par l'importance des services dans nombre d'économies. Deuxièmement, en raison du dynamisme du secteur des services, le poids de l'ajustement que requiert la libéralisation des échanges de services pourrait bien être plus facile à supporter que celui associé aux biens. Troisièmement, la libéralisation des services qui entrent dans la production agricole et manufacturière est susceptible d'alléger le fardeau de l'ajustement dans ces secteurs.

29. Bien que l'on ne se soit pas attardé sur son impact dans la présente étude, le secteur des services représentait environ $50 \%$ du PIB dans les pays étudiés (Chili - $48 \%$, Équateur - $48 \%$, Philippines - $53 \%$ et Thaillande - $46 \%$ en 2005, Indicateurs du développement dans le monde). Comme nous le verrons ci-dessous dans la section sur la protection sociale, le secteur informel, qui repose dans une large mesure sur les services, a absorbé une partie du chômage de courte durée engendré par l'ajustement.

30. L'essor des technologies des télécommunications permet à certains pays en développement de tirer parti de l'abondance de main-d'œuvre et des possibilités d'externalisation. La croissance rapide des processus administratifs et des services informatiques en sous-traitance aux Philippines en est un bon exemple $^{23}$. Dans ce pays, ainsi qu'en Équateur, les envois de fonds des travailleurs expatriés ${ }^{24}$ ont contribué dans une large mesure à la stabilité macroéconomique au moment où les autorités n'arrivaient plus à financer le déficit à l'étranger. En 1999, après la crise asiatique, les Philippins expatriés ont transféré dans leur pays d'origine 10.7 milliards USD par l'entremise des banques, un montant qui excédait le déficit de la balance commerciale de 7.5 milliards USD. De plus, ces envois ont pris de l'importance en tant que source de financement des petites entreprises, qui sont généralement concentrées dans les micro-services tels que la vente au détail (par exemple, les petits commerces de proximité), les transports (par exemple, les véhicules de transport en commun) et les services personnels (par exemple, les salons de coiffure pour hommes). En Équateur, les envois des travailleurs expatriés ont également connu une forte croissance, s'établissant à $7 \%$ du PIB en 2006, et procurent plus de devises au pays que l'investissement direct étranger. En Thaillande, les recettes touristiques et les envois des travailleurs expatriés, dont la valeur était

\section{Voir également Engman (2007).}

24. Il convient de souligner que les envois ne rendent pas parfaitement compte des activités relevant du mode 4 parce qu'ils surestiment les échanges de services selon le mode 4 en incluant les paiements internationaux qui sont (1) associés à l'emploi dans l'agriculture, les activités extractives ou manufacturières à l'étranger et (2) associés aux transferts liés à une présence relativement longue à l'étranger que l'AGCS n'envisage pas, alors qu'ils sous-estiment ces échanges en (3) couvrant une partie seulement des gains. Malgré leurs inconvénients, les envois de fonds des travailleurs expatriés semblent être des indicateurs utiles de la valeur des échanges selon le mode 4 (OCDE, 2007b). 
négligeable dans les années 70, ont atteint 69.2 milliards et 21.1 milliards THB en 1989, soit $57 \%$ et $17 \%$ du déficit commercial ${ }^{25}$.

31. Les études de cas nationales témoignent également de l'importance des services pour la production et la livraison d'autres services et de biens ${ }^{26}$. En Thaillande, les monopoles et les oligopoles, des réglementations déficientes et la concurrence inefficace ont fait grimper les coûts de télécommunication, soit de 80 à $90 \%$ (Dee, 2004), notamment pour les entreprises exportatrices. Elles font également ressortir la difficulté de réaliser une réforme de la réglementation des services de réseau ${ }^{27}$. Aux Philippines, l'infrastructure de transport relativement déficiente est un des principaux obstacles auxquels le secteur de la transformation alimentaire est confronté : d'après les estimations de l'État, environ 30 à $40 \%$ des récoltes sont perdues, et il pourrait en coûter plus de 1.5 fois plus qu'en Thaïlande pour exporter un conteneur type. Par contre, la déréglementation des télécommunications a été le moteur du développement $\mathrm{du}$ secteur philippin des processus administratifs et des services informatiques externalisés. En Équateur, l'amélioration du transport aérien a grandement contribué à la réussite des exportateurs de fleurs coupées. D'après les études de cas, une libéralisation accrue des échanges de services peut faciliter l'ajustement structurel en créant des emplois et en améliorant la productivité des utilisateurs dans les secteurs de l'agriculture et de la fabrication.

e)

Politique d'investissement direct étranger

32. S'agissant de la politique d'investissement, les Recommandations incitent les pays à optimiser les possibilités de flux d'investissement direct étranger (IDE) qui accompagnent une politique commerciale libérale. Une économie à vocation exportatrice peut être plus en mesure d'attirer l'IDE, lequel peut accroître la compétitivité des exportations (OCDE, 2004a).

33. Cela ne fait aucun doute d'après les quatre études de cas, car l'IDE joue un rôle important dans les quatre pays, quoique à des degrés divers. C'est en Thaïlande que sa contribution a été la plus décisive, alimentant la croissance des exportations dans des secteurs tels que l'électronique et l'automobile. L'IDE a également aidé la Thaïlande à se relever de la crise asiatique en lui permettant de restructurer sa dette. Aux Philippines, les retards dans la déréglementation des restrictions à l'IDE alliés à la situation politique instable se sont avérés coûteux, empêchant le pays de profiter de la première vague d'IDE en Asie au début et au milieu des années 80 . L'IDE revêt une plus grande importance depuis que le pays s'est ouvert à l'IDE, comme en témoigne l'essor de l'électronique. Le secteur philippin du ciment, qui était fragmenté et inefficient, a également pu se restructurer grâce à l'IDE, qui a donné naissance à de grands groupes efficients. Au Chili, l'investissement intérieur a été prédominant en volume, surtout jusqu'au début des années 90. L'IDE a joué un rôle secondaire, mais néanmoins important, en tant que source de savoir-faire

25. Geloso Grosso et al. (2007) ont mis en relief l'importance cruciale que le tourisme peut représenter pour les pays en développement en tant que source de devises, et ont fait remarquer que la libéralisation des échanges peut contribuer au développement de ce secteur.

26. Lesher et Nordas (à publier en 2007) examinent les liens entre l'ouverture aux échanges de services et les résultats commerciaux dans l'industrie manufacturière et constatent qu'une augmentation de l'indice de restrictivité de l'IDE dans certains services tels que les services aux entreprises, les services financiers et les transports par eau a eu en moyenne un impact négatif non négligeable sur la part exportée de la production brute des industries manufacturières.

27. Geloso Grosso (2006) examinent les principaux problèmes posés par la libéralisation des services d'infrastructure de réseau, dont les télécommunications, les activités de poste et de courrier, l'énergie, la distribution d'eau et l'assainissement, et constatent que, à condition d'être bien conçue, la libéralisation peut contribuer au développement, mais que c'est un processus délicat qui nécessite une réglementation saine et des institutions efficaces capables de remédier aux défaillances du marché et d'assurer les objectifs de politique publique. 
et de technologie dans certains secteurs (par exemple le cuivre, le vin et le saumon). En Équateur, la contribution de l'IDE a été plus modeste, bien qu'elle ait été pour beaucoup dans la croissance des entreprises de fleurs coupées et de transformation du thon. Par conséquent, les quatre pays à l'étude font ressortir l'importance de jumeler la réforme des échanges et la réforme du cadre réglementaire de l'IDE.

34. Si l'IDE peut être avantageux, il faut veiller à ce que les mesures destinées à le promouvoir, le cas échéant, ne soient pas excessives. Souvent, l'investissement continue de reposer principalement sur les entreprises nationales. Bien que certains pays aient accordé des incitatifs afin d'aiguiller l'IDE axé sur les exportations vers les industries très prometteuses au plan des gains de productivité et des relations industrielles verticales avec les entreprises nationales, et que cette stratégie puisse être judicieuse en raison des économies d'échelle et des gains dynamiques provenant des échanges, il n'est pas forcément justifié d'encourager fortement l'investissement. Les généreux incitatifs à l'IDE sont accordés au détriment d'autres facteurs, l'investissement intérieur notamment; ils créent d'autres distorsions et compromettent l'impact favorable de l'IDE sur l'efficience. Si on reconnait généralement que le contexte global, par exemple la stabilité politique et macroéconomique, et la qualité des infrastructures ont une plus grande incidence sur l'investissement, on obtient de meilleurs résultats en cherchant avant tout à créer un cadre propice aux affaires pour tous les investisseurs ${ }^{28}$.

\section{2) Politique macroéconomique}

35. Sur la question de la politique macroéconomique, les Recommandations incitent les pays à promouvoir la stabilité macroéconomique et la croissance afin de mettre en place un cadre propice à l'ajustement qui contribue au bon fonctionnement du marché du travail et de l'économie en général, et qui, surtout dans les pays en développement, complète le processus de libéralisation des échanges 1) par une absence de biais anti-exportation et une politique de change appropriée, et 2) en encourageant la réforme de la fiscalité afin de compenser la diminution des recettes publiques suite aux réductions tarifaires. Dans la présente section, nous nous pencherons d'abord sur la stabilité macroéconomique, puis sur les taux de change et l'impact budgétaire.

36. Les quatre études de cas témoignent de l'importance de la stabilité macroéconomique dans le processus d'ajustement, tout en soulignant certains problèmes propres aux pays en développement (voir les encadrés 1 et 2). Au Chili avant les années 90 et en Thaïlande avant la crise asiatique, la stabilité macroéconomique a manifestement facilité l'ajustement structurel, alors qu'en Équateur et aux Philippines, l'instabilité macroéconomique a entravé son bon déroulement pendant de longues périodes. Donc, il ne fait aucun doute que la stabilité macroéconomique est souhaitable. Il convient de se demander si elle est essentielle à la réussite de la réforme des échanges. D'après les quatre études de cas nationales, la réponse est négative. Les programmes de réforme des échanges ont souvent été amorcés en période de crise et d'instabilité macroéconomique ${ }^{29}$.

37. Il n'est pas rare que la réforme des échanges soit enclenchée sur fond de crise, c'est notamment parce qu'elle est souvent prescrite par le FMI et la Banque mondiale (c'est ce qui s'est produit au Chili au début des années 80, aux Philippines dans les années 80 et en Thaïlande après la crise asiatique $)^{30}$. Toutefois, il y a eu des cas où la réforme a été mise en œuvre en période de crise, sans intervention

28. Pour une analyse détaillée de l'IDE, voir le Cadre d'action de l'OCDE pour l'investissement (OCDE, 2006).

29. Les économistes n'ont pas été en mesure de trancher la question de savoir si la libéralisation des échanges entrave la stabilité macroéconomique ou y contribue. Voir Papagiorgiou et al. (1990), Nash et Takacs (1998), Goldsbrough et al. (1996), entre autres.

30. On pourrait soutenir que les autorités de ces pays ont été contraintes d'attendre que la situation macroéconomique se soit stabilisée pour réaliser la réforme des échanges. 
extérieure (au Chili dans les années 70 et aux Philippines dans les années 90). À cet égard, on peut avancer une explication économique et politico-économique. D'un point de vue économique, les distorsions des échanges créées par les droits de douane élevés ont souvent été la cause principale des crises, de sorte que leur élimination arrivait en tête de liste des priorités de la réforme. Une forte baisse du taux de change engendrée par une crise monétaire pourrait également ouvrir la voie à la libéralisation des échanges qui priverait la plupart des obstacles commerciaux de leur raison d'être (comme en Thaïlande après la crise asiatique). D'un point de vue d'économie politique, la crise constitue pour un nouveau gouvernement une occasion unique de réaliser une réforme qui pourrait être difficile à faire accepter dans d'autres circonstances ${ }^{31}$.

38. Bien qu'elle ne soit pas une condition préalable à la réforme des échanges ${ }^{32}$, la stabilité macroéconomique est néanmoins nécessaire pour assurer sa viabilité à long terme ${ }^{33}$. Le Chili et les Philippines dans les années 80, et l'Équateur au milieu de cette décennie sont des exemples de pays qui ont dû suspendre la réforme en raison de crises de l'endettement ou de la balance des paiements, qui étaient en partie liées à la diminution du financement international et/ou au recul des prix des produits de base, ainsi qu'au manque d'harmonisation des politiques complémentaires. Cependant, il s'agissait d'interruptions provisoires, les réformes des échanges ayant été relancées avec plus de succès dans les quatre pays à l'étude ${ }^{34}$. Si un échec peut réduire la crédibilité de la réforme, la réorientation de la stratégie n'entache pas forcément la crédibilité des autorités.

31. Une analyse empirique portant sur plusieurs pays confirme qu'un ralentissement économique marqué est généralement associé à une intensification des réformes. Parmi les pays de l'OCDE où ces conditions ont été observées, mentionnons le Royaume-Uni à la fin des années 70, les Pays-Bas et la Nouvelle-Zélande dans les années 80 et l'Italie au début des années 90 (OCDE, 2007a).

32. Sur le fait de savoir si la stabilisation et la réforme des échanges peuvent être engagées simultanément ou s'il convient plutôt de procéder successivement, Edwards (1989) estime que la réponse dépend en grande partie de l'importance du déséquilibre macroéconomique initial.

33. Selon Michaely et al. (1990), l'instabilité macroéconomique est la principale cause de la réorientation de la stratégie. Plusieurs mesures de libéralisation des échanges ont été annulées lorsque des problèmes macroéconomiques se sont posés ou se sont aggravés. Rajapatirana (1997) explique que la contraction des échanges qui s'est produite au Brésil (1973-74) et au Costa Rica (1974) était liée au premier choc pétrolier, tandis qu'en Argentine (1982), au Brésil (1981-84) et en Colombie (1982), elle a été accélérée par le second choc pétrolier. La crise de la dette a entraîné des restrictions aux échanges au Brésil (1981-84), au Costa Rica (1982-84) et au Mexique (1980-82).

34. Papageorgiou (1990) a étudié 13 pays dont la première tentative de libéralisation des échanges a avorté ou ne s'est poursuivie qu'en partie. Onze d'entre eux ont réitéré leurs efforts. Cinq de ces deuxièmes tentatives (Chili, Indonésie, Nouvelle-Zélande, Sri Lanka et Turquie) ont été soutenues, cinq (Colombie, Espagne, Pakistan, Philippines et Portugal) l'ont été en partie et une seule (Argentine) a échoué. Quatre des cinq réformes réussies à la deuxième tentative ont été réalisées avec vigueur alors que cinq des six tentatives qui ont été soutenues en partie ou ont avorté dénotaient un manque d'ardeur. 
TAD/TC/WP(2007)6/PART1/FINAL

\section{Encadré 1. Obstacles à la stabilité macroéconomique - libéralisation du marché des capitaux}

Les quatre études de cas montrent que la prudence est de mise dans la réalisation d'une réforme des marchés des capitaux, même si elle constitue un élément important de la réforme économique globale. L'accès au marché des capitaux à des taux concurrentiels est essentiel au développement et à une croissance accélérée. Cependant, l'ouverture du compte capital peut se traduire par une forte augmentation des entrées de capitaux si l'offre mondiale de capitaux est relativement excédentaire, quels que soient les besoins du pays à cet égard.

Par exemple, si un pays imposant des droits de douane élevés libéralise le compte capital, il peut y avoir surinvestissement dans les industries capitalistiques dont la production destinée à remplacer les importations est inefficiente (par exemple, ce fut le cas des Philippines dans les années 70 et du Chili dans les années 80). La hausse du taux de change provoquée par les entrées de capitaux accélère le mouvement des capitaux vers les secteurs de produits non échangeables tels que l'immobilier, ce qui est aux antipodes de l'objectif visé par la libéralisation des échanges (Chili dans les années 80 et Thaïlande avant la crise asiatique). En l'absence d'une réglementation prudentielle adéquate et d'un cadre réglementaire, ces mouvements de capitaux pourraient bien provoquer une crise financière si le contexte change (évolution de l'offre mondiale de capitaux, variations du taux de change, etc.).

\section{Encadré 2. Les défis macroéconomiques des pays riches en ressources - Chili et Équateur}

Le Chili et l'Équateur offrent deux exemples de pays qui ont été confrontés à des chocs des termes de l'échange au niveau macroéconomique. Du fait que leurs exportations et leurs recettes publiques reposent sur les produits de base, ils ont eu du mal à gérer les cycles d'expansion et de ralentissement, et à ne pas suivre une politique par à coup alternant les réformes structurelles et les retours en arrière. Leur dépendance envers certains produits de base les a exposés à ce qui est communément appelé le syndrome hollandais. Le renchérissement des produits de base peut entraîner une appréciation de la monnaie, car la demande de la monnaie nationale suit les exportations des produits de base. Une telle hausse de la monnaie nuit à la diversification des exportations. De plus, lorsque les recettes publiques sont exceptionnelles, les autorités sont incitées à trop dépenser en période d'expansion, ce qui se traduit par un déficit budgétaire élevé durant la phase de ralentissement subséquente.

Le Chili est progressivement arrivé à mieux gérer le cycle du cuivre en établissant des règles budgétaires qui dissocient les dépenses publiques des rentrées exceptionnelles et des ralentissements, et en adoptant une politique de change prudente visant à assurer la symétrie des taux de change réels et à éviter les erreurs macroéconomiques et monétaires de la fin des années 70 et du début des années 80 , lesquelles avaient provoqué la crise des banques et de l'endettement en 1983. Cela a permis au pays de diversifier de plus en plus ses exportations.

L'Équateur est un exemple de pays dont les efforts ont été moins fructueux. Des années 80 à 2000, le pays a procédé par à coups, les épisodes de resserrement budgétaire ayant été interrompus par des augmentations incontrôlées des dépenses publiques qui se sont soldées par de gros déficits et une escalade de l'endettement, et, par conséquent, plusieurs défauts de paiement ou suspensions temporaires des paiements. En 2002, le gouvernement a adopté une loi sur la gestion responsable des finances qui, entre autres, a plafonné la croissance des dépenses réelles de l'administration centrale et a créé un fonds pétrole hors budget (FEIREP) à partir du produit de la vente de brut lourd. Les ressources du fonds devaient être affectées au rachat de créances, à la stabilisation des recettes et aux dépenses sociales. Le plafond n'a été respecté qu'une fois, et la loi a été révisée en 2005. Cette année-là, le FEIRIP a été intégré au budget, et les recettes correspondantes ont servi à financer les dépenses sociales, la relance économique et d'autres projets. Si les objectifs de réduction du déficit hors pétrole et de la dette publique ont été atteints en 2005, la pente demeure raide en ce qui a trait à la diversification des exportations. 
39. Les Recommandations soulignent l'importance de mettre fin au biais anti-exportation et de suivre une politique de change appropriée. Ainsi que Corden (1997) l'a fait remarquer, la libéralisation des échanges requiert vraisemblablement une dépréciation ${ }^{35}$ du taux de change réel pour que le solde courant demeure constant. L'appréciation du taux de change réel peut entraver l'ajustement, car l'offre d'exportations reste inchangée, et une incitation accrue à l'importation de produits est observée. Cela entraîne une détérioration du compte courant $^{36}$ et peut conduire à une progression du chômage ${ }^{37}$. La sous-évaluation peut aussi compenser les lacunes institutionnelles/contractuelles et les déficiences du marché qui sont à l'origine d'une affectation sous-optimale des ressources au secteur des produits échangeables (Rodrik, 2007) ${ }^{38}$. Par conséquent, à l'amorce de la libéralisation des échanges, il est important que la diminution du taux de change fasse contrepoids au biais anti-exportation ${ }^{39}$.

40. Dans les quatre pays à l'étude, la libéralisation des échanges n'a pas toujours été accompagnée d'une dépréciation de la monnaie. Cela peut s'expliquer en partie par des problèmes politiques de mise en œuvre, mais aussi par le fait que les autorités de nombre de pays en développement ont été réticentes à dévaluer la monnaie pour plusieurs raisons; par exemple 1) le taux de change nominal sert de point d'ancrage de l'inflation (voir encadré 3) ; 2) la faiblesse de la monnaie est généralement associée à

35. Si le taux de change nominal est constant et que l'inflation intérieure excède l'inflation extérieure, le taux de change réel augmente. Par conséquent, la dépréciation du taux de change réel s'accompagne souvent d'une baisse du taux de change nominal.

36. La détérioration du compte courtant n'est pas nécess airement un signal négatif. Le solde courant est strictement égal à l'excédent de l'épargne privée sur l'investissement privé, majoré de l'excédent budgétaire, et on peut parfaitement imaginer des situations dans lesquelles l'excédent de l'investissement privé et/ou le déficit budgétaire sont justifiés ; par conséquent, le solde courant idéal n'est pas forcément égal à zéro. Voir par exemple Pitchford (1992).

37. L'augmentation pourrait être plus marquée dans les petits pays en développement qui dépendent davantage des échanges.

38. Selon Rodrik (2007), les déficiences des institutions et des marchés ont une incidence disproportionnée sur le secteur des produits échangeables par comparaison au secteur des produits non échangeables, dans les pays en développement. Le coiffeur n'a besoin que de quelques instruments, d'un fauteuil et de son savoirfaire pour vendre ses services. Le fabricant doit s'assurer la coopération d'une multitude de fournisseurs et réaliser d'innombrables transactions avec des clients, ce qui suppose des institutions fiables et un marché efficace. Si la création d'institutions fiables et la correction des déficiences du marché représentent la solution optimale, la sous-évaluation pourrait bien être la stratégie de second choix pouvant compenser ces déficiences.

39. Des mises en garde s'imposent. Premièrement, le taux de change n'est pas une variable de la politique à proprement parler. Cependant, plusieurs politiques nationales peuvent influer sur le taux de change, et on peut maintenir le taux de change à un niveau plus bas en augmentant l'épargne par rapport à l'investissement ou en diminuant les dépenses par rapport aux recettes. À cette fin, on peut utiliser divers instruments, notamment la politique budgétaire (un important excédent structurel), la politique d'épargne (épargne forcée) et l'intervention monétaire (accumulation de réserves de change) (Rodrik, 2007). Deuxièmement, il est notoirement difficile de déterminer le niveau «approprié » du taux de change. Par conséquent, le gouvernement (ou la banque centrale) peut, au mieux, toujours tenir compte des effets de la politique de change sur les exportations. Troisièmement, bien qu'une diminution du taux de change puisse faire partie intégrante de la réforme des échanges à l'amorce du processus, le taux de change pourrait bien augmenter au cours des années subséquentes, suite à l'accélération de la croissance économique et à l'amélioration de la productivité (l'effet Balassa-Samuelson). S'il est important d'éviter une surappréciation de la monnaie, le maintien de l'asymétrie des taux de change peut également s'avérer coûteux. 
l'incompétence des autorités (voir encadré 4); 3) l'impact sur la dette et les recettes publiques (voir encadré 5) ; 4) la dévaluation entraînerait une hausse des prix des matières importées utilisées par les industries de remplacement des importations, ce qui pourrait occasionner des pertes d'emploi. Ces considérations soulèvent souvent un dilemme qui doit être analysé au cas par cas ; un taux de change qui favorise la stabilité macroéconomique dans l'optique de l'inflation et des finances publiques peut tout aussi bien saper cette stabilité en nuisant aux exportations.

\section{Encadré 3. Chili — le taux de change : un point d'ancrage nominal}

Le Chili a fait du taux de change nominal un point d'ancrage anti-inflationniste ${ }^{40}$. En différant l'ajustement du taux de change nominal à l'inflation intérieure, les autorités ont tenté de changer les anticipations du taux d'inflation ${ }^{41}$. Si elle a eu une certaine efficacité, cette stratégie a créé d'autres problèmes lorsque le taux d'inflation s'est replié. Le gouvernement chilien avait adopté une politique d'indexation des salaires sur l'inflation intérieure afin de protéger les salariés. Or, le taux de change, en jouant son rôle d'ancrage anti-inflationniste et d'indexation des salaires ${ }^{42}$, envoyait des signaux contradictoires. Le taux de change fixe indiquait que le taux d'inflation devait être plus bas, alors que l'indexation des salaires reposait sur la stabilité de l'inflation. De plus, une telle politique de change s'est traduite par une augmentation du taux de change réel, qui confirmait aux exportateurs potentiels que le rendement réel actuel en monnaie locale des exportations allait diminuer (Krueger, 1997). Lorsque l'investissement dans une industrie exportatrice est risqué en soi, ce signal va à l'encontre d'un transfert des ressources. Cela démontre que la vigilance est de mise dans l'utilisation du taux de change comme point d'ancrage nominal.

\section{Encadré 4. Philippines et Thaïlande - le taux de change : miroir de la compétence du gouvernement}

Dans certains pays en développement ayant opté pour un taux de change fixe, les autorités ont eu tendance à éviter la dévaluation de la monnaie, craignant qu'elle ne soit perçue comme une indication de leur incompétence. Toutefois, ce phénomène peut nuire à l'ajustement. L'augmentation du taux de change réel entre 1987 et 1997 a eu un impact négatif sur l'ajustement structurel aux Philippines. En Thaïlande, la hausse du taux de change réel explique en partie la mauvaise affectation des ressources au profit du secteur des produits non échangeables, qui a mené à la crise asiatique. Donc, si le gouvernement veut éviter la dépréciation pour des raisons politiques, il ne doit pas négliger les répercussions défavorables que ce choix pourrait avoir sur l'économie réelle.

40. Dans un régime de change fixe, le taux de change nominal doit suivre les variations de l'inflation intérieure et de l'inflation extérieure. Lorsque le taux de change sert de point d'ancrage nominal, l'ajustement du taux de change nominal en fonction de ces variations est décalé. C'est ce qui s'est produit en Argentine, au Chili et en Uruguay dans les années 70, et au Mexique dès 1987 (Krueger, 1997).

41. Cette approche pourrait être plus efficace, car le taux de change pourrait être beaucoup plus à la portée des autorités que d'autres objectifs intermédiaires en vue de la réalisation des objectifs d'inflation (masse monétaire, etc.).

42. Les pays aux prises avec l'inflation chronique indexent souvent les salaires pour mettre les salariés à l'abri de ses effets. Par contre, si l'inflation est en baisse, cette mesure entraîne généralement une hausse des salaires réels. 


\section{Encadré 5. Le taux de change et son impact sur la dette publique}

Nombre de pays en développement ont une dette élevée, qui est souvent libellée en devises ${ }^{43}$. Dans leur cas, la dévaluation alourdit la dette et son service lorsqu'ils sont convertis en monnaie nationale. Selon la structure des recettes et des dépenses, le gouvernement peut aborder la dévaluation avec prudence. L'expérience de la Thaïlande révèle comment une hausse suivie d'une baisse soudaine de la monnaie peut provoquer une crise financière lorsque l'asymétrie de la dette (en dollars) et des sources de recettes futures (en monnaie nationale) est importante. En pareil cas, le gouvernement peut être contraint d'inclure la dette privée dans la dette publique afin de maintenir l'intégrité du système financier, comme on a pu le voir au Chili. Cela suppose que les autorités surveillent le niveau d'endettement non seulement de l'État, mais également du secteur privé.

b)

Impact budgétaire de la réforme des échanges

41. En matière budgétaire, les Recommandations se contentent de souligner l'importance de la stabilité macroéconomique et la nécessité de réaliser une réforme fiscale pour compenser la diminution des recettes publiques dans la foulée des réductions tarifaires. Un déficit budgétaire pouvant engendrer des problèmes macroéconomiques, les répercussions éventuelles sur les finances publiques de la réforme des échanges et de la réforme budgétaire doivent être analysées avec soin. La réforme des échanges peut influer sur l'équilibre budgétaire à bien des égards : 1) diminution potentielle des recettes douanières (voir encadré 6), 2) impact sur la dette et son service des variations du taux de change, le cas échéant, découlant de la libéralisation des échanges (voir encadré 5) et 3) augmentation éventuelle des dépenses publiques pour faciliter l'adaptation des entreprises et des salariés, entre autres. Si le déficit budgétaire peut être financé par des emprunts publics et/ou l'aide extérieure, une telle solution risque fort de ne pas être viable à long terme et peut porter atteinte à la crédibilité de la réforme des échanges.

42. Bien que cette question n'ait pas été analysée en profondeur dans les études de cas, on peut faire certaines constatations. Premièrement, les problèmes budgétaires sont effectivement au nombre des raisons invoquées par les autorités pour justifier l'annulation des mesures (en Thaillande dans les années 80 et aux Philippines en 1983). Deuxièmement, la réforme subséquente des échanges a été suivie presque immédiatement d'une mesure de réforme fiscale, par exemple la création d'une taxe à la valeur ajoutée (TVA) comme au Chili en 1975, aux Philippines en 1988 et en Thaïlande en 1992. Les autorités thaïlandaises étaient conscientes de la nécessité de la réforme douanière, mais n'ont abaissé les droits de douane que lorsque la situation budgétaire s'est améliorée. L'étude de cas semble donc indiquer que l'impact budgétaire de la réforme des échanges doit vraiment être analysé avec minutie et que les responsables de la politique commerciale et les autorités budgétaires doivent bien coordonner leurs efforts pour que cette réforme porte fruit.

43. Sans oublier que la réforme du système fiscal général (utilisation de l'impôt sur le revenu, des taxes de vente ou de la TVA pour éviter une diminution des recettes publiques) doit être planifiée dans les moindres détails, il convient d'analyser tout aussi attentivement les répercussions budgétaires de la réforme des échanges. Il faut également préciser que les obstacles non tarifaires tels que les formalités douanières lourdes peuvent être importants dans une optique budgétaire. Si les formalités douanières sont fastidieuses, les réductions tarifaires ne permettront pas nécessairement une augmentation des importations même si

43. Nombre de pays émergents ont nettement amélioré leurs résultats macroéconomiques depuis la crise asiatique, et sont beaucoup moins dépendants de la dette libellée en devises depuis la fin des années 90. Les réductions les plus marquées de la part de la dette en devises (de 1996 à 2004) ont été enregistrées en Thaïlande (62 points de pourcentage), au Mexique (42 points de pourcentage), au Venezuela (22 points de pourcentage) et en Hongrie ( 20 points de pourcentage). Par contre, elle a augmenté de 42 points de pourcentage en Russie, de 29 points de pourcentage au Chili et de 28 points de pourcentage aux Philippines (FMI, 2006). 
l'élasticité-prix de la consommation est très grande. Cela signifie que les effets néfastes des réductions tarifaires sur les recettes publiques seraient généralement plus prononcés lorsque les formalités douanières sont contraignantes. Par conséquent, la réduction des obstacles non tarifaires et la facilitation des échanges pourraient, en augmentant les flux commerciaux, offrir de bonnes possibilités d'accroissement des recettes douanières ${ }^{44}$.

\section{Encadré 6. Impact potentiel sur les recettes douanières}

Ainsi qu'il en est fait mention dans OCDE (2005), les répercussions budgétaires comptent parmi les arguments invoqués le plus souvent par les pays en développement qui refusent de réduire les droits de douane. Pour nombre d'entre eux, les droits d'importation représentent une bonne part des recettes publiques totales (voir graphique 4). La plupart du temps, les effets de la libéralisation des échanges sur les recettes publiques sont incertains : la situation budgétaire peut s'améliorer ou se détériorer. Les recettes douanières augmentent si les contingents et les autres restrictions quantitatives sont remplacés par des équivalents tarifaires et/ou si les exemptions tarifaires sont abolies ${ }^{45}$. Une baisse des taux de droit entraîne une diminution ou un accroissement des recettes douanières selon l'élasticité-prix des importations (le rythme de croissance du volume d'importations suite à un recul des prix). La réduction des droits de douane peut décourager la contrebande et ouvrir la voie à une augmentation du commerce « légal », qui peut aussi contribuer à l'augmentation des recettes douanières.

Selon Kowalski (2005), les chercheurs qui se sont penchés sur la question ont fait un vibrant plaidoyer économique en faveur d'une réforme douanière non discriminatoire qui, au besoin, serait accompagnée d'une réforme fiscale. La réforme douanière doit souvent être jumelée à une réforme fiscale exhaustive pour que les recettes de l'État demeurent au même niveau. D'un point de vue économique, la réforme des échanges semble pleinement justifiée, car les gains de bien-être sont généralement très importants et permanents, alors que les coûts d'élaboration et de mise en œuvre d'une mesure fiscale moins perturbatrice sont davantage de courte durée. On a fait remarquer que les pays en développement qui, à l'heure actuelle, ont tendance à maintenir des obstacles tarifaires plus élevés et plus dispersés sont particulièrement bien placés pour tirer parti d'une réforme douanière, car les gains de bien-être sont fortement positifs, même en tenant compte de l'éventuel manque à gagner fiscal, mais sont également plus vulnérables à la perte de recettes douanières. Les résultats des simulations font état de différences notables entre les pays au chapitre de l'impact sur les échanges, le bien-être et les recettes.

Baunsgaard et Keen (2005) ont constaté, au terme d'une analyse de 111 pays sur une période de 25 ans, que les pays à faible revenu pourraient avoir plus de difficulté à compenser la perte de recettes douanières découlant de la libéralisation des échanges, alors que les pays à revenu élevé ont comblé intégralement le manque à gagner par des recettes non douanières et que les pays à revenu intermédiaire ont recouvré entre 45 et $60 \%$ des recettes perdues. Glenday (2006) présente des conclusions similaires et soutient que l'importance de la TVA en tant que substitut aux recettes fiscales provenant des échanges pourrait avoir été surestimée du fait que cette taxe est difficile à administrer dans le secteur informel de nombreux pays en développement. Di John (2006), prenant l'exemple de l'Ouganda, affirme que sans la libéralisation progressive, les autorités n'auraient pu maintenir les recettes budgétaires jusqu'à ce que les problèmes politiques et administratifs liés à l'application de la TVA soient résolus. Pelzman (2004) a constaté que l'augmentation des taxes intérieures de la Jamaïque avait un rendement décroissant et que cela avait développé le secteur informel. Ces études récentes confirment la thèse voulant que la réforme des échanges doive être bien planifiée et ses répercussions budgétaires, analysées avec soin.

44. Plusieurs participants à la conférence ont confirmé que les réformes tarifaire et douanière augmentaient les recettes, et ont fait valoir qu'il était important d'améliorer l'administration des douanes. Fritz du Bois, du Pérou, a souligné que les recettes douanières ont grimpé en flèche, passant de 6 millions USD au début des années 90 à près de 2 milliards USD en 1994, suite à la réduction radicale des droits de douane, à l'élimination des restrictions quantitatives et à la réforme douanière. Emmanuel Tumusiime Mutebile attribue dans une large mesure à l'amélioration de l'administration douanière ougandaise l'augmentation des recettes enregistrées après la réforme des échanges (Nash et Takacs, 1998, p. 9).

45. Cette augmentation serait en grande partie directement attribuable à l'abolition des exemptions. Des effets indirects sur la fiscalité pourraient également être observés si les exemptions tarifaires avaient freiné l'activité économique dans d'autres secteurs pouvant être assujettis à des taux de droit plus élevés. 


\section{Graphique 4. Dépendance des pays envers les droits d'importation comme source de recettes fiscales}

\section{(\% des recettes fiscales)}

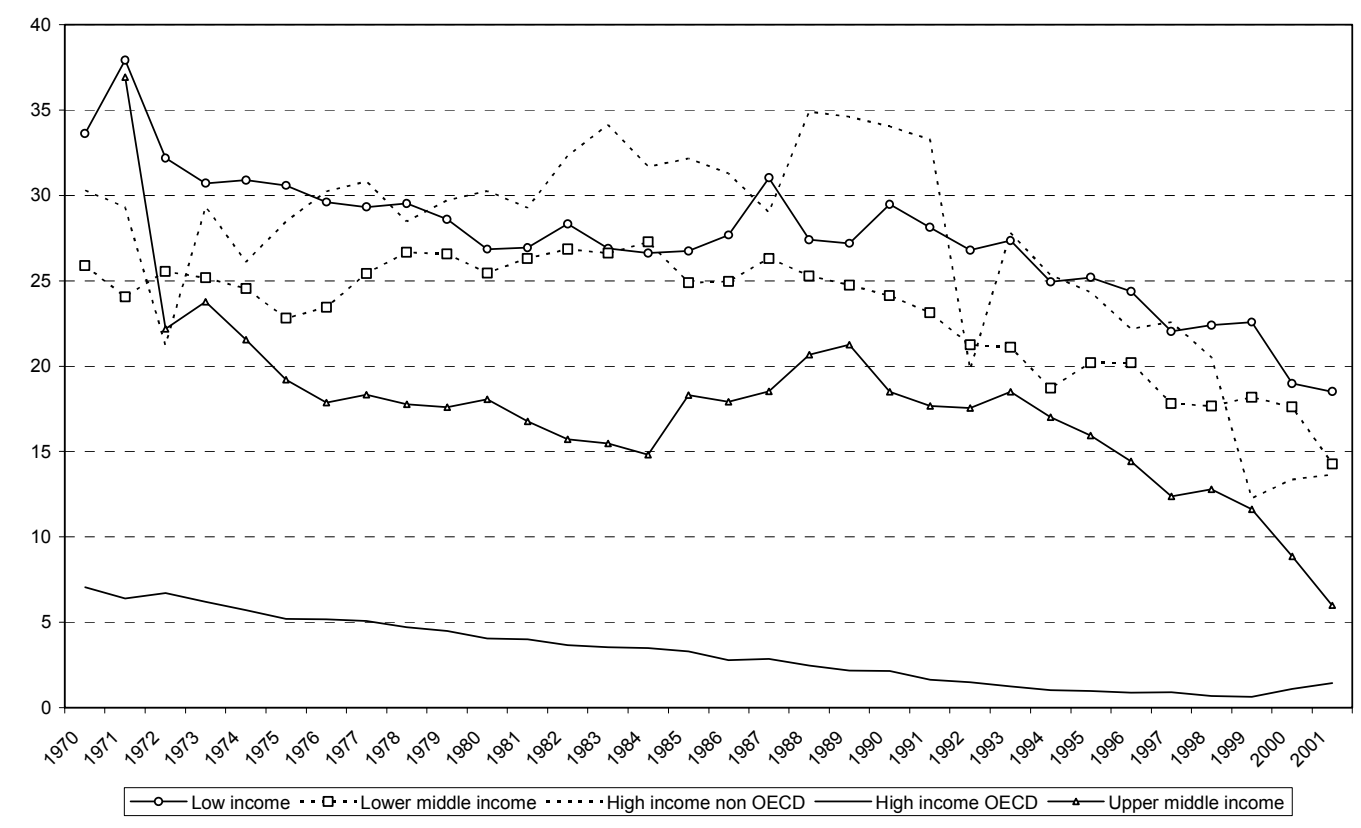

Source : Graphique 2 dans Kowalski (2005)

\section{3)}

\section{Protection sociale et politique du marché du travail}

44. S'agissant de la protection sociale, les Recommandations encouragent les pays à recourir, dans la mesure du possible, aux mesures d'ajustement qui s'offrent généralement à eux, notamment dans le cadre du système de sécurité sociale et du régime fiscal, et à s'assurer que, si les mesures d'ajustement sont motivées par des raisons d'économie politique, elles sont assorties d'une échéance et d'une stratégie de sortie bien déterminée, elles sont dissociées de la production, elles visent à réintégrer les salariés licenciés au marché du travail, elles sont compatibles avec les mesures générales de protection sociale, elles sont efficaces - entre autres par rapport aux coûts - transparentes et soumises à contrôle. Pour ce qui est de la politique du marché du travail, les Recommandations prônent une politique publique saine du marché du travail qui facilite le redéploiement de la main-d'œuvre vers des emplois plus productifs, qui assure des prestations de remplacement du revenu, qui englobe des programmes d'intervention sur le marché du travail, des mesures équilibrées de protection de l'emploi, des mécanismes flexibles de fixation des salaires, ainsi que des systèmes d'éducation et de formation appropriés. Toutes ces Recommandations sont conformes aux lignes directrices de l'OCDE en matière de politique de l'emploi et à la Stratégie révisée de l'OCDE pour l'emploi (2006), mais fournissent des instructions plus détaillées sur les meilleures pratiques pour faire face aux tensions générées par l'ajustement structurel sous l'effet de la libéralisation des échanges. Dans la présente section, nous nous pencherons sur ces deux questions étroitement liées. 
45. Dans les pays de l'OCDE, la protection sociale est un élément important de la réforme, car si elle est insuffisante, les autorités perdront des appuis. À priori, cette assertion pourrait s'appliquer tout particulièrement aux pays en développement, où la situation politique est souvent plus instable que dans nombre de pays développés. Dans les quatre pays à l'étude, les dispositifs formels de protection sociale sont généralement beaucoup moins élaborés que dans les pays développés. Le cas échéant, ils ne couvrent qu'un faible pourcentage de la population, c'est-à-dire les fonctionnaires et le personnel des grandes sociétés, et excluent le secteur informel et l'agriculture. En outre, en raison de l'instabilité macroéconomique et de la nécessité de réduire le déficit budgétaire, les autorités ont souvent dû comprimer, voire presque éliminer les programmes sociaux, comme au Chili dans les années 70.

46. Il ne faudrait cependant pas en déduire que ces pays en développement n'étaient pas préoccupés par la protection sociale. Par exemple, le gouvernement thaïlandais a créé des programmes de travaux publics, plus précisément de construction et de réfection d'infrastructures, à fort coefficient de maind'œuvre dans le sillage de la crise asiatique. Aux Philippines, les autorités ont mis en œuvre plusieurs programmes de protection sociale (par exemple, subventions alimentaires, emplois dans le secteur public et crédits de subsistance) afin d'atténuer les répercussions de la réforme économique sur les indigents ${ }^{46}$.

47. Certains pays en développement se sont relativement bien ajustés malgré les carences des dispositions de protection sociale. L'étude sur la Thaïlande indique que la croissance économique reposant sur un secteur des exportations en plein essor, un important secteur informel et une réglementation du travail flexible a largement compensé le manque de dispositifs formels de protection sociale. Par contre, cette étude révèle que plus le pays se développe, plus la population réclame de tels dispositifs. Le gouvernement thaïlandais a créé un régime d'assurance-chômage en 2004 et a mis en place un programme pour faciliter l'ajustement à la libéralisation des échanges à l'intention des entreprises en 2006. D'après l'étude sur les Philippines, la croissance des services alliée à la contribution accrue des envois de fonds des travailleurs expatriés à l'économie du pays a joué le rôle d'un mécanisme informel de protection sociale. La question de savoir s'il est efficace de laisser le marché contrer les effets redistributifs défavorables de la réforme peut dépendre dans une large mesure 1) de la croissance des industries exportatrices et 2) de la capacité du secteur informel et de l'agriculture d'assurer la protection sociale.

\section{Politique du marché du travail}

48. Les quatre études de cas montrent que le marché du travail est très différent selon que le pays est développé ou en développement. Le secteur informel, qui échappe aux règlements sur le lieu de travail ou aux dispositions officielles de protection sociale (même lorsqu'ils existent), est beaucoup plus important dans nombre de pays en développement ${ }^{47}$. Certains pays n'ont pas créé de régime d'assurance-chômage, et lorsque de telles dispositions ont été mises en œuvre, elles ne sont pas universelles. Dans le même ordre d'idées, les programmes publics de formation professionnelle et d'autres types d'interventions sur le

46. L'étude de l'OIT et de l'OMC (2007) décrit des initiatives d'entraide locales visant à offrir une assurance contre la maladie et la perte de revenu; des politiques actives du marché du travail telles que des programmes de garantie d'emploi s'inscrivant dans des initiatives de travaux publics ruraux et urbains à fort coefficient de main-d'œuvre, et diverses formes de programmes de micro-crédit destinés à promouvoir le travail autonome productif.

47. Selon Schneider (2004), le secteur informel représentait respectivement 19.8\% du PNB au Chili, $34.4 \%$ en Équateur, $43.4 \%$ aux Philippines et $52.6 \%$ en Thaïlande en 1999-2000. Ces pourcentages sont beaucoup plus élevés que ceux de la France (15.2), de l'Allemagne (16.0), du Japon (11.3) et des États-Unis (8.7). Perry et al. (2007) indiquent que l'emploi informel est de $37.0-38.8 \%$ (2003) au Chili et de 55.7 - $56.5 \%$ (2003) en Équateur, citant Gasparini et Tornarolli (2006) et l’OIT (2006). 
marché du travail sont soit très limités, soit totalement inexistants. C'est pourquoi les Recommandations concernant le remplacement du revenu, l'intervention sur le marché du travail et l'éducation et la formation sont moins pertinentes ou ne s'appliquent pas aux pays en développement.

49. Les Recommandations relatives à la flexibilité de la fixation des salaires et aux mesures équilibrées de protection de l'emploi sont toutefois valables pour les pays en développement, surtout dans le secteur formel. En Thaïlande, la croissance économique et un marché du travail relativement souple se sont historiquement traduits par un faible taux de chômage et ont contribué à la transformation réussie de l'économie. Par contre, l'indexation des salaires et d'autres mesures relativement contraignantes sont au nombre des raisons expliquant pourquoi l'ajustement a été coûteux au Chili à la fin des années 70 et au début des années 80 . Les réformes du travail qui ont suivi ont contribué à l'expansion de la main-d'œuvre durant la seconde moitié des années $80^{48}$. En Équateur, le code du travail rigoureux a nui à l'ajustement.

50. La possibilité que des travailleurs quittent le secteur formel pour le secteur informel est un enjeu important dans les pays en développement. Les données empiriques sur la relation entre les échanges et le secteur informel demeurent restreintes et non concluantes (BIT et OMC, 2007) ${ }^{49}$. Le rôle de ce secteur de l'économie est positif si l'on considère qu'il est une échappatoire à la pauvreté (OCDE, 2004b), et lorsque l'agriculture et le secteur informel, qui sont très flexibles, occupent un pourcentage plus élevé de la main-d'œuvre, les coûts d'ajustement peuvent être plus faibles (Matusz et Tarr, 1999). Un secteur informel démesuré peut toutefois entraver la croissance s'il se traduit par une augmentation des taux d'imposition du secteur formel, une faible capacité de dépense des administrations publiques, des dispositifs de protection sociale qui n'atteignent pas leurs objectifs et qui sont mal gérés, la concurrence déloyale pour les activités formelles, l'incitation aux activités improductives et l'inefficacité de la production (OCDE, 2004b). Un grand secteur informel moins productif que le secteur formel peut également accroître les écarts de revenu. Les principaux obstacles à l'intégration au secteur formel des entreprises opérant dans le secteur informel sont les coûts fiscaux et réglementaires liés à l'enregistrement en tant qu'entreprise déclarée. Par conséquent, la réduction de ces coûts et la rationalisation des diverses procédures publiques font partie intégrante des réformes complémentaires à la libéralisation des échanges.

51. La relation entre la libéralisation des échanges et le marché du travail a été analysée dans de nombreuses études ${ }^{5051}$. Il peut y avoir des effets à court et à long terme. Pour ce qui est de l'impact à court terme sur le chômage, si la réforme des échanges donne lieu à une contraction d'une industrie de remplacement des importations, laquelle peut engendrer une diminution de la main-d'œuvre en l'absence de création d'emplois dans les secteurs des produits d'exportation. Toutefois, l'emploi peut augmenter

48. Selon Harrison et al. (1998), la loi sur le salaire minimum n'a pas entravé l'ajustement, alors que Edwards (1982) a conclu que le salaire minimum et surtout, l'indexation des salaires sur l'inflation, pourraient avoir nui à l'ajustement au Chili, et estime que le salaire minimum allié aux réductions tarifaires explique tout au plus moins du tiers du chômage élevé de la fin des années 70. Parmi les autres explications pouvant être avancées, mentionnons la politique de stabilisation et la réduction de la taille du secteur public.

49. Voir également Perry et al. (2007) pour une analyse approfondie des avantages et des coûts de l'emploi informel.

50. L'OIT et l'OMC (2007) ont analysé plus en profondeur les études sur les échanges et l'emploi. Il ressort de cet examen que la libéralisation des échanges peut influer sur le revenu, le chômage et l'inégalité.

51. On a démontré que la libéralisation des marchés de produits est le prélude à une libéralisation du marché du travail. Cela pourrait s'expliquer du fait que, en raison de la concurrence accrue sur les marchés des produits, les entreprises sont moins en mesure de réaliser des bénéfices exceptionnels, ce qui sape les mécanismes institutionnels qui aident les salariés à bénéficier de cette manne. Il se pourrait également que la réforme des marchés de produits augmente la demande, les possibilités d'emplois et les salaires réels, et, ce faisant, facilite la réforme du marché du travail (OCDE, 2007a). 
même à court terme si la réaction des exportations est robuste ${ }^{52}$. Pour ce qui est des répercussions à moyen et à long terme, si les industries de produits exportables utilisent plus de main-d'œuvre que les industries de remplacement des importations, la réforme des échanges pourrait créer des emplois, comme cela s'est produit aux Philippines ${ }^{53}$.

\section{4) Politiques visant à faciliter la réaction des exportations à la réforme des échanges}

52. Les Recommandations ne font pas explicitement mention de la « réaction des exportations », bien qu'elles traitent de l'importance d'une politique macroéconomique sans biais anti-exportation, ainsi que de la nécessité d'améliorer l'accès aux importations essentielles. Cependant, ainsi qu'il en a été fait mention ci-dessus, une vive réaction au début du processus de libéralisation des échanges est cruciale, car elle peut influer sur la stabilité macroéconomique et l'emploi à court terme, et permettra de conserver les appuis à la réforme.

53. Toutefois, les exportations tardent parfois à réagir à la libéralisation des échanges pour plusieurs raisons, par exemple la distorsion constante des signaux de prix; le manque de crédibilité des politiques ; diverses contraintes des exportateurs telles que l'insuffisance d'intrants et de technologie vendus à des prix concurrentiels, de ressources humaines, de financement, d'infrastructures et d'informations. Comme nous l'avons vu plus tôt, la stabilité macroéconomique est importante, enrayant la distorsion des signaux de prix, et un taux de change relativement bas au début du processus de réforme des échanges favorise une plus forte réaction des exportations. Pour accroître la crédibilité des politiques, on peut employer les diverses méthodes qui seront abordées dans la section sur la nécessité d'inscrire la réforme dans une approche globale. Le perfectionnement des ressources humaines et l'aménagement d'infrastructures sont également essentiels au développement ${ }^{54}$. Dans la présente section, nous nous pencherons sur d'autres mécanismes permettant d'augmenter et de diversifier les exportations, par exemple l'accès à des intrants vendus à des prix concurrentiels, au financement, aux informations sur les marchés d'exportation et à la technologie, ainsi que la promotion des exportations.

\section{Intrants à prix concurrentiels}

54. À l'heure où la concurrence est de plus en plus vive sur le marché mondial, les pays en développement doivent souvent importer les intrants, car aucun d'entre eux ne peut s'approvisionner localement à prix concurrentiel pour répondre aux besoins de l'ensemble de ses industries d'exportation. Les zones franches d'exportation, les exemptions tarifaires, les ristournes de droit de douane et les régimes

52. Papagerorgiu et al. (1990) ont comparé l'emploi dans le secteur manufacturier dans 13 épisodes (9 pays) antérieurs et postérieurs à la réforme. À leur avis, les données probantes laissent entendre que les effets de la libéralisation des échanges sur le chômage sont peu prononcés, et que, règle générale, la libéralisation des échanges n'a pas entraîné une baisse de l'emploi, même à court terme, dans ces pays en développement.

53. Selon Krueger (1983), la réforme des échanges devrait créer des emplois dans les pays en développement au terme d'un transfert de la main-d'œuvre, c'est-à-dire du secteur de remplacement des importations (capitalistique) au secteur des produits exportables (à forte intensité de main-d'oeuvre). Harrison et al. (1998) ont constaté, en analysant des données chronologiques sur le Costa Rica, le Pérou, la Pologne, la Roumanie, la Tchécoslovaquie, et l'Uruguay, que l'emploi total a augmenté après la réforme des échanges partout, sauf dans les économies en transition, et ont observé la même tendance générale au Guatemala, au Maroc, en Mongolie, en Ouganda et au Vietnam.

54. Bhattacharya (1988) considère que les infrastructures et le soutien institutionnel dans des domaines comme les services publics, les transports, les ports et les douanes apportent une contribution significative à la baisse des coûts des exportations. Le soutien des pouvoirs publics par l'offre d'une formation, d'une assistance technique et d'une aide à la commercialisation revêt une moindre importance à cet égard. 
de l'entrepôt en douane ne sont que quelques-uns des mécanismes utilisés pour réduire ou éliminer les droits de douane sur les moyens de production des exportations.

55. La Thaïlande et, dans une moindre mesure, les Philippines, ont beaucoup utilisé ces mécanismes et ont obtenu de très bons résultats. Toutefois, il convient de souligner que la Thaïlande a jugé que l'administration de ces mécanismes était coûteuse, et que dans bien des cas, ils convenaient moins aux petites et moyennes entreprises. Avec le temps, le pays a jugé nécessaire de les affiner, précisant qu'ils n'ont été qu'une solution intérimaire ayant précédé la libéralisation générale des échanges.

56. De même, la réduction des droits de douane sur les biens de production et d'équipement est souvent envisagée. Toutefois, cette approche ouvre la voie à la progressivité des droits de douane et à l'augmentation du taux effectif de protection applicable aux produits finis, comme en témoignent nombre de régimes de remplacement des importations. Puisque non seulement les exportateurs, mais également les entreprises qui utilisent ces biens pour fabriquer des produits de consommation et des produits non échangeables destinés au marché intérieur en bénéficient, cette mesure pourrait introduire un biais antiexportations. Les activités des entreprises qui se contentent d'importer des demi-produits et de les monter pour écouler le produit fini sur le marché intérieur pourraient croître. Cette tendance s'accentue lorsque les droits de douane généraux sont plus élevés, comme aux Philippines dans les années 80, avant la réforme des échanges. Il faut donc veiller à ce que la structure tarifaire ne soit pas une source d'inefficience.

57. Une autre piste qui mérite d'être envisagée est la réforme réglementaire des industries de production d'intrants nationaux, comme nous l'avons vu dans la section sur les services. Les services et les autres intrants nationaux constituent un élément important du prix de revient. C'est pourquoi une réforme de la réglementation qui accroît la concurrence et l'efficience dans ces industries peut contribuer à la compétitivité des exportations. Il a été démontré que la conjoncture des marchés de produits extérieurs, ce qui comprend les droits de douane, peut influer sur la réforme des marchés de produits nationaux en soumettant les entreprises nationales à une concurrence accrue $(\mathrm{OCDE}, 2007 \mathrm{a})^{55}$. C'est manifestement ce qui s'est produit aux Philippines et en Thaïlande, où la concurrence plus vive sur les marchés d'exportation a été à l'origine de la réforme d'industries de services telles que les télécommunications et les transports. La facilitation des échanges et la réduction des obstacles non tarifaires peuvent aussi faciliter l'achat de biens de production à un prix concurrentiel.

\section{Financement à taux concurrentiels}

58. Les industries d'exportation doivent être en mesure d'obtenir du financement à taux concurrentiels pour effectuer les investissements nécessaires à leur croissance. Le pays a beaucoup à gagner de la capacité des entreprises de réunir des capitaux sur les marchés internationaux à un taux d'intérêt plus bas, de la possibilité pour les épargnants de diversifier leur portefeuille en investissant dans des avoirs étrangers susceptibles de leur procurer un rendement bonifié, et d'une meilleure répartition des ressources, conséquence d'une plus grande concurrence. Par conséquent, la libéralisation du compte capital fait partie intégrante de la réforme économique à long terme. Si le marché financier national est inefficient, la libéralisation des échanges risque d'empêcher les entreprises nationales de rivaliser avec les autres entreprises sur un pied d'égalité. C'est pourquoi certains pays, par exemple le Chili à ses premières

55. Les estimations de l'OCDE suggèrent que la conjoncture des marchés de produits extérieurs (politiques de l'emploi et sur les marchés des produits dans d'autres pays, obstacles tarifaires, participation à des organisations internationales, etc.) peut expliquer en grande partie la libéralisation des marchés des télécommunications dans l'OCDE intervenue au cours des deux dernières décennies. La libéralisation à l'étranger peut être une source d'inspiration. Associée à la libéralisation des échanges intérieurs, elle peut accroître les pressions concurrentielles sur les entreprises nationales et renforcer par là même les appuis à la réforme (OCDE, 2007a). 
tentatives dans les années 70 jusqu'aux années 80 et la Thailande avant la crise asiatique, ont libéralisé les échanges et le compte capital.

59. Cependant, comme en témoignent les quatre études de cas, il est très risqué de libéraliser le marché des capitaux en l'absence d'un cadre de réglementation adéquat. L'expérience du Chili et de la Thailande démontre qu'une telle libéralisation peut se traduire par un afflux rapide de capitaux étrangers et par des investissements improductifs en cas de distorsion des signaux de prix (voir l'encadré 1). Par conséquent, il pourrait être justifié de la retarder ${ }^{56}$. Toutefois, il est important de préciser que cela ne devrait pas entraîner de retard dans la réalisation de la réforme du marché financier national, car le problème de la pénurie de capitaux demeure entier. Si la libéralisation du compte capital est différée, il pourrait être nécessaire de prendre d'autres mesures afin que les entreprises nationales viables puissent obtenir du crédit à taux raisonnables ${ }^{57}$.

\section{Informations sur les marchés d'exportation et les technologies}

60. D'importantes contraintes de nature informationnelle font parfois obstacle à une réaction rapide et marquée de l'offre privée. Il n'est pas rare que les producteurs nationaux ne disposent pas de suffisamment d'informations sur 1) les technologies qui sont utilisées pour produire les biens ou services en demande à l'étranger ou qui les aideront à rivaliser avec les entreprises étrangères sur le marché intérieur; 2) les circuits de commercialisation et de distribution étrangers; (3) les préférences des consommateurs ou les besoins des producteurs dans des marchés potentiels; (4) les normes et la réglementation sanitaire et phytosanitaire étrangères. Cette tendance est accentuée lorsque l'économie est très dépendante d'un nombre limité de produits de base.

61. Ces informations sont coûteuses et ont la nature d'un bien public (non exclusif et non rival) ${ }^{58}$. Leur acquisition constitue un investissement, car le rendement est incertain. Souvent, les petits entrepreneurs et entreprises sont sous-capitalisés et ne sont pas en mesure de réaliser un tel investissement. Le rendement social de ces informations peut souvent excéder largement le rendement privé, ce qui a tendance à se traduire par une offre socialement insuffisante. Les administrations publiques pourraient donc jouer un rôle important a) en subventionnant la collecte d'informations sur les technologies, les marchés extérieurs et les préférences des clients étrangers ; b) en versant des subventions aux producteurs nationaux qui s'efforcent de se tailler une réputation; c) en aidant les entreprises à se doter de nouveaux outils, à recentrer leurs activités sur les marchés internationaux et à mieux rivaliser avec les producteurs étrangers sur le marché intérieur (Agosin, 2002).

62. L'expérience chilienne illustre bien comment une administration publique peut promouvoir les exportations en facilitant l'accès à l'information. ProChili, l'office national de promotion des échanges, a soutenu et continue de soutenir la croissance et la diversification des exportations en fournissant des

56. Cela ne peut se justifier dans le cas de l'IDE. Comme Johnston et al. (1997) l'ont fait remarquer, alors que la libéralisation des capitaux de portefeuille a généralement été coordonnée avec la libéralisation et la réforme du secteur financier national, les entrées d'IDE ont souvent été libéralisées dans le cadre des réformes visant à renforcer le secteur réel et le potentiel d'exportation de l'économie.

57. Bhattacharya (1988) étudie les pays d'Asie de l'Est et constate par exemple que certains d'entre eux ont introduit une forme de soutien financier en faveur des exportateurs, le plus souvent par des prêts à court terme préalables à l'expédition accordés par la banque centrale à des taux préférentiels.

58. L'information est un bien non exclusif, c'est-à-dire qu'il est difficile d'empêcher les autres de l'utiliser. Elle est non rivale en cela que sa consommation par agent ne diminue pas forcément sa valeur pour un autre agent. Au terme d'études approfondies (et éventuellement, d'essais), une entreprise peut juger rentable de produire des pommes au Chili et de les exporter aux États-Unis. Or, un autre exportateur pourrait facilement profiter de ses efforts de recherche. 
informations sur les marchés et les clients étrangers, en cherchant à développer les exportations du pays dans le cadre de campagnes de publicité génériques et des missions spécialisées, et en s'employant à résoudre les problèmes administratifs des exportateurs. En assurant des services uniquement à des corporations ou à des groupes de sociétés, il encourage les exportateurs à se regrouper. Ces derniers peuvent collaborer en partageant les coûts de la collecte des données et en conjuguant leurs efforts pour conquérir les marchés étrangers, tout en demeurant des rivaux. L'étude sur l'Équateur nous apprend également que Corpei, l'organisme national (privé) de promotion des exportations, a contribué de façon décisive à la croissance de l'industrie des fleurs coupées. Selon une étude récente de la Banque mondiale, les organismes de promotion des exportations ont généralement un impact marqué et statistiquement significatif sur les exportations : chaque dollar de promotion investi par l'organisme médian de promotion des exportations générerait 300 USD d'exportations (Banque mondiale, 2006a) ${ }^{59}$.

\section{Les subventions à l'exportation : des avantages douteux}

63. On peut recourir aux mécanismes de promotion des exportations pour inciter les producteurs nationaux à accroître leurs ventes à l'étranger. Le soutien apporté par certains de ces mécanismes peut être considéré comme une subvention à l'exportation, qui est généralement prohibée en vertu des règles de $l^{\prime} \mathrm{OMC}^{60}$. Il faut donc s'assurer qu'ils sont conformes à ces règles. Toutefois, des exceptions ont été prévues pour les pays en développement, en raison de l'apport au développement économique que les subventions peuvent avoir.

64. Les mécanismes de promotion des exportations n'ont souvent pas été à la hauteur des attentes et peuvent entraîner un gaspillage de fonds publics restreints. Le système de ristourne simplifiée du Chili ${ }^{61}$ démontre que des incitatifs modestes, bien administrés, peuvent être efficaces. S'apparentant à une subvention à l'exportation, cette ristourne assurait à l'exportateur un pourcentage fixe de la valeur des exportations afin de «compenser» les droits de douane sur les intrants. La ristourne cessait d'être versée lorsque les exportations d'un produit donné atteignaient un certain niveau. Selon Agosin (2002), ce type d'incitatif s'approche de l'optimalité économique sur la base des caractéristiques susmentionnées de l'information: le premier ou le deuxième entrant sur le marché touche une ristourne qui lui permet de

59. L'étude fait état d'un degré élevé d'hétérogénéité entre les régions et les pays. Chaque dollar inscrit au budget de l'organisme de promotion des exportations rapporte en moyenne 490 USD d'exportations en Amérique latine et dans les Caraïbes, 227 USD en Asie, 160 USD dans les pays de l'OCDE, 137 USD en Afrique subsaharienne et 96 USD au Moyen-Orient et en Afrique du Nord. L'étude fait également ressortir des rendements décroissants importants, ce qui laisse entendre qu'une augmentation simple du budget n'est pas nécessairement rentable. De plus, l'étude fait valoir 1) que de nombreux sièges au conseil d'administration de l'organisme de promotion devraient être réservés au secteur privé, mais qu'il devrait être en grande partie financé par l'État ; 2) qu'un seul organisme efficace est préférable à la pléthore d'organismes parfois observée dans certains pays; 3) que l'organisme devrait faire la promotion d'exportations non traditionnelles ou avoir une orientation sectorielle assez générale ; 4) qu'il devrait axer principalement ses efforts sur les grandes entreprises qui n'exportent pas encore (bien que cet argument soit fragile d'un point de vue statistique). Dans les pays en développement, la promotion de l'investissement et le financement des exportations devraient être du ressort de cet organisme, et le gros de son budget devrait être consacré au soutien aux exportateurs sur le territoire national, plutôt qu'à la promotion de l'image de marque du pays ou à la commercialisation et aux études de marché (Banque mondiale, 2006a).

60. Aux termes de l'article 1 de l'Accord sur les subventions et les mesures compensatoires de l'OMC, une subvention est une contribution financière des pouvoirs publics ou de tout organisme public qui confère un avantage, et les subventions subordonnées aux résultats à l'exportation sont prohibées par l'article 3.1 a). L'article 27 accorde un traitement spécial et différencié aux pays en développement (voir Engman et al., 2007, partie 3, pour une analyse plus détaillée).

61. Ce système a été modifié, car on avait jugé qu'il ne respectait pas les règles de l'OMC. 
recouvrer les frais de lancement liés à la collecte des informations et qui compense les risques initiaux. Lorsque les exportations atteignent un certain seuil (et que les coûts externes relatifs à l'information sont éliminés), la ristourne est annulée. Cette caractéristique est également importante, car il est extrêmement difficile d'abolir ces mesures une fois qu'elles ont été prises.

65. Les zones franches d'exportation des Philippines et de la Thaillande sont d'autres exemples de mesure de promotion des exportations qui ont contribué au développement ${ }^{62}$. Si cela peut indiquer qu'une politique de promotion des exportations peut jouer un rôle ${ }^{63}$, il convient d'insister sur le fait que les subventions à l'exportation ne constituent pas une solution optimale d'un point de vue économique ${ }^{64}$ et que les exportations ne sont pas une fin en soi. Les mesures qui encouragent fortement l'exportation vont à l'encontre de l'objectif de la libéralisation des échanges, soit de réduire la distorsion dans l'économie. Par conséquent, la politique de promotion des exportations devrait uniquement chercher à corriger les déficiences du marché, respecter les règles de l'OMC qui interdisent les subventions à l'exportation, et être subordonnée au besoin (les avantages devraient être supprimés lorsque la déficience du marché a été corrigée et/ou les exportations ont atteint un certain niveau).

\section{5) Cadre institutionnel et environnement réglementaire et concurrentiel}

66. Les Recommandations soulignent l'importance d'un cadre institutionnel et politico-administratif qui favorise la réforme structurelle, tout en permettant que les mesures de réforme soient mieux comprises et acceptées par le public grâce à des examens, des évaluations et des consultations efficaces, ainsi que des institutions solides. Par ailleurs, elles incitent les gouvernements à promouvoir un environnement réglementaire et concurrentiel sain qui permet les mutations au sein des entreprises, ainsi que les entrées et sorties dans tous les secteurs en facilitant les fusions et la redéfinition de la culture d'entreprise, en maintenant au minimum nécessaire les obstacles réglementaires gênant les entreprises et en réduisant les effets de distorsion des échanges de la réglementation nationale. L'expérience des quatre pays à l'étude confirme dans une large mesure ce qui précède. La présente section est consacrée a) à la solidité des institutions publiques, b) à l'efficacité du processus de consultation, et c) à l'environnement concurrentiel.

\section{Environnement institutionnel et réglementaire sain}

67. Des institutions saines et un environnement réglementaire approprié facilitent les échanges économiques sous toutes les formes en minimisant les risques inhérents aux transactions économiques ${ }^{666}$.

62 Voir Engman et al. (2007) pour une analyse plus approfondie des avantages et des inconvénients des zones franches d'exportation comme outil de développement.

63. D’après Rodrik (2007), en général, les déficiences des institutions et du marché ont un impact disproportionné sur le secteur des produits échangeables par rapport au secteur des produits non échangeables dans les pays en développement. Si la création d'institutions fiables et la correction des déficiences du marché représentent la solution optimale, la sous-évaluation ou les subventions à l'exportation pourraient être la solution de second choix pour compenser ces lacunes.

64. L'octroi de subventions qui cibleraient avec précision les distorsions perçues équivaudrait à une forme très complexe de politique industrielle, avec son lot de problèmes liés à l'information et à la maximisation de la rente.

65. Par exemple, l'entreprise qui achète un produit ou un service pourrait ne pas payer, et la qualité du bien acheté pourrait ne pas correspondre à la description initiale.

66. Rodrik (1999) juge utile de considérer les institutions comme un ensemble de règles de comportement établies par l'homme qui régissent et façonnent les interactions des personnes, en partie en les aidant à anticiper les actes d'autrui (Lin et Nugent, 1995). Il analyse ensuite cinq types d'institution pouvant appuyer les marchés: les droits de propriété, les organismes de réglementation, les organismes de 
Les institutions, ce qui englobe, par exemple, les droits de propriété ${ }^{67}$ et l'exécution des contrats, permettent aux entreprises et aux particuliers de réaliser des transactions économiques même s'ils n'ont jamais eu de contact. Cela met en relief l'importance des institutions en période d'ajustement structurel, lorsque les entreprises et les particuliers doivent entretenir de nouvelles relations d'affaires et élargir leur sphère d'activités ${ }^{68}$. Les quatre pays à l'étude témoignent de l'importance des institutions et du cadre de réglementation pour assurer la prévisibilité nécessaire à l'investissement. En Équateur et aux Philippines, les changements fréquents de gouvernement et de politique, ainsi que l'élément d'incertitude que cela a apporté au cadre institutionnel, n'ont pas favorisé l'ajustement. En revanche, la Thaïlande offre une particularité intéressante : la stabilité du cadre institutionnel général ${ }^{69}$ a permis une croissance soutenue malgré l'instabilité politique. De plus, l'étude de cas montre que le renforcement des institutions formelles telles que la banque centrale, l'organisme responsable du budget et l'organisme de planification économique ont joué un rôle déterminant dans le développement de la Thaïlande. Il ressort des quatre études de cas 1) que le renforcement de l'indépendance de la banque centrale a nettement contribué au rétablissement et à la restauration de la stabilité macroéconomique ; 2) que, bien que la libéralisation du marché des capitaux soit extrêmement importante, il est crucial de mettre en place un mécanisme efficace de contrôle financier et de réglementation prudentielle avant de libéraliser le compte capital.

68. Certaines des analyses sectorielles ont également fait ressortir l'importance des institutions et du cadre réglementaire. Un cadre réglementaire clair et stable, permettant aux investisseurs privés nationaux et étrangers d'investir dans les concessions minières, a été extrêmement important pour l'IDE et le développement du secteur du cuivre au Chili. De même, le cadre juridique, notamment une déclaration garantissant que les terres reboisées par le secteur privé n'allaient pas être expropriées, a été essentiel au développement du secteur de l'exploitation forestière. Par contre, l'inquiétude suscitée par la réforme agraire aux Philippines a entravé l'investissement en agriculture. L'étude du secteur thaïlandais des télécommunications révèle comment un régime réglementaire déficient peut freiner l'essor d'un secteur.

69. La libéralisation des marchés des capitaux dans les quatre pays à l'étude met en relief les difficultés soulevées par les modifications apportées aux cadres institutionnel et réglementaire. En général, les arrangements institutionnels harmonieux tiennent compte de l'histoire du pays et sont mis en place progressivement. L'ouverture des marchés des capitaux requiert une refonte en profondeur des institutions publiques et du cadre réglementaire, et oblige le secteur privé à changer son comportement. Toutefois, comme le démontrent les études de cas, les quatre pays se sont heurtés à des difficultés de taille à cet égard, ce qui semble confirmer que la modification du cadre institutionnel est une entreprise ardue et justifier l'approche graduelle en matière de réforme. L'étude sur le secteur du ciment des Philippines

stabilisation macroéconomique; les organismes d'assurance sociale et les organismes chargés de régler les différends. Les institutions peuvent être formelles ou informelles.

67. Les droits de propriété ont plusieurs fonctions : 1) établir le potentiel économique des actifs et permettre le nantissement des biens, ce qui accroît fortement la capacité d'investir ; 2) intégrer dans un système (le prix) des données éparpillées, ce qui crée d'autres possibilités de produire une valeur excédentaire dans le cadre de transactions ; 3) accroître la responsabilité et réduire les coûts de transaction ; 4) rendre les actifs fongibles et divisibles ; 5) amener les personnes à former des réseaux et améliorer les communications sur les actifs et leur potentiel ; 6) protéger les transactions (De Soto, 2000).

68. Rodrik (2007) soutient que des institutions inefficaces pourraient avoir plus d'impact sur le secteur de produits échangeables que sur le secteur des produits non échangeables du fait que les systèmes de production des biens échangeables ont tendance à être plus complexes, ce qui donne plus de poids à la possibilité d'adjuger des marchés et à leur exécution par des tiers fiables.

69. L'importance de préserver les traditions et les institutions thaïlandaises, qui fait consensus chez les principales parties prenantes ; l'attachement profond à la monarchie ; le degré élevé d'indépendance de la bureaucratie par rapport au pouvoir politique expliquent la stabilité du cadre institutionnel général. Le cadre institutionnel repose donc sur des institutions formelles et informelles. 
fournit un exemple similaire. L'État philippin, qui avait été très présent dans le secteur et l'avait remis sur ses rails à plusieurs reprises, a décidé de ne plus intervenir. Cependant, les cimenteries ont eu du mal à changer leur comportement et leurs anticipations face à l'État. Afin de tirer parti du boum temporaire que connaissait le secteur de la construction, elles ont investi massivement dans l'extension de leurs capacités en supposant qu'elles pourraient continuer à obtenir du financement. Le ralentissement de l'économie et la décision de l'État de ne plus intervenir ont eu pour conséquence la faillite de nombreuses cimenteries. Cet exemple révèle que l'industrie a parfois besoin de temps pour s'adapter à la modification des cadres institutionnel et réglementaire.

70. Un processus de consultation efficace peut faciliter l'ajustement en éliminant en partie l'asymétrie informationnelle entre l'État, l'industrie et le public. Grâce à la consultation, les autorités peuvent recueillir davantage d'informations sur l'impact des réformes à venir sur différentes parties prenantes, et ces dernières peuvent en savoir davantage sur la direction des réformes, leur bien-fondé et leur impact sur leur existence ${ }^{70}$. L'étude sur le Chili nous apprend que les consultations limitées auprès de l'industrie ont eu pour conséquence de sous-estimer systématiquement les répercussions négatives des premières grandes réformes économiques. Un processus de consultation efficace durant les deuxième et troisième phases a permis aux décideurs de faire preuve de plus de pragmatisme et a facilité l'ajustement. De plus, il se peut que les autorités arrivent ainsi à prendre conscience des contraintes des industries de produits exportables (par exemple, en ce qui concerne les ressources humaines, les infrastructures, le financement, l'information, etc.) et à réagir efficacement. Comme l'a souligné l'étude sur la Thaïlande, le manque de transparence et l'absence de participation élargie ${ }^{71}$ au processus de réforme expliquent l'érosion progressive des appuis à la libéralisation des échanges et à la privatisation parmi la population.

c)

Environnement concurrentiel

71. L'environnement concurrentiel a été un facteur extrêmement important du processus d'ajustement structurel. Une saine concurrence favorise un redéploiement des ressources au profit des entreprises les plus efficientes et, par conséquent, encourage une efficience accrue. Il y a des synergies entre les échanges, l'investissement et la politique de concurrence: les gains engendrés par un de ces facteurs sont augmentés par les réformes des deux autres facteurs. La libéralisation des échanges a des retombées plus importantes dans un régime de concurrence et de libre circulation des capitaux (Bartok et Miroudot, 2007). Bien que cette question n'ait pas été analysée en profondeur dans les études, et que des pays comme la Thaïlande n'aient adopté une loi sur la concurrence qu'en 1999, certaines études de cas sectorielles en font mention. Si l'intervention de l'État dans le secteur des véhicules et des pièces d'automobile a été relativement fructueuse en Thaïlande, c'est entre autres en raison de la concurrence efficace, qui s'explique par l'envergure relativement grande du marché intérieur et les nombreux entrants étrangers. Au Chili, la société nationale du cuivre (CODELCO) et la société minière nationale (ENAMI) ont été relativement efficientes malgré la participation de l'État, en partie grâce à la concurrence efficace livrée par le secteur privé. En revanche, le secteur thaïlandais des télécommunications démontre qu'une concurrence restreinte est source d'inefficience.

70. Voir également Engman et al. (2006). Les entretiens entre l'administration centrale et l'industrie chimique japonaise et l'industrie américaine du tabac sont des exemples de dialogue entre les autorités et l'industrie qui contribue à faire accepter les réformes.

71. Il convient de remarquer que des mécanismes de consultation restreints peuvent entraîner une captation réglementaire et favoriser dans certains cas la corruption. 
72. Au regard de la coopération multilatérale et des initiatives régionales et bilatérales, les Recommandations prônent la coopération multilatérale dans des domaines liés entre eux : les échanges et le financement - à cette fin, il convient d'éviter les représailles commerciales, et d'ancrer solidement les réformes intérieures, tout en s'attaquant plus particulièrement aux problèmes liés à l'ajustement des pays en développement - le renforcement des capacités, la responsabilité des entreprises et les normes fondamentales du travail. Suivant les Recommandations, il faut encourager les initiatives régionales et bilatérales là où une coopération dans le domaine de la réglementation peut créer des possibilités par le biais des échanges ou atténuer les difficultés d'ajustement dans certains secteurs.

73. Ainsi qu'il a en été fait mention ci-dessus, les initiatives multilatérales, régionales et bilatérales peuvent être révélatrices de la détermination des autorités à libéraliser les échanges, accroître la crédibilité des réformes ${ }^{72}$ et servir de déclencheur des réformes économiques et de l'ajustement structurel. Si les pays en développement ont souvent réformé unilatéralement les échanges afin d'atteindre des objectifs de politique intérieure ${ }^{73}$, les engagements multilatéraux peuvent ancrer ces initiatives antérieures (Engman et al., 2006) et établir une limite supérieure advenant un retour en arrière. Le Chili constitue un bon exemple à cet égard. Après avoir annulé les premières réformes des échanges dans les années 70 et 80 en raison d'une crise de la balance des paiements et d'une crise financière, les autorités chiliennes ont majoré les droits de douane pour les porter à $35 \%$, ce qui correspondait au droit consolidé en vertu du GATT. Au Chili, les ALE ont contribué, non seulement à améliorer l'accès aux marchés d'exportation, mais également à renforcer les institutions en ancrant les diverses réformes réalisées en conformité à l'accord de libre-échange.

74. Étant donné que les droits consolidés des pays en développement dans le cadre de l'OMC sont souvent beaucoup plus élevés que les droits appliqués, les négociations en cours du PDD se traduiront par une augmentation des consolidations et une réduction des taux de droit consolidé, et, par conséquent, une plus grande prévisibilité. Toutefois, elles ne permettront pas une nouvelle ouverture des marchés si les droits de douane appliqués ne sont pas également réduits. À l'heure actuelle, les engagements régionaux et bilatéraux jouent un rôle important, contribuant à accroître la libéralisation en l'absence de progrès dans les discussions multilatérales. L'établissement de règles multilatérales, régionales ou bilatérales peut également servir à promouvoir les bonnes pratiques (par exemple, le Document de référence dans le cadre des négociations sur les télécommunications de base) ${ }^{74}$.

75. Bien que cet aspect ne soit pas traité de façon très explicite dans les Recommandations, la libéralisation multilatérale des échanges, ainsi que les initiatives régionales et bilatérales peuvent, en donnant accès aux marchés, faciliter la réaction des exportations et, par conséquent, l'ajustement structurel. L'Équateur constitue l'exemple le plus manifeste à cet égard. La Loi relative aux préférences commerciales en faveur des pays andins (ATP) et son prolongement assorti d'un volet d'éradication de la drogue (ATPDEA) ont ouvert les marchés américains, une condition essentielle à la croissance des industries d'exportation non traditionnelles telles que les fleurs coupées et le thon transformé en Équateur. D'après l'étude de cas, la compétitivité de ces industries pourrait être compromise si les exportations

72. Le processus d'adhésion à l'Union européenne a été l'élément déclencheur des réformes des échanges en Europe de l'Est, leur a donné de la crédibilité, et a facilité la répartition des ressources.

73. Cela vaut pour les pays étudiés dans le cadre de ce projet à l'exception de l'Équateur.

74. Le Document de référence donne des directives aux décideurs pour instaurer un régime de concurrence viable dans les marchés des télécommunications. Cela comprend les disciplines réglementaires telles que les sauvegardes contre les pratiques anticoncurrentielles, les garanties en matière d'interconnexion, la transparence des procédures de licences, l'indépendance des organes réglementaires, et la nondiscrimination (Engman et al., 2006). 
équatoriennes sont de nouveau assujetties à des droits de douane NPF. L'accès aux marchés permis par l'Arrangement multifibres a eu une influence déterminante sur le développement de l'industrie thaïlandaise des textiles et des vêtements. La Communauté andine, l'Accord de libre-échange de l'ANASE et les différents accords commerciaux régionaux signés par le Chili sont d'autres exemples d'initiatives régionales et bilatérales ayant facilité l'ajustement par le biais de l'accès aux marchés d'exportation. Les études laissent entendre que l'accès à ces marchés, tant dans les pays développés que dans les pays en développement, dans le cadre des négociations du PDD, pourrait faciliter l'ajustement dans les pays en développement ${ }^{75}$.

76. Bien que la présente étude n'ait pas mis l'accent sur l'assistance multilatérale pour le renforcement des capacités, les études de cas indiquent que, sous forme d'aide, elle a fortement contribué à la croissance de certaines industries. Dans le sillage de la crise asiatique, la Thaïlande a mis en œuvre des programmes de travaux publics temporaires à fort coefficient de main-d'oeuvre avec le soutien financier de la Banque mondiale et du Japon. En Équateur, l'industrie des fleurs coupées a obtenu du financement en partie auprès de la Banque interaméricaine de développement et de la Banque mondiale, et a bénéficié de l'assistance technique des États-Unis. Le secteur équatorien de transformation du thon a pu compter sur l'aide officielle au développement du Royaume-Uni. Ces cas indiquent que la coopération multilatérale axée sur le renforcement des capacités demeurera un élément important de l'ajustement structurel dans les pays en développement.

\section{7) Approche élargie et crédibilité}

77. Aux termes des Recommandations, les autorités devraient «entreprendre les réformes dans différents domaines d'intervention des pouvoirs publics sur un large front et de façon complémentaire afin d'optimiser les synergies entre les diverses mesures et de réduire la résistance à la restructuration en faisant en sorte que les personnes défavorisées par une réforme puissent bénéficier d'une autre ». Elles ne font pas explicitement mention de la question de la crédibilité des réformes.

78. Les quatre études de cas révèlent que la réforme des échanges s'est inscrite dans une réforme économique globale et que les diverses mesures relevant entre autres de la politique commerciale, de la politique d'IDE, de la politique macroéconomique, de la politique de change, de la politique budgétaire, de la politique du marché du travail et de la politique du marché des capitaux sont étroitement liées. Comme nous l'avons vu dans les sections qui précèdent, cela suppose une coordination tout aussi étroite des activités des organismes publics de manière que les politiques soient cohérentes et que l'enchainement des réformes soit optimal. Les autres réformes, par exemple celles du secteur public et des pensions, pourraient également accroître l'efficacité de réformes telles que celle du marché des capitaux. Au Chili, la réforme du secteur public s'est traduite par une augmentation du nombre de sociétés cotées en bourse, et la réforme des pensions a contribué à l'augmentation de l'investissement sur le marché des capitaux.

79. La crédibilité des réformes est importante, car le secteur privé réaffectera les ressources en réaction à la réforme des échanges uniquement si elle semble viable (Rodrik, 1989b). S'il s'attend à ce que les autorités fassent marche arrière, le secteur privé aura une attitude attentiste. Les producteurs en concurrence avec les importations n'investiront pas pour trouver de nouveaux débouchés à l'exportation ; qui pis est, ils pourraient intensifier leurs efforts de lobbying. Certains consommateurs pourraient même devancer leurs achats de produits importés en prévision des droits de douane élevés qui seront remis en vigueur. Les entreprises déficitaires pourraient s'endetter afin de poursuivre leurs activités jusqu'à ce que les mesures de libéralisation soient annulées (Edwards, 1986). Paradoxalement, certaines entreprises pourraient également être incitées à ne pas s'efforcer vraiment de s'adapter à l'environnement en devenir :

75. Kowalski et Shepherd (2006) et Dihel et al. (2006) soulignent l'importance croissante des échanges SudSud de biens et services. 
une détérioration de la situation pourrait leur assurer une protection accrue suite à l'annulation de la réforme. Donc, le gouvernement qui va de l'avant avec une réforme des échanges doit trouver des moyens de la rendre plus crédible. La crédibilité peut reposer sur: 1) des réformes en profondeur ${ }^{76} ; 2$ ) des politiques cohérentes et synergiques ${ }^{77}$; 3) de bons résultats obtenus durant une longue période; 4) les engagements internationaux.

80. L'expérience des quatre pays à l'étude diffère relativement à la crédibilité des réformes des échanges. Après avoir échoué à sa première tentative de réforme des échanges, l'Équateur a renforcé la crédibilité de sa deuxième série de réformes à la fin des années 80 en faisant valoir son appartenance à la Communauté andine et à l'OMC. Dans le cas du Chili, la première réforme réalisée dans les années 70 et au début des années 80 a donné plus de crédibilité à la deuxième série de réformes à la fin des années 80 , en faisant une plus large place au secteur privé dans l'élaboration des politiques, et en mettant l'accent sur la cohérence et la synergie de politiques pro-exportations. Fait intéressant à souligner, en annonçant le retrait du pays de la Communauté andine, le gouvernement chilien pourrait avoir donné une indication de sa détermination à réformer les échanges et l'investissement ${ }^{78}$. Les pays ont également utilisé les programmes de la Banque mondiale et du FMI pour donner de la crédibilité à leurs initiatives et signifier leur empressement à les réaliser ; mentionnons notamment les réformes de la Thaïlande au lendemain de la crise asiatique et la deuxième série de réformes du Chili ${ }^{79}$. Toutefois, il faut veiller à ne pas recourir à outrance aux forces extérieures pour ne pas entamer la légitimité des réformes (Engman et al., 2006). Celles qui semblent avoir été imposées de l'extérieur pourraient être plus susceptibles d'être annulées.

\section{4.}

\section{Conclusions}

81. En conclusion, les pays en développement ont réalisé des réformes graduelles des échanges, dans le cadre d'une réforme économique globale. Ces réformes des échanges diffèrent quant à leur contenu, à leur rythme, à leur ampleur, ainsi qu'à leurs résultats. L'enchaînement et la synchronisation des réformes, et le choix des mesures sont importants. Si l'approche graduelle est souvent justifiée, de manière que les institutions, les organismes publics et les entreprises puissent s'adapter, une approche plus radicale peut être envisagée dans certains cas. Les restrictions quantitatives et les distorsions des échanges les plus graves devraient être supprimées durant la première phase de la réforme.

82. La réforme des échanges et les autres mesures portant, entre autres, sur la politique d'IDE, la politique macroéconomique, la politique de change, la politique budgétaire et les politiques des marchés du travail et des capitaux sont étroitement liées. Cela signifie que les organismes publics doivent coordonner minutieusement leurs actions afin que les politiques soient cohérentes et que l'enchaînement des réformes se traduise par de meilleurs résultats. Par exemple, la réforme des échanges devrait être alignée sur la politique destinée à accroître les flux d'IDE. Par contre, une approche prudente pourrait s'imposer à l'égard de la libéralisation des marchés des capitaux, afin que le cadre de réglementation du secteur

76. Voir la section sur le rythme de la libéralisation des échanges et la note 14 sur la relation entre la profondeur des réformes et la crédibilité.

77. Lorsque les politiques sont complémentaires, il en coûte davantage pour annuler un élément du train de mesures.

78. Le Chili s'est retiré de la Communauté andine parce qu'il n'a pas réussi à convaincre les autres membres d'abaisser les droits de douane communs élevés.

79. Rajapatirana et al. (1997) indiquent que le critère de conditionnalité rattaché aux prêts concernés était relativement souple comparativement à la libéralisation engagée par les pays et qu'en réalité, les initiatives de libéralisation les plus ambitieuses comme celles menées en Argentine (1991), au Chili (1974) et en Colombie (1991) n'étaient pas associées à des prêts d'ajustement structurel de la Banque mondiale pour soutenir la réforme des échanges ou des réformes de plus large portée. 
financier et la communauté financière puissent s'adapter aux changements institutionnels. De plus, il pourrait être nécessaire d'accompagner la réforme des échanges d'une réforme du marché du travail comportant un mécanisme flexible de fixation des salaires et une protection équilibrée de l'emploi. Elle pourrait également être complétée par une réforme fiscale, par exemple l'imposition d'une taxe sur la valeur ajoutée. Les pays en développement n'ont pas toujours suffisamment de ressources pour mettre en place des dispositifs formels de protection sociale ; cependant, la croissance économique, un marché du travail flexible, et un grand secteur informel peuvent servir de substituts, s'ils sont complétés par des programmes ciblés.

83. Les pays en développement pourraient tenir compte de l'importance de la réaction des exportations pendant la première phase de la réforme des échanges. Dans cette optique, la politique de change et les autres politiques destinées à faciliter les exportations (intrants, financement et informations sur les marchés) pourraient être déterminantes.

84. La transparence et la prévisibilité des réformes ont joué un rôle clé en facilitant l'ajustement structurel. Logiquement, un manque de transparence et de prévisibilité a retardé l'ajustement. En ce sens, la stabilité politique, la stabilité macroéconomique et la cohérence des politiques sont des facteurs décisifs. Les initiatives régionales, bilatérales et multilatérales, de même que le cadre institutionnel et les mécanismes de consultation peuvent rendre les réformes plus transparentes et plus prévisibles.

85. Fait encore plus important, le PDD et, dans une moindre mesure, les diverses initiatives régionales et bilatérales de libre-échange peuvent contribuer à l'ajustement structurel dans les pays en développement qui réalisent une réforme des échanges, en leur donnant accès aux marchés susceptibles de provoquer la réaction des exportations et de faciliter l'ajustement dans les secteurs d'avantage comparatif. 


\section{RÉFÉRENCES}

Agosin, M.R. (2002), « Export Performance in Chile: Lessons for Africa » dans G.K. Helleiner (dir. pub.) Non-Traditional Export Promotion in Africa: Experience and Issues, Université des Nations Unies, Palgrave, NY, États-Unis

Antonio, E. et O. Onodera (2007), « Faciliter les échanges et l'ajustement structurel : l'expérience des économies non membres - Étude de cas sur les Philippines » [TAD/TC/WP(2007)6/PART2/D], Document de travail de l'OCDE sur la politique commerciale $n^{\circ} 59, \mathrm{OCDE}$, Paris

Bacchetta, M. et M. Jansen (2003), « Adjusting to Trade Liberalisation - The Role of Policy, Institutions and WTO Disciplines », Dossier spécial n ${ }^{\circ}$ 7, OMC, Genève

Banque mondiale (2005), « Chapter 2 - Regional Trade and Preferential Trade Agreements: A Global Perspective », Perspectives économiques mondiales 2005, Banque mondiale, Washington D.C.

Banque mondiale (2006a), « Export Promotion Agencies: What Works and What Does Not», Trade Note No. 30, Banque mondiale, Washington D.C.

Banque mondiale (2006b), Assessing World Bank Support for Trade, 1987-2004 - An IEG Evaluation, Groupe d'Evaluation Indépendante, Banque mondiale, Washington D.C.

Bartok, C. et S. Miroudot (2007), « The Interaction amongst trade, investment and competition policies », Document de travail sur la politique commerciale $\mathrm{n}^{\circ} 60$, OCDE, Paris

Bartok, C. et O. Onodera (2007), «Faciliter les échanges et l'ajustement structurel : l'expérience des économies non membres - Étude de cas sur le Chili » [TAD/TC/WP(2007)6/PART2/B], Document de travail de l'OCDE sur la politique commerciale $n^{\circ} 56$, OCDE, Paris

Baunsgaard, T. et M. Keen (2005), « Tax Revenue and (or?) Trade Liberalization », Document de travail $d u F M I \mathrm{n}^{\circ} \mathrm{WP} / 05 / 112$, FMI, États-Unis

Bevan, D., P. Collier, N. Gemmell et D. Greenaway (dir. pub.) (2000), Trade and Fiscal Adjustment in Africa, MacMillan, Royaume-Uni

Bhattacharya, A. et J. F. Linn (1988), « Trade and Industrial Policies in the Developing Countries of East Asia $»$, Documents de discussion de la Banque mondiale $n^{\circ} 27$, Banque mondiale, Washington D.C.

BIT et OMC (2007), Commerce et emploi : un défi pour la recherche en matière de politiques, Genève

Choksi, A. et D. Papageorgiou (dir. pub.) (1986), Economic Liberalization in Developing Countries, Banque mondiale, Basil Blackwell, États-Unis

Collier, P. et J.W. Gunning (1999), Trade Shocks in Developing Countries, Oxford University Press, ÉtatsUnis 
Corbo, Vittorio (1992), «Economic Transformation in Latin America, Lessons for Eastern Europe », European Economic review, Vol. 36.

Cordoba, S.F. et S. Laird (dir. pub.) (2006), « Coping with Trade Reforms: A Developing Country Perspective on the WTO Industrial Tariff Negotiations », Palgrave Macmillan, Hampshire

Czaga, P. (2005), «Les interdictions et les contingentements à l'exportation », Au-delà des tarifs: Le rôle des obstacles non tarifaires dans le commerce mondial, OCDE, Paris

De Melo, J. « Macroeconomic Management and Trade Reform: A Political Economy Perspective », Chapitre 2 de Nash (dir. pub., 1998)

De Soto, H. (2000), The Mystery of Capital - Why Capitalism Triumphs in the West and Fails Everywhere Else, Basic Books, Etats-Unis

Dihel, N., F. Eschenbach et B. Shepherd (2006), « South-south services trade », Document de travail sur la politique commerciale $\mathrm{n}^{\circ} 39$, OCDE, Paris

Di John, J. (2006), « The Political Economy of Taxation and Tax Reform in Developing Countries », Université des Nations Unies, Institut mondial de recherche sur les aspects économiques du développement, Research Paper No. 2006/74

Duran Lima, J.E. et N. Mulder (2008), « Faciliter les échanges et l'ajustement structurel : l'expérience des économies non membres - Étude de cas sur l'Équateur » [TAD/TC/WP(2007)6/PART2/C], Document de travail de l'OCDE sur la politique commerciale $n^{\circ} 64$, OCDE, Paris

Duran Lima, J.E., N. Mulder et Osamu Onodera (2008), «Libéralisation des échanges et performances économiques : comparaison entre l'Asie de l'Est et l'Amérique latine, 1970-2006 » [TAD/TC/WP(2007)6/PART2/A], Document de travail de l'OCDE sur la politique commerciale $n^{\circ}$ 70, OCDE, Paris

Edwards, S. (1982), « Trade Liberalization, Minimum Wages and Employment in the Short Run: Some Reflections based on the Chilean Experience », UCLA Department of Economics Working Paper $n^{\circ}$ 230, téléchargé du site www.econ.ucla.edu

Edwards, S. (1989), « On the Sequencing of Structural Reforms », Document de travail du Département des affaires économiques et statistiques de l'OCDE $n^{\circ} 70, \mathrm{OCDE}$, Paris

Edwards, S. et A. Edwards (1991), «The Sequencing of the Liberalization Reforms in Chile» dans S. Edwards et A.C. Edwards, Monetarism and Liberalization: The Chilean Experiment, University of Chicago Press, Chicago

Engman, M. (2007), « L'extension des chaînes d'approvisionnement internationales : le rôle des économies émergentes dans la fourniture de services informatiques et de services aux entreprises, Document de travail de l'OCDE sur la politique commerciale $\mathrm{n}^{\circ} 52$, OCDE, Paris

Engman, M., O. Onodera et N. Wilson (2006), « Facilitating Adjustment: Sector Experiences from Agriculture, Telecommunications and Chemicals », Document de travail de l'OCDE sur la politique commerciale $\mathrm{n}^{\circ} 41, \mathrm{OCDE}$, Paris 
Engman, M., O. Onodera et E. Pinali (2007), « Export Processing Zones: Past and Future Role in Trade and Development », Document de travail de l'OCDE sur la politique commerciale $\mathrm{n}^{\circ} 53, \mathrm{OCDE}$, Paris

Fernandez, R. et D. Rodrik (1991), « Resistance to Reform: Status Quo Bias in the Presence of Individual Specific Uncertainty », The American Economic Review, Vol. 81, No.5, pp. 1146-1155

FMI (2006), « Chapter III: Structural Changes in Emerging Sovereign Debt and Implications for Financial Stability », World Economic and Financial Surveys - Global Financial Stability Report - Market Developments and Issues, FMI, Washington D.C.

Gasparoni, L., et L. Tornarolli (2006), « Labor informality in Latin America and the Caribbean: Patterns and Trends from Household Survey Micro data », Banque mondiale, Washington D.C.

Geloso Grosso, M. (2006), « La libéralisation des services d'infrastructure de réseau et l'AGCS », Document de travail de l'OCDE sur la politique commerciale $\mathrm{n}^{\circ} 34, \mathrm{OCDE}$, Paris

Geloso Grosso, M., M. Lesher et E. Pinali (2007), « Services trade liberalisation and tourism development $»$, Document de travail de l'OCDE sur la politique commerciale $\mathrm{n}^{\circ} 57, \mathrm{OCDE}$, Paris

Glenday, G. (2006), « Towards Fiscally Feasible and Efficient Trade Liberalization », communication rédigée dans le cadre du Fiscal Reform in Support of Trade Liberalization Project, USAID, Washington D.C.

Goldsbrough, D. et al. (1996), « Reinvigorating Growth in Developing Countries - Lessons from Adjustment Policies in Eight Economies », IMF Occasional Paper No. 139, FMI, Washington D.C.

Haggard, S. et Webb (dir. pub.) (1994), Voting for Reform: Democracy, Political Liberalization, and Economic Adjustment, Banque mondiale, Washington D.C.

Harrison, A. et A. Revenga (1998), «Labor markets, Foreign Investment and Trade Policy Reform » dans Nash et Takacs (dir. pub.) (1998)

Johnson, R.B. et al. (1997), « Sequencing Capital Account Liberalization: Lessons from the Experiences in Chile, Indonesia, Korea, and Thailand », Document de travail du FMI n WP/97/157, FMI, Washington D.C.

Kowalski, P. (2005), « Répercussions des modifications des droits de douane sur les recettes publiques des pays en développement », Document de travail de l'OCDE sur la politique commerciale $\mathrm{n}^{\circ} 18$, OCDE, Paris

Kowalski, P. et B. Shepherd (2006), « South-south trade in goods », Document de travail de l'OCDE sur la politique commerciale $\mathrm{n}^{\circ} 40$, OCDE, Paris

Kramer, M. (1999), « The Changing Economic Complexion of Eastern Europe and Russia: Results and Lessons of the 1990s », SAIS Review, volume 19, n² 2, pp. 16-45, the John Hopkins University Press, États-Unis

Krueger, A. (1978) Liberalisation Attempts and Consequences, Cambridge, MA

Krueger, A. (1981) Trade and Employment in Developing Countries, University of Chicago Press, ÉtatsUnis 
Krueger, A. (1997) « Nominal Anchor Exchange Rate Policies as a Domestic Distortion », NBER Working Paper Series No. 5968

Kuczynski, P-P et J. Williamson (dir. pub.), «After the Washington Consensus - Restarting Growth and Reform in Latin America », Institute for International Economics, Washington D.C.

Lal, D. (1995), « India and China: Contrasts in Economic Liberalization? », World Development 23(9): pp. 1475-94

Lesher,M. et H. Nordas (2007, à paraître), « The Impact of Services Trade Liberalisation on Trade in NonAgricultural Products », TAD/TC/WP(2007)21

Manelli, J.M. et G. McMahon (1994), «Economic Lessons for Eastern Europe from Latin America », Documento CEDES/107 Serie Economia, CEDES, Buenos Aires, Argentine

Matusz, S.J. et D. Tarr (1999), « Adjusting to Trade Policy Reform », Policy Research Working Paper 2142, Banque mondiale, Washington D.C.

Michaely, M., A. Choksi et D. Papageorgiu (1990), Liberalizing Foreign Trade: The Lessons of Experience in the Developing World, Basil Blackwell, Cambridge, MA

Michalopoulos, C. (1999), «Trade Policy and Market Access Issues for Developing Countries », World Bank Policy Research Working Papers No. 2214, Banque mondiale, Washington D.C.

Mussa, M. (1986), «The Adjustment Process and the Timing of Trade Liberalisation » dans Choksi et. al. (dir. pub.) (1986)

Nash, J. et W. Takacs (dir. pub., 1998), « Trade Policy Reform: Lessons and Implications », World Bank Regional and Sectoral Studies, Banque mondiale, Washington D.C.

OCDE (2004a), Trade and Competitiveness in Argentina, Brazil and Chile - Not as Easy as ABC

OCDE (2004b), "Chapitre 5. L'emploi informel - Promouvoir la transition vers une économie salariée », Perspectives de l'emploi de l'OCDE 2004

OCDE (2005a), Les échanges et l'ajustement structurel : Les enjeux de la mondialisation

OCDE (2005b), Au-delà des tarifs : Le rôle des obstacles non tarifaires dans le commerce mondial

OCDE (2005c), Policy Coherence Towards East Asia - Development Challenges for OECD Countries

OCDE (2006), Stimuler l'emploi et les revenus : les leçons à tirer de la réévaluation de la Stratégie de l'OCDE pour l'emploi

OCDE (2007a), « Chapitre 7. La mise en œuvre des réformes structurelles : quels sont ses déterminants? », Réformes économiques : Objectif croissance - Édition 2007

OCDE (2007b), Statistiques de l'OCDE sur les échanges internationaux de service : Volume I : Tableaux détaillés par catégories de services - 1996-2005 - Édition 2007

OMC (2003), « Incidences de la libéralisation des échanges sur les recettes - Communication des EtatsUnis », TN/MA/W/18/Add.2 
OMC (2005), Rapport sur le commerce mondial 2005, Organisation mondiale du commerce, Genève

Panagariya, A. (1990), « How should tariffs be structured? », World Bank Working Paper Series No.353, Banque mondiale, Washington D.C.

Panagariya, A. et D. Rodrik (1993), « Political Economy Arguments for a Uniform Tariff», International Economic Review, 34:687-703

Panagariya, A. (1996), « The Economics and Politics of Uniform Tariffs », communication présentée lors d'une conférence en 1997, téléchargée en janvier 2007 du site www.bsos.umd.edu

Papageorgiu, D., A.M. Choksi et M. Michaely (1990), Liberalising Foreign Trade in Developing Countries: The Lessons of Experience, Banque mondiale, Washington D.C.

Parikh, A. (2002), «Impact of Liberalization, Economic Growth and Trade Policies on Current Accounts of Developing Countries, An Econometric Study », Institut mondial de recherche sur l'économie du développement, Discussion Paper, No. 2002/63.

Peltzman, J. (2004), « Trade Liberalization and Fiscal Reform: Evidence from Two Case Studies Morrocco and Jamaica _ and a General Cross-Country Econometric Analysis », communication rédigée pour USAID, téléchargée en février 2007 du site www.fiscalreform.net

Perry, G.E., W.F. Maloney, O.S. Arias, P. Fajnzylber, A.D. Mason et J. Saavedra-Chanduvi (2007), Informality: Exit and Exclusion, Banque mondiale, Washington D.C.

Pitchford, J. (1992), « Current Account Deficits, External Liabilities and Economic Policy », Document de travail du FMI WP/92/54, FMI, Washington D.C.

Rajapatirana, S. L. M. de la Mora et R.A. Yatawara (1997), « Political Economy of Trade Reforms, 19651994: Latin American Style », The World Economy, Volume 20 Issue 3 Page 307-338, Blackwell

Rodrik, D. (1989a), « Promises, Promises: Credible Policy Reform via Signalling », The Economic Journal, Vol. 99, No. 397, pp. 756-772, Royal Economic Society

Rodrik, D. (1989b), «Credibility of Trade Reform - A Policy Maker's Guide », The World Economy, Vol. 12, pp. 1-16

Rodrik, D. (1999), «Institutions for high quality growth: What they are and how to acquire them », version provisoire rédigée pour la conférence du FMI sur les réformes de la deuxième génération, téléchargée en novembre $2007 \mathrm{du}$ site http://ksghome.harvard.edu/ drodrik/institutions.pdf

Rodrik, D. (2003), « Growth Strategies », NBER Working Paper Series No. 10050

Rodrik, D. (2004), «Industrial Policy for the Twenty-First Century », John F. Kennedy School of Government, Harvard University, téléchargé le 24 août 2006 du site http://ksghome.harvard.edu/ drodrik/papers.html

Rodrik, D. (2007), "The Real Exchange Rate and Economic Growth: Theory and Evidence, » John F. Kennedy School of Government, Harvard University, téléchargé le 15 novembre 2006 du site http://ksghome.harvard.edu/ drodrik/papers.html 


\section{TAD/TC/WP(2007)6/PART1/FINAL}

Santos-Paulino, A. et A.P. Thirlwall (2004), « The Impact of Trade Liberalisation on Exports, Imports, and the Balance of Payments of Developing Countries », Economic Journal, 114(1), pp. 50-72, Royal Economic Society

Schneider, F. (2004), « The Size of the Shadow Economies of 145 Countries all over the World: First Results over the Period 1999 to 2003 », Iza Discussion Paper No. 1431, Institute for the Study of Labor (IZA), Bonn

Tangkitvanich, Somkiat et O. Onodera (2008), «Faciliter les échanges et l'ajustement structurel :

l'expérience des économies non membres - Étude de cas sur la Thaillande »

[TAD/TC/WP(2007)6/PART2/E], Document de travail de l'OCDE sur la politique commerciale $n^{\circ}$ 63, OCDE, Paris

Thomas, V. et John Nash (dir. pub.) (1991), Best Practices in Trade Policy Reform, Banque mondiale et Oxford Press, États-Unis

Wei, S.J. (1997), « Gradualism versus Big Bang: Speed and Sustainability of Reforms », The Canadian Journal of Economics, Vol. 30, No. 4b, pp. 1234-1247 


\section{ANNEXE 1. ÉCHANGE ET AJUSTEMENT STRUCTUREL : RECOMMANDATIONS DE BONNES PRATIQUES ${ }^{80}$}

Sur la base des cas examinés dans la présente étude et de l'expérience acquise dans le cadre de la procédure d'examen préalable mutuel de l'OCDE, il est recommandé aux gouvernements des pays développés et des pays en développement de:

1. Recourir, dans toute la mesure du possible, à des mesures applicables à tous, notamment par le biais du système d'imposition et de sécurité sociale, afin de contribuer à renforcer les effets positifs de l'ouverture tout en réduisant les coûts de l'ajustement.

2. Veiller à ce que les mesures d'ajustement ciblées, si leur application est jugée nécessaire pour des raisons d'économie politique, soient:

2.1 liées à des échéances précises dans le cadre d’une stratégie de sortie bien définie

2.2 découplées de la production

2.3 axées sur la réintégration des victimes de suppressions d'emplois au marché du travail

2.4 compatibles avec les systèmes généraux de protection sociale

2.5 efficaces par rapport à leur coût

2.6 transparentes et soumises à contrôle

3. En oeuvrant en faveur de la stabilité macroéconomique et de la croissance, faire régner un climat propice à l'ajustement qui permette aux marchés du travail et à l'économie en général de fonctionner efficacement et qui, surtout dans le cas des pays en développement, complète le processus de libéralisation des échanges en:

3.1 supprimant les biais anti-exportations et maintenant des politiques de taux de change appropriées

3.2 encourageant les réformes fiscales pour compenser les baisses de recettes publiques résultant des réductions tarifaires.

4. Adopter de saines politiques du marché du travail qui facilitent le redéploiement de la maind'oeuvre vers des emplois plus productifs et aident ainsi les économies - et leurs habitants -à recueillir les fruits des échanges, et qui englobent :

4.1 des prestations de remplacement de revenu qui offrent aux victimes de suppressions d'emplois une garantie de revenu tout en favorisant leur retour à l'emploi. Les prestations sociales doivent donc soutenir les incitations à travailler et non pas servir au retrait de la population active des victimes de suppressions d'emplois (comme cela a souvent été le cas avec les systèmes de préretraite et d'invalidité) ;

80. Reproduit de OCDE (2005a). 


\section{TAD/TC/WP(2007)6/PART1/FINAL}

4.2 des programmes actifs du marché du travail - incluant une aide à la recherche d'emploi, des services de conseil, des indemnités de déménagement et des mesures permettant d'anticiper activement les licenciements collectifs - ce qui implique :

4.2.1 une coopération tripartite active entre le patronat, les représentants des travailleurs et les pouvoirs publics dans le respect des pratiques nationales

4.2.2 une évaluation réaliste des possibilités d'emploi des travailleurs et des besoins en matière d'aide à l'ajustement

4.2.3 un recours à des experts extérieurs en cas de licenciements de grande ampleur

4.2.4 des programmes qui soient suffisamment longs pour apporter un soutien réel mais qui empêchent en même temps un relâchement de l'effort

4.2.5 l'octroi d'une aide complémentaire par le biais de prestations de compensation de la perte de revenu

4.3 des mesures de protection de l'emploi qui permettent de réduire les coûts d'ajustement sans freiner le dynamisme des entreprises

4.4 des systèmes souples de fixation des salaires, la possibilité de transférer les droits à pension et des marchés du logement fluides

4.5 des systèmes d'éducation et de formation qui favorisent le développement du capital humain et permettent d'assurer l'adaptation des compétences de la main-d'œuvre à l'évolution des besoins du marché du travail.

5. Promouvoir un environnement réglementaire et concurrentiel sain qui permette les mutations au sein des entreprises ainsi que les entrées et sorties dans tous les secteurs en facilitant les fusions et les redéfinitions de cultures d'entreprise, en maintenant au minimum nécessaire les obstacles réglementaires gênant les entreprises et en réduisant les effets de distorsion sur les échanges des réglementations nationales à l'aide du renforcement :

\section{1 de la transparence}

5.2 de la non-discrimination

$5.3 d u$ non-recours à des restrictions pénalisant inutilement les échanges

\section{4 de l'harmonisation internationale des normes}

5.5 de la simplification des évaluations de conformité

5.6 de l'application résolue des principes de la concurrence

6. Encourager la mise en place d'un cadre institutionnel et politico-administratif solide qui favorisera la réforme structurelle tout en permettant que les mesures de réforme soient mieux comprises et acceptées par le public, grâce à :

6.1 une évaluation ex ante efficace de l'action publique permettant notamment d'établir si la réforme structurelle envisagée est dans l'intérêt général de la population 
6.2 des processus d'examen indépendants pour faire en sorte que les avantages soient supérieurs aux coûts tout en évitant les conflits d'intérêts

6.3 une évaluation à mi-parcours et ex post pour permettre de garantir que les politiques seront modifiées, s'il y a lieu, en fonction des résultats obtenus ainsi que des difficultés inattendues éventuellement rencontrées

6.4 un processus de consultation efficace entre le gouvernement et la société civile, y compris les entreprise privées

6.5 de solides institutions publiques pour gérer les services et les incitations offerts aux investisseurs, aux importateurs et aux exportateurs.

7. Adopter des politiques commerciales libérales, qui soutiennent l'ajustement structurel en contribuant à la croissance économique, favorisant la compétitivité et l'innovation, améliorant l'accès aux importations essentielles et encourageant les synergies entre pays dotés d'avantages comparatifs dans des domaines différents, et qui :

7.1 optimisent les effets positifs pour le bien-être social qui découlent de la libéralisation des échanges de services;

7.2 soient mises en cuvre sur une période assez longue pour permettre aux parties affectées de s'adapter mais suffisamment courte pour éviter un retour en arrière;

7.3 n'aient recours que de façon limitée aux mesures de sauvegarde et qu'après avoir soigneusement établi si les avantages potentiels qu'elles apportent, en offrant un répit pour l'ajustement structurel et en permettant que celui-ci soit mieux accepté par la population, justifient le coût qu'elles impliquent;

7.4 optimisent les possibilités pour les flux d'investissement direct étranger qui les accompagneront.

8. Entreprendre les réformes dans différents domaines d'intervention des pouvoirs publics sur un large front et de façon complémentaire afin d'optimiser les synergies entre les diverses mesures et de réduire la résistance à la restructuration en faisant en sorte que les personnes défavorisées par une réforme puissent bénéficier d'une autre.

9. Encourager les initiatives bilatérales et régionales là où une coopération dans le domaine de la réglementation peut ouvrir des possibilités par le biais des échanges ou réduire les difficultés d'ajustement dans certains secteurs, et là où un ajustement et une ouverture au niveau des échanges peuvent être entrepris entre partenaires à l'échelon bilatéral ou régional pour ouvrir la voie ou apporter un prolongement à de plus larges engagements multilatéraux.

10. Favoriser une coopération multilatérale dans les domaines liés entre eux et à l'ajustement suivants, à savoir :

10.1 les échanges et le financement, en évitant de recourir à des mesures de représailles commerciales mutuellement préjudiciables et en contribuant à ancrer solidement les réformes intérieures tout en s'attaquant plus particulièrement aux problèmes des pays en développement liés à l'ajustement, par le biais : 


\section{TAD/TC/WP(2007)6/PART1/FINAL}

10.1.1 d'un engagement soutenu à l'égard des objectifs de libéralisation des échanges et de renforcement des règles du Programme de Doha pour le développement

10.1.2 de l'application effective d'un traitement spécial et différencié aux pays en développement

10.1.3 d'un durcissement des règles applicables pour l'octroi de crédits à l'exportation bénéficiant d'un soutien public

10.1.4 d'une coopération renforcée entre l'OMC, la Banque mondiale et le FMI pour obtenir une plus grande cohérence dans le processus de décision économique au niveau mondial

10.2 le renforcement des capacités, par le biais:

10.2.1 d'une coordination efficace entre l'OMC, le FMI, la Banque mondiale, l'OIT, les donneurs bilatéraux et les autres organismes multilatéraux permettant de renforcer les capacités institutionnelles et les capacités du côté de l'offre existant dans les pays en développement

10.2.2 d'une coordination des activités des donneurs

10.3 la responsabilité des entreprises et les normes fondamentales du travail, par le biais:

10.3.1 d'efforts constants déployés pour que les Principes directeurs de l'OCDE à l'intention des entreprises multinationales soient appliqués avec plus d'efficacité, de transparence et d'opportunité

10.3.2 de l'application suivie des lignes directrices de l'OCDE relatives à la gouvernance sociale des entreprises pour l'octroi des crédits à l'exportation bénéficiant d'un soutien public

10.3.3 de l'application suivie des normes fondamentales du travail et de la promotion du travail décent notamment en encourageant la ratification des conventions pertinentes et en veillant en permanence à ce que les dispositions de la Déclaration de l'OIT relative aux principes et droits fondamentaux du travail soient respectées. 
ANNEXE 2

Tableau A. Taux de droits de douane appliqués des membres de l'OMC

\begin{tabular}{|c|c|c|}
\hline $\begin{array}{c}\text { TAUX DE } \\
\text { DROITS } \\
\text { APPLIQUÉS } \\
\text { NPF (\%) }\end{array}$ & PRODUITS AGRICOLES & PRODUITS NON AGRICOLES \\
\hline $\begin{array}{l}\text { Plus de } \\
30\end{array}$ & $\begin{array}{l}\text { Bhoutan (41.2), Burundi (33), Corée (41.6), } \\
\text { Îles Salomon (34.0), Inde (37.4), Iran (32.3), } \\
\text { Maroc (48.6), Nigeria (50.4), Seychelles } \\
\text { (38.4), Soudan (34.6), Tunisie (66.5), Turquie } \\
(42.3)\end{array}$ & Bahamas (31.5), Djibouti (32.6) \\
\hline $25-30$ & $\begin{array}{l}\text { Barbade (29.3), Thaïlande (29.6), Zimbabwe } \\
(25.7)\end{array}$ & $\begin{array}{lllll}\text { Inde }(27.9), \quad \text { Maroc } & (21.5), & \text { Nigeria } & (25.8), \\
\text { Seychelles (26.8) } & & & \\
\end{array}$ \\
\hline $20-25$ & $\begin{array}{l}\text { Algérie (23), Bahamas (24.3), Bangladesh } \\
\text { (20.6), Cameroun (22.0), Tchad (22.0), Congo } \\
\text { (22.0), Djibouti (20.5), Égypte (22.5), Éthiopie } \\
\text { (21.7), Gabon (22.0), Guinée équatoriale } \\
\text { (22.0), Guyana (20.1), Kenya (23.6), Libye } \\
\text { (22.4), Mexique (24.5), République } \\
\text { centrafricaine (22.0), Roumanie (24.4), Sri } \\
\text { Lanka (22.5), Syrie (20.6), Vietnam (24.5) }\end{array}$ & $\begin{array}{l}\text { Burundi (22.0), Îles Salomon (20.5), Iran (20.5), } \\
\text { Maldives (20.5), Soudan (22.9), Tunisie (22.4) }\end{array}$ \\
\hline $15-20$ & 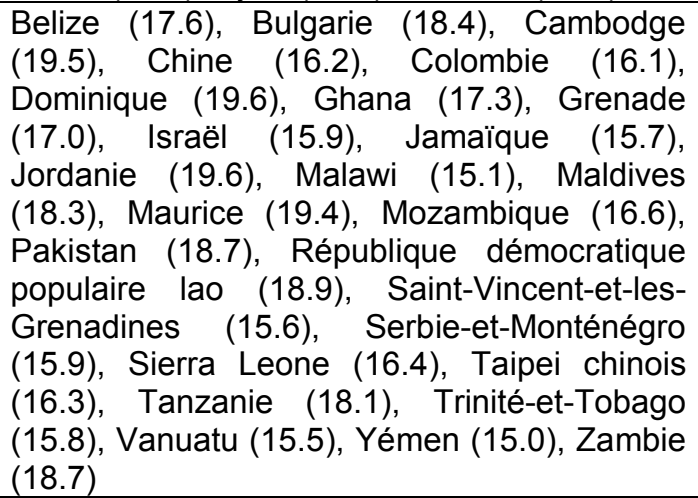 & $\begin{array}{l}\text { Algérie (18.1), Bangladesh (18.3), Bermudes } \\
\text { (18.8), Bhoutan (19.2), Cambodge (15.9), } \\
\text { Cameroun (17.5), Congo (17.4), Éthiopie (18.4), } \\
\text { Égypte (19.5), Gabon (17.4), Guinée équatoriale } \\
\text { (17.4), Kenya (15.7), Libye (16.3), Maurice (17.3), } \\
\text { Mexique (17.1), Pakistan (16.2), République } \\
\text { centrafricaine (17.4), Roumanie (15.8), Rwanda } \\
\text { (18.0), Syrie (19.5), Tchad (17.4), Vietnam (15.7), } \\
\text { Zimbabwe (15.2) }\end{array}$ \\
\hline
\end{tabular}




\begin{tabular}{|c|c|c|}
\hline $\begin{array}{c}\text { TAUX DE } \\
\text { DROITS } \\
\text { APPLIQUÉS } \\
\text { NPF }(\%)^{*}\end{array}$ & PRODUITS AGRICOLES & PRODUITS NON AGRICOLES \\
\hline $10-15$ & $\begin{array}{l}\text { Antigua-et-Barbuda (14.6), Argentine (12.0), } \\
\text { Azerbaïdjan (12.7), Bénin (14.3), Bolivie } \\
\text { (10.0), Brésil (10.3), Burkina Faso (14.0), } \\
\text { Costa Rica (12.2), Cuba (10.9), Côte d'lvoire } \\
\text { (14.3), El Salvador (11.7), Équateur (14.7), } \\
\text { Érythrée (10.0), ex-République yougoslave de } \\
\text { Macédoine (12.7), Gambie (14.9), Géorgie } \\
\text { (11.7), Guatemala (10.0), Guinée-Bissau } \\
\text { (14.3), Liban (14.7), Mali (14.3), Mauritanie } \\
\text { (12.4), Moldova (10.2), Népal (13.5), Niger } \\
\text { (14.3), Oman (10.2), Ouganda (12.0), } \\
\text { Ouzbékistan (10.5), Panama (14.8), } \\
\text { Papouasie Nouvelle-Guinée (14.7), Paraguay } \\
\text { (10.1), Pérou (13.6), République } \\
\text { démocratique du Congo (13.0), République } \\
\text { dominicaine (13.0), Rwanda (13.5), Saint- } \\
\text { Kitts-et-Nevis (13.1), Sainte-Lucie (14.8), } \\
\text { Sénégal (14.3), Togo (14.3), Turkménistan } \\
\text { (13.2), Uruguay (12.0), Venezuela (14.8) }\end{array}$ & $\begin{array}{l}\text { Argentine (12.0), Barbade (11.2), Belarus (10.1), } \\
\text { Bénin (11.6), Brésil (12.7), Burkina Faso ((11.7), } \\
\text { Colombie (11.6), Cuba (10.9), Côte d'Ivoire (11.6), } \\
\text { Équateur (11.5), Gambie (12.5), Ghana (12.5), } \\
\text { Guinée-Bissau (11.6), Jordanie (12.1), Malawi } \\
\text { (12.9), Mali (11.6), Mauritanie (10.3), Maroc (11.7), } \\
\text { Népal (13.7), Niger (11.6), Paraguay (10.9), } \\
\text { République démocratique du Congo (11.9), } \\
\text { Russie (10.1), Sénégal (11.6), Sierra Leone } \\
\text { (13.3), Tanzanie (12.9), Thaïlande (13.3), Togo } \\
\text { (11.6), Uruguay (13.5), Ouzbékistan (11.1), } \\
\text { Vanuatu (13.6), Venezuela (12.4), Yémen (12.5), } \\
\text { Zambie (13.2) }\end{array}$ \\
\hline $5-10$ & $\begin{array}{l}\text { Afrique du Sud (9.1), Albanie (9.0), Angola } \\
\text { (9.4), Arabie saoudite (6.8), Arménie (6.6), } \\
\text { Belarus (9.0), Bermudes (8.0), Bolivie (6.8), } \\
\text { Botswana (9.1), Chili (6.0), Communautés } \\
\text { européennes (5.9), Croatie (9.3), Fidji (8.4), } \\
\text { Guinée (6.6), Honduras (9.8), Islande (6.5), } \\
\text { Indonésie (8.2), Japon (7.3), Kazakhstan } \\
\text { (8.8), Lesotho (8.8), Madagascar (5.7), } \\
\text { Mongolie (5.1), Myanmar (8.5), Namibie (9.1), } \\
\text { Nicaragua (9.5), Philippines (9.5), Qatar (6.3), } \\
\text { République kirghize (7.0), Russie (8.9), } \\
\text { Swaziland (9.1), Tadjikistan (9.4) }\end{array}$ & $\begin{array}{l}\text { Afrique du Sud (5.3), Albanie (7.2), Angola (8.7), } \\
\text { Antigua-et-Barbuda (8.9), Arabie saoudite (6.0), } \\
\text { Azerbaïdjan (8.3), Belize (9.5), Bolivie (9.3), } \\
\text { Bosnie-Herzégovine (6.2), Botswana (5.3), } \\
\text { Bulgarie (8.8), Chili (9.5), Corée (6.7), Dominique } \\
\text { (8.4), El Salvador (6.6), Erythrée (7.6), ex- } \\
\text { République yougoslave de Macédoine (8.7), Fidji } \\
\text { (7.2), Géorgie (6.9), Grenade (9.4), Guatemala } \\
\text { (5.7), Guinée (6.4), Guyana (9.6), Honduras (5.3), } \\
\text { Indonésie (6.7), Jamaïque (5.9), Kazakhstan (9.5), } \\
\text { Lesotho (7.9), Madagascar (5.1), Malaisie (9.1), } \\
\text { Myanmar (5.0), Namibie (5.3), Oman (5.0), } \\
\text { Ouganda (7.2), Panama (7.4), Pérou (9.7), } \\
\text { Philippines (5.8), République dominicaine (7.8), } \\
\text { République démocratique populaire lao (8.2), } \\
\text { Saint-Kitts-et-Nevis (8.8), Saint-Vincent-et-les- } \\
\text { Grenadines (8.9), Sainte-Lucie (8.0), Serbie-et- } \\
\text { Monténégro (8.4), Sri Lanka (8.3), Swaziland } \\
\text { (5.3), Tadjikistan (8.1), Taipei chinois (5.5), Trinité- } \\
\text { et-Tobago (6.6), Turquie (5.3), Ukraine (6.9). }\end{array}$ \\
\hline $0-5$ & $\begin{array}{l}\text { Australie (1.2), Bosnie-Herzégovine (4.8), } \\
\text { Brunéi Darussalam (0), Canada (3), États- } \\
\text { Unis (x), Hong Kong Chine (0), Koweït (1.7), } \\
\text { Macao Chine (0), Malaisie (3.3), Norvège (x), } \\
\text { Nouvelle-Zélande (1.7), Singapour (0), Suisse } \\
\text { (x), Suriname (x) }\end{array}$ & $\begin{array}{l}\text { Arménie (2.3), Australie (4.6), Bahreïn (4.9), } \\
\text { Brunéi (3.0), Canada (4.0), Communautés } \\
\text { européennes (4.0), Costa Rica (4.9), Croatie (4.1), } \\
\text { États-Unis (3.3), Hong Kong, Chine (0), Islande } \\
\text { (2.4), Israël (4.0), Japon (2.5), Koweït (3.9), Liban } \\
\text { (4.0), Macao (0), Moldova (4.1), Mongolie (4.9), } \\
\text { Nicaragua (4.0), Nouvelle-Zélande (3.4), Norvège } \\
\text { (0.6), Papouasie Nouvelle-Guinée (4.7), Qatar } \\
\text { (4.9), République kirghize (4.8), Singapour (0), } \\
\text { Suisse (x), Suriname (x), Turkménistan (3.9) }\end{array}$ \\
\hline
\end{tabular}

Source : OMC (2005) : Rapport sur le commerce mondial, pp. 337-341 
Tableau B. Études sur la réforme des échanges et l'ajustement

\begin{tabular}{|c|c|c|}
\hline Titre et auteur & Sujet principal / Pays étudiés & Principales leçons \\
\hline $\begin{array}{l}\text { Trade and Employment in } \\
\text { Developing Countries } \\
\text { A. Krueger (1981) }\end{array}$ & $\begin{array}{l}\text { - Effets du remplacement des } \\
\text { importations et de la promotion des } \\
\text { exportations sur l'emploi } \\
\text { - Études de cas : Brésil, Chili, } \\
\text { Colombie, Corée, Côte d'Ivoire, } \\
\text { Indonésie, Pakistan, Thaïlande, } \\
\text { Tunisie, Uruguay }\end{array}$ & $\begin{array}{l}\text { - Les politiques axées sur les exportations ont } \\
\text { souvent créé davantage d'emplois que les } \\
\text { politiques de remplacement des importations, } \\
\text { car elles se traduisent par une utilisation plus } \\
\text { intensive de main-d'oeuvre. } \\
\text { - Le potentiel de gain est dans une très large } \\
\text { mesure tributaire du bon fonctionnement des } \\
\text { marchés de facteurs. }\end{array}$ \\
\hline $\begin{array}{l}\text { Export Orientated } \\
\text { Development Strategies } \\
\text { Corbo, V., A. Krueger, et } \\
\text { F. Ossa (dir. pub.) (1985) }\end{array}$ & $\begin{array}{l}\text { - Stratégies de croissance axées sur } \\
\text { les exportations } \\
\text { - Études de cas : Hong Kong, Chili } \\
\text { République de Corée, Singapour et } \\
\text { Taipei chinois }\end{array}$ & $\begin{array}{l}\text { - Cadre macroéconomique stable } \\
\text { - Le taux de change réel doit être stable et } \\
\text { approprié, c'est-à-dire produire une balance } \\
\text { commerciale adaptée à l'expansion des } \\
\text { dépenses et viable à moyen terme. } \\
\text { - Les exportateurs devraient être assujettis à un } \\
\text { régime de quasi-libre-échange. Les prix des } \\
\text { matières premières échangées et des services } \\
\text { non échangeables devraient être concurrentiels. } \\
\text { - Les marchés financiers devraient offrir du } \\
\text { financement à des taux concurrentiels à } \\
\text { l'échelle nationale. } \\
\text { - Toute discrimination contre l'épargne devrait } \\
\text { être éliminée. }\end{array}$ \\
\hline $\begin{array}{l}\text { Economic Liberalization in } \\
\text { Developing Countries, } \\
\text { Choksi et al. (dir. pub.) } \\
(1986)\end{array}$ & $\begin{array}{l}\text { - Diverses questions } \\
\text { - Étude de cas : Chili }\end{array}$ & $\begin{array}{l}\text { - Synchronisation et enchaînement, ajustement, } \\
\text { compensation, et ordre de libéralisation du } \\
\text { compte capital et du compte courant. }\end{array}$ \\
\hline $\begin{array}{l}\text { Liberalising Foreign Trade } \\
\text { in Developing Countries: } \\
\text { The Lessons of } \\
\text { Experience } \\
\text { Papagiorgiou et al. (1990) }\end{array}$ & $\begin{array}{l}\text { - Étude exhaustive de la Banque } \\
\text { mondiale portant sur } 36 \text { épisodes de } \\
\text { réforme des échanges dans } 19 \text { pays, } \\
\text { dont l'Argentine, le Brésil, le Chili, la } \\
\text { Corée, le Pérou, les Philippines, } \\
\text { Singapour, le Sri Lanka et la Turquie }\end{array}$ & $\begin{array}{l}\text { - Les programmes aux objectifs audacieux } \\
\text { avaient une plus longue durée. } \\
\text { - La réduction des restrictions quantitatives est } \\
\text { primordiale. } \\
\text { - La plupart des programmes qui ont donné de } \\
\text { bons résultats ont débuté par une diminution du } \\
\text { taux de change. } \\
\text { - Une politique macroéconomique prudente est } \\
\text { essentielle. } \\
\text { - L'enchaînement (la libéralisation des } \\
\text { échanges doit précéder celle du compte capital) } \\
\text { est important. } \\
\text { - Les coûts transitionnels de la libéralisation } \\
\text { sont inférieurs à ceux que l'on redoute } \\
\text { habituellement (la libéralisation des échanges } \\
\text { n'a pas, règle générale, entraîné une hausse du } \\
\text { chômage). }\end{array}$ \\
\hline $\begin{array}{l}\text { Best Practices in Trade } \\
\text { Policy Reform } \\
\text { Thomas et Nash (1991) }\end{array}$ & $\begin{array}{l}\text { - Étude de la Banque mondiale } \\
\text { réalisée à partir d'études de cas } \\
\text { (Bangladesh, Chili, Colombie, Corée, } \\
\text { Côte d'lvoire, Ghana, Guyana, } \\
\text { Jamaïque, Madagascar, Malawi, } \\
\text { Maurice, Pakistan, Panama, } \\
\text { Philippines, Sénégal, Thaïlande, } \\
\text { Togo, Turquie, Yougoslavie, Zambie, } \\
\text { Zimbabwe) }\end{array}$ & $\begin{array}{l}\text { - Au départ, il faudrait accorder la priorité à la } \\
\text { réduction des restrictions quantitatives. } \\
\text { - Des mesures énergiques doivent être prises } \\
\text { pour diminuer la protection à l'importation. } \\
\text { - Des droits de douane relativement bas et } \\
\text { uniformes sont préférables pour des raisons } \\
\text { d'efficience. } \\
\text { - Il est plus facile de faire accepter la réforme de } \\
\text { la politique commerciale lorsqu'on dispose } \\
\text { d'études coûts-avantages. } \\
\text { - Il convient de renforcer la capacité de suivi et } \\
\text { d'évaluation. } \\
\text { - Si les réformes ne peuvent pas être } \\
\text { simultanées, il faut accorder une attention } \\
\text { particulière à l'enchaînement. } \\
\text { - Les répercussions de la réforme des échanges }\end{array}$ \\
\hline
\end{tabular}


TAD/TC/WP(2007)6/PART1/FINAL

\begin{tabular}{|l|l|l|}
\hline & $\begin{array}{l}\text { sur les finances publiques et, en dernière } \\
\text { analyse, sur la stabilité macroéconomique } \\
\text { devraient être prises en compte. Lorsque } \\
\text { l'inflation est très élevée, les autres réformes } \\
\text { peuvent être précédées d'efforts de } \\
\text { stabilisation. }\end{array}$ \\
& $\begin{array}{l}\text { - Si on met davantage l'accent sur les politiques } \\
\text { complémentaires, l'investissement et les } \\
\text { réformes institutionnelles, la réforme des } \\
\text { échanges donnera de meilleurs résultats. }\end{array}$ \\
\hline
\end{tabular}


Tableau B. Études sur la réforme des échanges et l'ajustement (suite)

\begin{tabular}{|c|c|c|}
\hline Titre et auteur & Sujet principal / Pays étudiés & Principales leçons \\
\hline $\begin{array}{l}\text { Trade Policy Reform: } \\
\text { Lessons and Implications } \\
\text { Nash et Takacs (1998) }\end{array}$ & $\begin{array}{l}\text { Leçons des programmes d'expansion } \\
\text { des échanges réalisés par la Banque } \\
\text { mondiale dans } 17 \text { pays (Costa Rica, } \\
\text { Géorgie, Guatemala, Kenya, } \\
\text { Madagascar, Mali, Maroc, Maurice, } \\
\text { Mongolie, Ouganda, Pologne, Pérou, } \\
\text { Roumanie, Tchécoslovaquie, } \\
\text { Uruguay, Vietnam, Zimbabwe). }\end{array}$ & $\begin{array}{l}\text { - La stabilité macroéconomique facilite la } \\
\text { réforme des échanges, mais n'est pas } \\
\text { forcément un préalable. } \\
\text { - Le succès de la réforme des échanges passe } \\
\text { par un mécanisme de répartition des devises. } \\
\text { - Il y aura ajustement uniquement si la réforme } \\
\text { des échanges est crédible. } \\
\text { - L'impact budgétaire de la réforme des } \\
\text { échanges doit être analysé avec soin ; il faudra } \\
\text { peut-être ajuster les autres impôts et dépenses. } \\
\text { - Dans la plupart des pays en développement, } \\
\text { la réforme des échanges avantage l'agriculture. } \\
\text { - Les mesures de protection spéciales sont à } \\
\text { proscrire. } \\
\text { - II est essentiel que les producteurs puissent } \\
\text { acheter des intrants aux prix du marché mondial } \\
\text { pour assurer l'expansion des exportations. } \\
\text { - La libéralisation des marchés de facteurs } \\
\text { complète la réforme des échanges, laquelle } \\
\text { influe sur ces marchés. }\end{array}$ \\
\hline Harrison et al. (1998) & $\begin{array}{l}\text { Chapitre de Nash et Takacs (1998) } \\
\text { consacré à l'emploi ; données de } \\
16 \text { pays }\end{array}$ & $\begin{array}{l}\text { - Partout sauf dans les économies en transition, } \\
\text { la réforme des échanges a été suivie d'une } \\
\text { hausse de l'emploi total. }\end{array}$ \\
\hline $\begin{array}{l}\text { Reinvigorating Growth in } \\
\text { developing Countries - } \\
\text { Lessons from Adjustment } \\
\text { Policies in Eight } \\
\text { Economies } \\
\text { Goldsbrough et al. (1996) }\end{array}$ & $\begin{array}{l}\text { Étude du FMI qui analyse la politique } \\
\text { d'ajustement de nombreux pays } \\
\text { (Bangladesh, Chili, Ghana, Inde, } \\
\text { Maroc, Mexique, Sénégal, Thaïlande) }\end{array}$ & $\begin{array}{l}\text { - La réforme des échanges devrait 1) débuter } \\
\text { par un effort substantiel ; 2) prévoir l'élimination } \\
\text { rapide des restrictions quantitatives ; 3) } \\
\text { s'appuyer sur un taux de change constant ; 4) } \\
\text { être accompagnée d'une libéralisation des } \\
\text { marchés intérieurs et d'un contrôle des prix. } \\
\text { - En général, la réaction des exportations a été } \\
\text { des plus positives, et s'est concrétisée un ou } \\
\text { deux ans après le début de la réforme. } \\
\text { - L'incohérence des politiques (par exemple, de } \\
\text { la politique de change, de la politique } \\
\text { budgétaire et de la politique salariale) a } \\
\text { amoindri la réaction de l'offre et a parfois amené } \\
\text { les autorités à faire marche arrière. }\end{array}$ \\
\hline $\begin{array}{l}\text { Trade Shocks in } \\
\text { Developing Countries } \\
\text { Collier et Gunning (1999) }\end{array}$ & $\begin{array}{l}\text { - Étude sur les chocs des échanges } \\
\text { survenus dans divers pays en } \\
\text { développement, par exemple les } \\
\text { boums des produits de base (café, } \\
\text { cacao, pétrole, sucre, cuivre, diamants } \\
\text { et uranium). } \\
\text { - Études de cas : Bangladesh, Bolivie, } \\
\text { Botswana, Cameroun, Colombie, } \\
\text { Costa Rica, Côte d'Ivoire, Égypte, } \\
\text { Ghana, Indonésie, Kenya, Malaisie, } \\
\text { Malawi, Maurice, Mexique, Niger, } \\
\text { Nigeria, Philippines, Sénégal, Sri } \\
\text { Lanka, Thaïlande, Venezuela, Zambie }\end{array}$ & $\begin{array}{l}\text { - Les boums des produits de base ont souvent } \\
\text { amené les administrations publiques à } \\
\text { augmenter leurs dépenses, de sorte que la } \\
\text { chute des prix a provoqué une crise. } \\
\text { - Les boums des produits de base ont } \\
\text { également été à l'origine du syndrome } \\
\text { hollandais et d'un boum de la construction. }\end{array}$ \\
\hline
\end{tabular}


Tableau B. Études sur la réforme des échanges et l'ajustement (suite)

\begin{tabular}{|c|c|c|}
\hline Titre et auteur & Sujet principal / Pays étudiés & Principales leçons \\
\hline $\begin{array}{l}\text { Adjusting to trade } \\
\text { liberalisation: The Role of } \\
\text { Policy Institutions and } \\
\text { WTO Disciplines } \\
\text { Baccheta et Jansen } \\
\text { (2003) }\end{array}$ & $\begin{array}{l}\text { - Analyse du processus d'ajustement } \\
\text { après une modification de la politique } \\
\text { commerciale } \\
\text { - Aucune étude de cas }\end{array}$ & $\begin{array}{l}\text { - La libéralisation des échanges n'est pas le } \\
\text { principal moyen pouvant être utilisé pour } \\
\text { modifier la structure de production globale du } \\
\text { pays. } \\
\text { - Les coûts d'ajustement sont généralement } \\
\text { inférieurs aux gains tirés des échanges. } \\
\text { - Les gouvernements peuvent élaborer des } \\
\text { politiques ciblant les personnes et les groupes } \\
\text { qui souffrent de l'ajustement. } \\
\text { - Les coûts d'ajustement peuvent être réduits si } \\
\text { la politique commerciale repose sur des } \\
\text { engagements internationaux. } \\
\text { - Le rythme des réformes peut avoir un impact } \\
\text { favorable sur les coûts d'ajustement. } \\
\text { - Une approche graduelle peut réduire la } \\
\text { résistance, mais risque de compromettre la } \\
\text { réforme. } \\
\text { - Dans bien des cas, un ajustement efficace à la } \\
\text { libéralisation des échanges passe par une } \\
\text { expansion des exportations. } \\
\text { - Les accords de l'OMC donnent aux États la } \\
\text { latitude nécessaire pour s'attaquer aux } \\
\text { problèmes d'ajustement. }\end{array}$ \\
\hline $\begin{array}{l}\text { Coping with Trade } \\
\text { Reforms: A Developing } \\
\text { Country Perspective on } \\
\text { the WTO Industrial Tariff } \\
\text { Negotiations } \\
\text { Cordoba et Laird (2006) }\end{array}$ & $\begin{array}{l}\text { - Analyse de réformes des échanges } \\
\text { en vue de tirer des conclusions dans } \\
\text { l'optique des négociations du PDD } \\
\text { - Études de cas : Bangladesh, Brésil, } \\
\text { Bulgarie, Inde, Jamaïque, Malawi, } \\
\text { Philippines et Zambie }\end{array}$ & $\begin{array}{l}\text { - II n'existe pas de programme universel. II } \\
\text { convient d'élaborer le programme en fonction } \\
\text { du niveau de développement, de la qualité des } \\
\text { institutions, des ressources et des moyens } \\
\text { financiers pouvant être utilisés pour soutenir les } \\
\text { réformes. } \\
\text { - Au terme de la libéralisation des importations, } \\
\text { celles-ci ont augmenté plus rapidement que les } \\
\text { exportations, et la production intérieure et } \\
\text { l'emploi en ont souffert. } \\
\text { - Le contexte macroéconomique, la stabilité } \\
\text { politique, la solidité des institutions, l'offre de } \\
\text { main-d'œuvre et les infrastructures sont souvent } \\
\text { déterminants. } \\
\text { - Le taux de change effectif réel est important. } \\
\text { - Dans les pays qui se sont d'abord ouverts à } \\
\text { l'investissement, IDE a afflué et la croissance } \\
\text { économique s'est fortement accélérée. } \\
\text { - Le fonctionnement des marchés des capitaux } \\
\text { est important, surtout pour les PME (par } \\
\text { exemple, BNDES, la banque de développement } \\
\text { du Brésil). } \\
\text { - La rigidité du marché du travail a tendance à } \\
\text { favoriser la croissance du secteur informel. } \\
\text { - L'OMC, le processus d'adhésion à l'UE, les } \\
\text { accords commerciaux régionaux, et les } \\
\text { programmes de la Banque mondiale et du FMl } \\
\text { ont joué, à divers degrés, un rôle important } \\
\text { dans les pays. }\end{array}$ \\
\hline $\begin{array}{l}\text { Assessing World Bank } \\
\text { Support for Trade, 1987- } \\
2004-\text { An IEG } \\
\text { Evaluation, } \\
\text { Banque mondiale (2006) } \\
\text { Appendice B1 }\end{array}$ & Examen de la documentation & $\begin{array}{l}\text { - La stabilité macroéconomique est nécessaire. } \\
\text { - Le taux de change réel est extrêmement } \\
\text { important. } \\
\text { - Les mesures compensatoires destinées à } \\
\text { corriger le biais anti-exportations et les autres } \\
\text { incitatifs visant à résoudre certains problèmes }\end{array}$ \\
\hline
\end{tabular}




\begin{tabular}{|c|c|c|}
\hline & & $\begin{array}{l}\text { liés aux exportations sont des instruments clés } \\
\text { de promotion des exportations. } \\
\text { - Le contenu de la réforme des échanges, sa } \\
\text { durée et l'enchaînement des mesures }{ }^{2} \text { ont une } \\
\text { grande incidence. La question de savoir si une } \\
\text { réforme éclair est préférable à une réforme } \\
\text { graduelle n'a pas été tranchée. } \\
\text { - Les contraintes extérieures telles que l'accès } \\
\text { aux marchés industriels du pays sont } \\
\text { importantes. } \\
\text { - Il pourrait être nécessaire de prendre des } \\
\text { mesures d'atténuation complémentaires afin de } \\
\text { réduire les coûts d'ajustement. }\end{array}$ \\
\hline Titre et auteur & Sujet principal / Pays étudiés & Principales leçons \\
\hline $\begin{array}{l}\text { Banque mondiale (2006) } \\
\text { Chapitre } 4 \text { - Études de } \\
\text { cas }\end{array}$ & $\begin{array}{l}\text { Inde, Indonésie, Maroc, Mozambique, } \\
\text { Sénégal et Zambie }\end{array}$ & $\begin{array}{l}\text { - Une crise peut hâter le déclenchement de la } \\
\text { réforme, mais une vaste internalisation assure } \\
\text { sa viabilité. } \\
\text { - L'enchaînement des politiques } \\
\text { macroéconomiques a parfois été sous-optimal } \\
\text { (par exemple, la libéralisation des échanges et } \\
\text { la surévaluation de la monnaie) } \\
\text { - La nécessité des politiques complémentaires } \\
\text { (par exemple, la déréglementation industrielle } \\
\text { en Inde, et la gestion de l'offre en Indonésie) a } \\
\text { souvent été sous-estimée. } \\
\text { - Les institutions jouent un rôle prépondérant et } \\
\text { assurent la viabilité de la réforme (par exemple, } \\
\text { le Ministère du commerce et de l'industrie, les } \\
\text { autorités portuaires, l'administration douanière } \\
\text { et les associations du secteur privé). } \\
\text { - La plupart des facteurs externes n'ont pas été } \\
\text { analysés comme il se doit (chevauchement des } \\
\text { accords commerciaux régionaux et chaînes de } \\
\text { valeur mondiales). } \\
\text { - Les résultats de la répartition sont négligés. }\end{array}$ \\
\hline
\end{tabular}

2. La réforme type des échanges comprend deux volets. Le volet exportations englobe l'élimination des restrictions quantitatives, les mesures visant à corriger le biais anti-exportations (surtout l'accès aux intrants importés aux prix du marché mondial), les incitations à l'exportation et la facilitation des échanges, y compris l'administration douanière. Le volet importations comprend généralement l'élimination des restrictions quantitatives, la réduction de la dispersion des droits de douane, la diminution des droits de douane moyens, et les mesures visant à uniformiser les taux de droit.

Source : données établies par l'auteur 


\section{ANNEXE 3 : SURVOL DES AUTRES ÉTUDES}

1) "Libéralisation des échanges et performances économiques : comparaison entre l'Asie de l'Est et l'Amérique latine, 1970-2006 ", (Duran Lima et al., 2008)

86. L'Asie de l'Est et l'Amérique latine constituent des cas intéressants pour une comparaison des expériences en matière de libéralisation des échanges et d'ajustement structurel. Ces deux régions présentaient des points communs aux alentours de 1980 : elles exportaient principalement des ressources naturelles et des produits qui leur étaient liés ( $80 \%$ environ des exportations des deux régions) et leurs politiques commerciales étaient orientées vers le remplacement des importations. Elles sont passées, au cours des décennies suivantes, à un régime davantage orienté vers les exportations en procédant, unilatéralement, à une libéralisation tarifaire poussée, complétée par des initiatives multilatérales et régionales. L'Asie de l'Est a connu une croissance économique supérieure et plus stable, des volumes d'échanges plus élevés en proportion du PIB et une contribution beaucoup plus forte des exportations et du solde extérieur à l'accroissement du PIB. L'Asie de l'Est a créé de nouveaux avantages comparatifs dynamiques et a diversifié la structure de ses exportations, tandis que l'Amérique latine est restée spécialisée dans les produits de base et les produits manufacturés qui en contiennent une forte proportion. La restructuration des industries manufacturières a aussi été plus marquée en Asie de l'Est qu'en Amérique latine.

87. La réussite relative des pays d'Asie de l'Est traduit l'efficacité avec laquelle ils sont parvenus à susciter une réaction plus forte et plus large des exportations. De nombreux facteurs ont contribué à ce succès, notamment : institutions, capital humain et infrastructures de meilleure qualité ; différences dans les politiques mises en œuvre à l'égard de la main-d'œuvre, des marchés financiers et dans l'étendue de la libéralisation des services effectuée. Si l'ajustement a été dans l'ensemble plus réussi en Asie de l'Est, c'est en raison 1) de différences dans l'échelonnement et la teneur de la réforme des échanges ; 2) de la stabilité macroéconomique; (3) de la prévention d'une surévaluation des taux de change; et 4) du rôle efficace joué par l'investissement direct étranger (IDE) et par les réseaux de production.

88. S'agissant des réformes de la politique commerciale, la plupart des pays d'Amérique latine ont réduit rapidement leurs droits de douane entre le milieu des années 80 et le début des années 90 , tandis que les pays d'Asie de l'Est ont dans l'ensemble adopté une démarche plus progressive. Beaucoup d'entre eux ont d'abord utilisé divers dispositifs comme les exemptions de droits à l'exportation, les remboursements de droits de douane et l'instauration de zones franches d'exportation afin d'éliminer le biais anti-exportations, avant de procéder à des réductions tarifaires entre le milieu et la fin des années 90 . En revanche, ils ont réduit relativement tôt leurs obstacles non tarifaires alors que de nombreux pays d'Amérique latine les ont maintenus jusqu'au début des années 90 . On peut en tirer deux enseignements : 1) les réformes des échanges doivent être menées à un rythme et d'une façon qui facilitent la réaction des exportations, et 2) les obstacles non tarifaires comme les restrictions quantitatives doivent être réduits pendant la première phase des réformes.

89. S'agissant de la stabilité macroéconomique, la croissance économique des pays d'Asie de l'Est a été nettement moins instable que celle des pays d'Amérique latine avec des taux d'inflation et d'intérêt relativement bas. L'Amérique latine a connu des crises récurrentes dans les années 80 comme dans les années 90, tandis que l'Asie de l'Est a bénéficié d'une plus grande stabilité, sauf pendant la crise de la fin des années 90. Les crises ont souvent entraîné des réformes commerciales, parfois avec le concours de la 
Banque mondiale et du FMI, avec plus ou moins de réussite. Dans certains cas, les réformes des échanges ont été engagées en l'absence de crise et ont généralement été plus concluantes. Bien que la stabilité économique ne soit pas une condition préalable à la réforme des échanges, l'instabilité macroéconomique a parfois provoqué des retours en arrière temporaires, ce qui démontre que la stabilité est importante pour assurer la viabilité de la réforme des échanges.

90. Empêcher une surévaluation du taux de change réel est essentiel pour que la réforme des échanges réussisse. Alors qu'en Asie de l'Est, des taux de change réels d'un niveau généralement approprié ont réduit le biais anti-exportations, ce taux a été surévalué pendant de longues périodes en Amérique latine et, de ce fait, la réforme des échanges n'a pas produit tous ses effets. Des taux de change appropriés et la stabilité macroéconomique ont permis une réaction plus profonde et plus étendue des exportations et une diversification des exportations. Pour ce qui est du rôle joué par l'IDE, les deux régions ont bénéficié de niveaux d'entrées comparables, mais l'Asie de l'Est a mieux réussi à les attirer dans le secteur manufacturier. Les pays d'Asie de l'Est, ainsi que le Costa Rica et le Mexique, sont mieux parvenus à s'intégrer dans les réseaux mondiaux de production, ce qui a contribué à la valorisation de leurs exportations.

\section{2) Survol des études de cas nationales}

a) Chili (Bartok et Onodera, 2007)

91. Le Chili est considéré comme le pays type qui a emprunté avec succès une trajectoire de développement reposant sur une ouverture vers l'extérieur. Il avait adopté une politique de remplacement des importations et était caractérisé par un imposant secteur public, un taux d'inflation élevé, une grave répression financière, des distorsions prolongées des prix, ainsi qu'une économie coupée des marchés de produits et financiers internationaux. Au début des années 70, le Chili met en œuvre une réforme économique et commerciale radicale. Les restrictions quantitatives sont éliminées et les droits de douane sont abaissés - un taux uniforme de $10 \%$ est appliqué - en un peu plus de cinq ans. Les droits de douane uniformes ont créé un sentiment d'équité, freiné les efforts des groupes de pression et renforcé le soutien à la libéralisation des échanges. L'utilisation du taux de change comme point d'ancrage de l'inflation, la libéralisation du compte capital en l'absence d'une réforme poussée des marchés financiers et d'un contrôle réglementaire suffisant, ainsi que l'indexation des salaires sur l'inflation ont provoqué une crise de la balance des paiements et une crise financière dans les années 80 et l'annulation des mesures de libéralisation. On pouvait croire que des politiques complémentaires inadéquates avaient engendré des coûts d'ajustement élevés à court terme. Fait intéressant à souligner, l'expérience chilienne était parfois qualifiée d'échec à cette époque. La réforme des échanges a été relancée en 1985. En se préoccupant davantage des politiques complémentaires (par exemple, la politique de change, la promotion des exportations, etc.), le Chili a pu enregistrer une forte croissance tirée par les exportations et récolter les fruits de la libéralisation des échanges. Après 1990, un gouvernement démocratiquement élu a poursuivi la réforme des échanges en mettant davantage l'accent sur la politique sociale. Récemment, le Chili a délaissé sa politique de libéralisation unilatérale pour une politique reposant sur les accords commerciaux régionaux, qui semble avoir contribué à la diversification des échanges.

92. Les principaux enseignements à tirer de cette étude de cas sont les suivants : (1) importance d'un environnement macroéconomique stable; (2) importance de supprimer rapidement les restrictions quantitatives; (3) avantages de droits de douane fixes ou uniformes ; (4) importance d'une politique de change cohérente afin de solliciter la réaction des exportations; (5) risques posés par la libéralisation financière lorsqu'elle est mal encadrée; (6) importance d'un cadre institutionnel solide, d'une réglementation claire et de la primauté du droit afin de promouvoir l'investissement (ex. exemples des secteurs du cuivre et de la forêt) ; (7) rôle des engagements multilatéraux pour limiter les retours en arrière 
(droit consolidé de $35 \%$ en vertu du GATT) ; (8) rôle utile de la promotion des exportations; et (9) avantages de l'IDE.

\section{b) Équateur (Duran Lima et Mulder, 2008)}

93. Les résultats des efforts de libéralisation des échanges et des autres réformes structurelles de l'Équateur ont été contrastés. D'une part, le pays a réussi son intégration à l'économie mondiale, et bien que les exportations demeurent fortement dépendantes du pétrole, les produits non traditionnels ont également gagné du terrain. D'autre part, l'Équateur a obtenu des résultats lamentables au plan de la croissance économique et de la réduction de la pauvreté du fait que les réformes étaient incomplètes et que les politiques économiques étaient imprévisibles, conséquence de l'instabilité politique et de la faiblesse des institutions. Pour ce qui est de la dynamique sectorielle, certaines industries (par exemple les fleurs coupées et la transformation du poisson) ont réussi à augmenter la production et les exportations, tandis que d'autres (par exemple, les céréales et les textiles) se sont repliées suite à la libéralisation des échanges. La récente reprise de la croissance économique et des exportations, ayant pour toile de fond les cours élevés du pétrole et la stabilité accrue découlant de la dollarisation, est prometteuse à court terme, bien que ces perspectives soient tributaires d'une politique macroéconomique prudente et de la prolongation de l'accord d'accès préférentiel avec les États-Unis, le principal partenaire commercial de l'Équateur, au-delà de février 2008.

94. Les principaux enseignements à tirer de cette étude de cas sont les suivants : (1) difficultés générées par un environnement macroéconomique instable ; (2) nécessité de poursuivre les réformes pour pérenniser la croissance ; (3) coûts du maintien de la progressivité des droits de douane et des obstacles non tarifaires ; (4) risques posés par la libéralisation financière lorsqu'elle est mal encadrée ; (5) avantages de l'IDE (fleurs coupées, thon); (6) rôle de facilitation que les institutions internationales peuvent jouer dans l'ajustement par l'octroi de prêts, d'une assistance technique, etc.; (7) rôle des engagements multilatéraux pour amorcer les réformes et éviter les retours en arrière (adhésion à l'OMC); et (8) avantages procurés par un meilleur accès aux marchés grâce aux initiatives commerciales multilatérales/bilatérales (ex. ATPDEA avec les États-Unis).

c)

Philippines (Antonio et Onodera, 2007)

95. En matière de libéralisation des échanges, le bilan des Philippines est également contrasté. Ce pays met en œuvre avec vigueur des réformes structurelles depuis le milieu des années 80 . En moyenne, les taux de droits NPF ont été inférieurs à $10 \%$ depuis 1999. La mauvaise répartition des ressources, qui a atteint des proportions relativement grandes dans les années 70 et au début des années 80 , l'instabilité politique, un taux de change réel assez élevé, les retards dans la mise en place d'un cadre propice à l'investissement, ainsi que des institutions relativement déficientes sont au nombre des causes des résultats économiques relativement décevants enregistrés durant les année 80. Cependant, certains éléments semblent indiquer que l'économie des Philippines a pris une trajectoire de croissance plus stable. L'envol de l'industrie des produits électroniques, l'augmentation des envois de fonds des expatriés et la croissance de l'impartition sont de nouvelles tendances prometteuses. Cependant, certains secteurs ayant un plus grand potentiel de croissance, par exemple la transformation des aliments, demeurent négligés, et la diversification des exportations a été plus limitée. Il convient de maintenir des conditions favorables à l'investissement privé, soit la stabilité macroéconomique (gestion budgétaire prudente), la stabilité politique, le respect des droits de propriété et l'amélioration des infrastructures.

96. Les principaux enseignements à tirer de cette étude de cas sont les suivants : (1) difficultés générées par un environnement macroéconomique instable; (2) coût d'un biais prononcé contre l'utilisation des taux de change comme moyen de corriger les déséquilibres commerciaux ; (3) coûts d'une mauvaise répartition du capital dans un environnement où les signaux transmis par les prix sont faussés ; 
(4) coûts de l'élimination tardive des restrictions quantitatives ; (5) rôle de l'économie informelle et des envois de fonds des expatriés en tant que dispositif informel de protection sociale; (6) coûts liés aux retards de la déréglementation relative aux restrictions de l'IDE ; (7) rôle important joué par les services en tant qu'intrants (ex. services de télécommunications dans l'externalisation des processus opérationnels, et services d'infrastructure dans la transformation alimentaire) ; (8) avantages potentiels des zones franches d'exportation pour alléger la bureaucratie et améliorer l'infrastructure ; (9) défis posés par le passage d'une économie dirigée à une économie de marché (ex. secteur des cimenteries).

97. Si l'on en juge par sa très forte croissance économique, la Thaïlande est dans le peloton de tête des pays en développement. La stabilité macroéconomique et des institutions solides ont été les fondements de sa croissance impressionnante. Cependant, la Thailande demeure une énigme lorsque l'on tente d'établir un lien entre la libéralisation des échanges et la croissance. Elle est généralement considérée comme une économie ouverte : les restrictions de change n'étaient pas contraignantes, et les restrictions quantitatives, peu nombreuses; son ratio échanges/PIB est passé de $35 \%$ en 1970 à $72 \%$ en 1990 et à $136 \%$ en 2005. Par contre, la Thaïlande appliquait des droits de douane plus élevés que les autres pays ayant sensiblement le même revenu, et ce n'est que dans les années 90 qu'elle a vraiment commencé à les abaisser. Ce paradoxe apparent s'explique principalement du fait que, à l'origine, la Thaïlande avait recours aux exemptions tarifaires et aux ristournes pour corriger les distorsions dans une économie reposant sur le remplacement des importations. De telles mesures annulent le biais anti-exportations du régime des échanges, surtout en permettant aux exportateurs d'acheter des intrants importés aux prix du marché mondial. À moyen terme, les coûts d'une telle stratégie sont manifestes, tout particulièrement pour les petites et moyennes entreprises. La Thaïlande a donc adopté une stratégie de réduction tarifaire globale au début des années 90 .

98. Les principaux enseignements à tirer de cette étude de cas sont les suivants : (1) importance d'un environnement macroéconomique sain, de finances publiques viables, d'un cadre politique et économique relativement stable, d'un marché du travail flexible et d'infrastructures fiables pour soutenir la croissance ; (2) avantages procurés par l'ouverture aux échanges internationaux et à l'investissement étranger et différents moyens pour un pays d'y parvenir; (3) avantages et coûts d'une politique industrielle interventionniste ; (4) nécessité d'assurer une conception et un échelonnement adéquats des réformes ; (5) importance de la transparence et d'une participation élargie aux réformes pour s'assurer d'un soutien général. 